\title{
Interpretation, meaning-making, and civic engagement at Little Rock Central High School National Historic Site
}

\author{
Sandy Strickland \\ West Virginia University
}

Follow this and additional works at: https://researchrepository.wvu.edu/etd

\section{Recommended Citation}

Strickland, Sandy, "Interpretation, meaning-making, and civic engagement at Little Rock Central High School National Historic Site" (2011). Graduate Theses, Dissertations, and Problem Reports. 4798. https://researchrepository.wvu.edu/etd/4798

This Dissertation is protected by copyright and/or related rights. It has been brought to you by the The Research Repository @ WVU with permission from the rights-holder(s). You are free to use this Dissertation in any way that is permitted by the copyright and related rights legislation that applies to your use. For other uses you must obtain permission from the rights-holder(s) directly, unless additional rights are indicated by a Creative Commons license in the record and/ or on the work itself. This Dissertation has been accepted for inclusion in WVU Graduate Theses, Dissertations, and Problem Reports collection by an authorized administrator of The Research Repository @ WVU. For more information, please contact researchrepository@mail.wvu.edu. 


\title{
Interpretation, meaning-making, and civic engagement at
}

\section{Little Rock Central High School National Historic Site}

\author{
Sandy Strickland
}

\author{
A dissertation submitted to the \\ Davis College of Agriculture, Natural Resources \& Design \\ at \\ West Virginia University \\ in partial fulfillment of the requirements \\ for the degree of \\ Doctor of Philosophy \\ in \\ Forest Resources Science
Dave Smaldone, Ph.D., Chair
Steve Selin, Ph.D.
Robert Burns, Ph.D.
Dave McGill, Ph.D.
Jaci Webb-Dempsey, Ph.D.

Morgantown, West Virginia

2011

Keywords: Interpretation; Meaning-making; Constructivist Learning Theory; Civic Engagement; NPS

Copyright 2011 Sandy A. Strickland 


\title{
ABSTRACT \\ Interpretation, meaning-making, and civic engagement at Little Rock Central High School National Historic Site
}

\author{
Sandy A. Strickland
}

Using qualitative methodology, this study investigated interpretation, meaning-making, and civic engagement at Little Rock Central High School National Historic Site. Based upon constructivist learning theory, the research focused on eight research questions including:

1) What memories do visitors recall from their visit to CHSNHS?

2) What kind of knowledge do visitors remember?

3) Are visitors making meaningful connections to the resource?

4) What meanings are visitors making?

5) How are the meanings made?

6) Are these meanings connected to civic engagement?

7) What types of citizens are visitors to Central High School NHS?

8) Longitudinal changes in knowledge, meaningful connections, and how meanings were constructed?

Visitors exhibited four types of memories: declarative, experiential, episodic and structural, and five different types of knowledge: declarative, experiential, episodic, structural and socio-cultural. Visitors made meaningful connections which were cognitive and emotional, which were both positive and negative, and these meanings were made through evaluation, establishment, personal experience, absolute description, and special knowledge. Visitors participated in various community activities, but their knowledge and feeling about the site did not translate into action. There were six passive citizens, seven active, and four civically engaged citizens. Longitudinally, there were increases in types of knowledge, changes in meaningful connections, and differences in how meanings were made. Future research should focus on the role of churches in civic engagement and conversations with others when investigating interpretation, meaningmaking, and civic engagement. 


\section{DEDICATION}

For my friend, Karen

who started this journey with me

but will never finish

Sorrow quells my triumph

and I miss you 


\section{ACKNOWLEDGEMENTS}

I could not have completed this journey without the support of numerous individuals. First, and foremost, my husband, Jason, whom I can turn to for unwavering belief, without judgment but unshakable acceptance, and without whose encouraging words and financial support I would have given up long ago.

To my advisor, Dr. Dave, who believed in me when no one else would, not once, but twice. I am forever grateful. I could not have picked a more perfect fit for an advisor; your collected demeanor and patient guidance are virtues worthy of striving.

To my committee members: Dr. Selin, the vast scope of your ideas always makes me delve deeper into thought. Dr. Burns, I am continually awed by your research and admire your work profusely. Your benevolent words are always a source of encouragement. Dr. McGill, your unique perspective and attention to detail are not only noticed, but esteemed. And finally, Dr. Webb-Dempsey, the depth of your knowledge astounds me, and you are a beacon of hope and inspiration to aspiring female faculty and researchers.

Finally, I would like to express my gratitude to Radley Miller for his dependable transcription talent and to Theresa Coble, Catherine McCarthy, and Dr. Dave for allowing me to join their research project. Without their project and Radley's help, I would have been SOL! 


\section{TABLE OF CONTENTS}

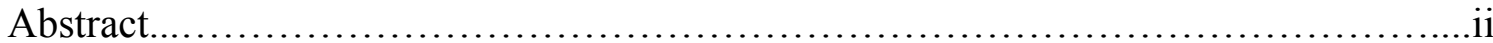

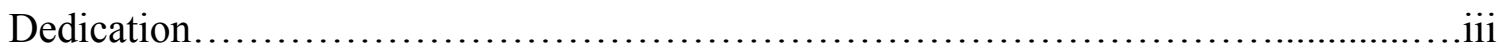

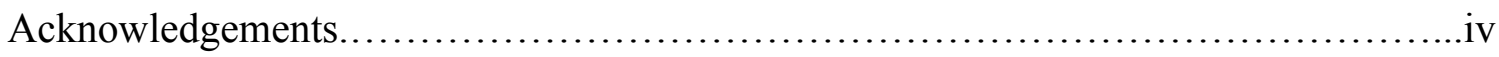

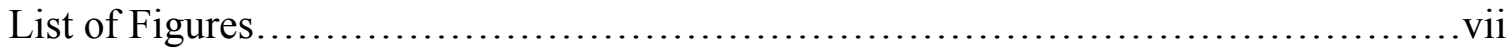

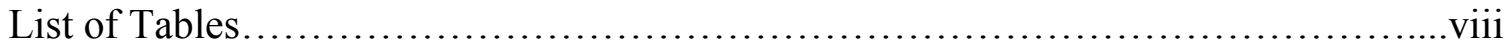

CHAPTER 1: INTRODUCTION.....................................................

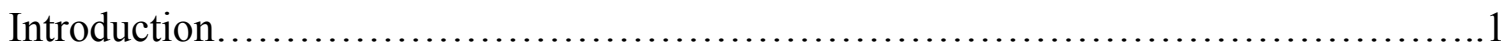

Statement of the Problem..........................................................

Study Locale................................................................

Rationale for Study/ Purpose/ Objectives......................................... 10

Research Questions...................................................... 11

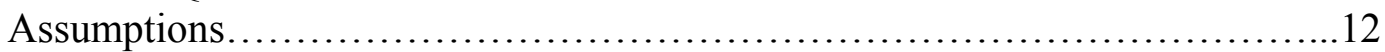

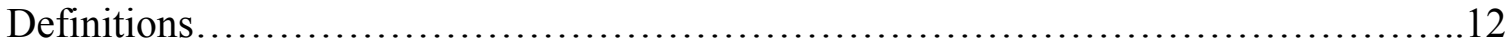

CHAPTER 2: LITERATURE REVIEW ......................................... 14

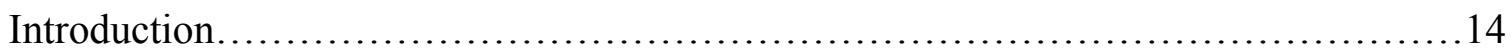

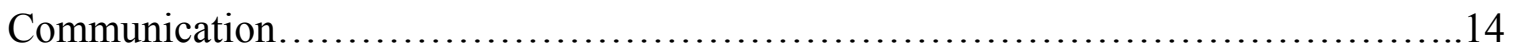

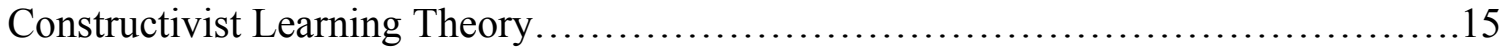

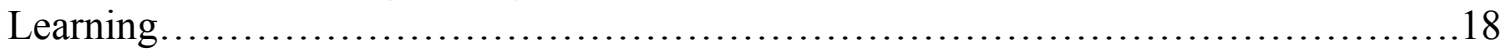

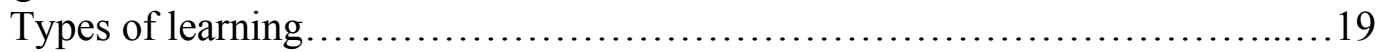

Documenting learning................................................. 19

Factors in learning...................................................... 20

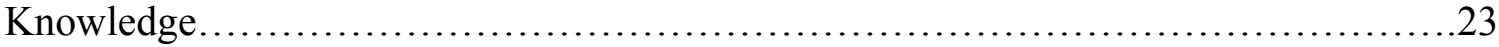

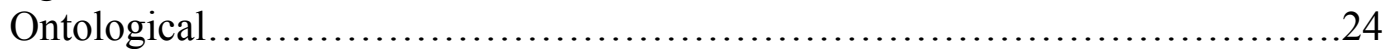

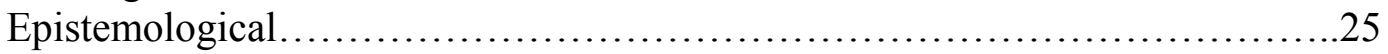

Phenomenological...................................................25

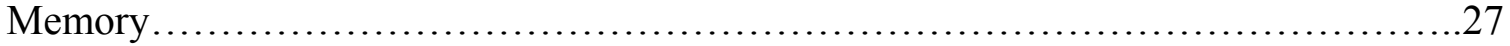

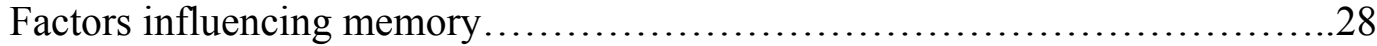

Emotion, Learning, and Memory............................................. 30

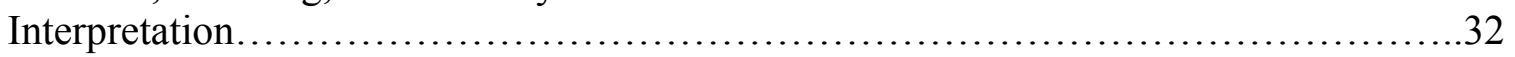

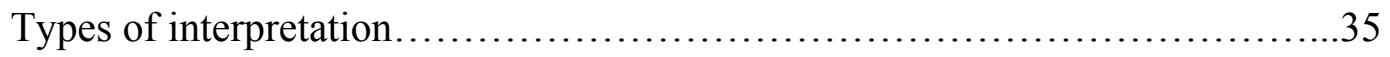

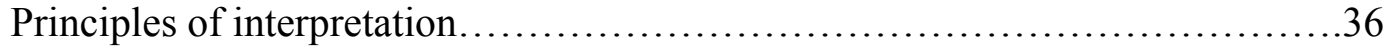

Studies in Interpretation...................................................... 41

Meaning-Making............................................................ 47

How meaning is made................................................. 51

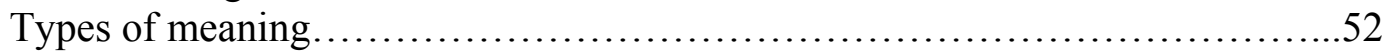

Civic Responsibility/ Engagement............................................ 53

Civic education/ Civic knowledge........................................59

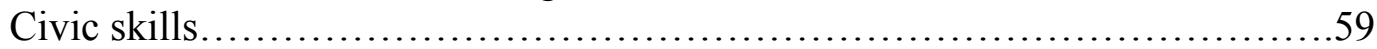

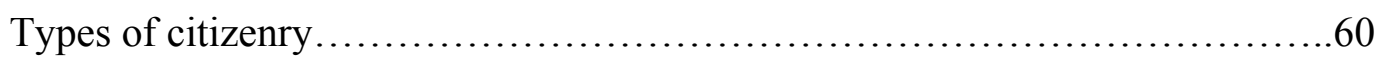

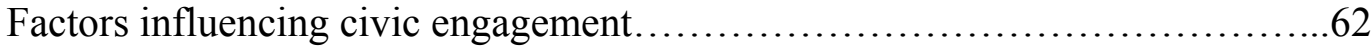

Obstacles to civic engagement.........................................67

Civic Engagement and Constructivist Learning....................................68 
Civic Education, Civic Engagement and their Relationship to Interpretation....

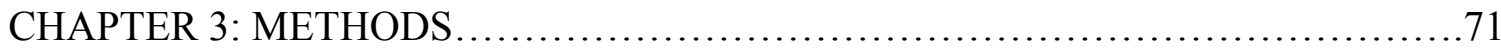

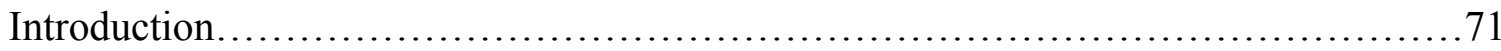

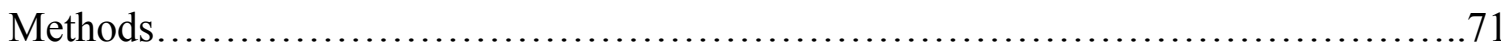

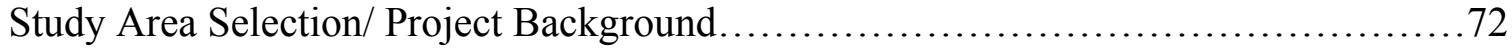

Research Questions................................................. 72

Study Population/ Sampling Procedures \& Problems................................. 73

Data Collection.............................................................. 74

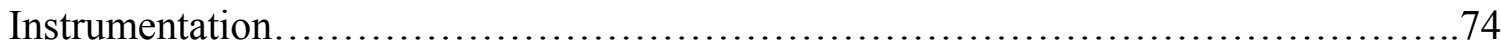

Data Analysis/ Treatment of Data................................................ 76

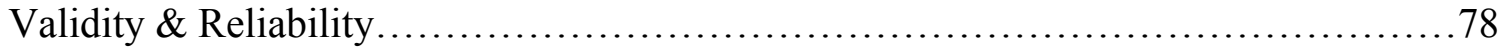

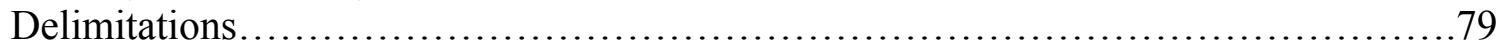

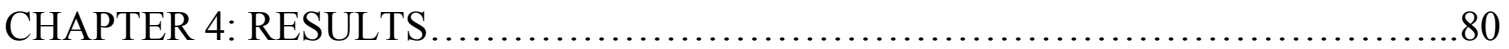

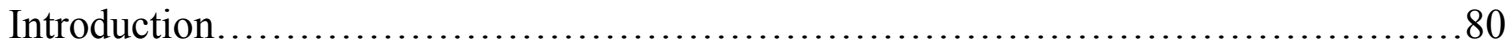

Demographics............................................................... 81

Research Question \#1: Memories.............................................. 81

Research Question \#2: Types of Knowledge..................................... 85

Research Questions \#3 \& \#4: Meaningful Connections.............................. 85

Research Question \#5: How Meanings were Made................................. 92

Research Question \#6: Meaning and Civic Engagement................................94

Research Question \#7: Types of Citizens......................................96

Research Question \#8: Longitudinal Results...................................... 100

Additional Findings........................................................ 104

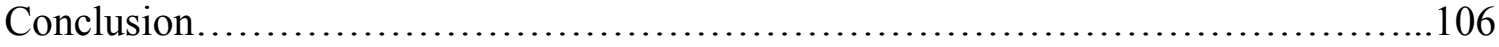

CHAPTER 5: DISCUSSION .................................................. 108

Demographics............................................................. 108

Research Question \#1: Memories............................................. 109

Research Question \#2: Types of Knowledge....................................... 113

Research Questions \#3 \& \#4: Meaning-Making........................................ 114

Research Question \#5: How Meanings were Made.................................. 118

Research Questions \#6 \& \#7: Meaning and Civic Engagement, Types of Citizens, \&

Additional Findings...............................................................119

Research Question \#8: Longitudinal Assessment................................126

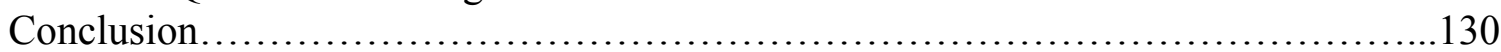

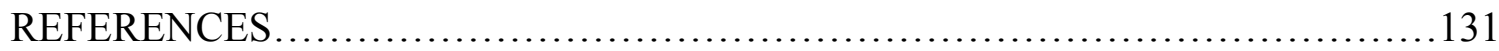

ADDENDUM.............................................................. 138 


\section{LIST OF FIGURES}

Figure 1

National Park Service Interpretation and Education Program Logic

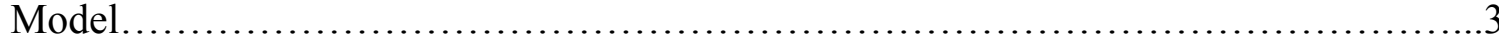

Figure 2

National Park Service Interpretation and Education Program Logic

Model.......................................................................... 57

Figure 3

Citizenry Continuum................................................... 123 


\section{LIST OF TABLES}

Table 1

Types of Declarative Memories by Number of Remarks and Respondents

Table 2

Frequency of Types of Memories.

Table 3

Frequency of Types of Meanings Made.

Table 4

Categories of Meaningful Cognitive Connections by Frequency of Remarks and

Respondents........................................................... 86

Table 5

Categories of Meaningful Emotional Connections by Frequency of Respondents and

Remarks...................................................................... 90

Table 6

Frequency of How Meanings were Made by Category..............................93

Table 7

Frequency of Participation in Civic Activities...................................97

Table 8

Coding Scheme for Types of Citizenry Based on Activities. .98

Table 9

Differences and Similarities in Longitudinal Assessment of Exit Interviews and One-year Follow-up. 


\section{CHAPTER 1: INTRODUCTION}

The first requisite of a good citizen in this republic of ours is that he shall be able and willing to pull his own weight. Theodore Roosevelt

Responsibility is the price of freedom. - Elbert Hubbard

We need to restore the full meaning of that old word, duty. It is the other side of rights. -Pearl Buck

Every right implies a responsibility; every opportunity, an obligation; every possession, a duty. - John D. Rockefeller Jr.

The world is a dangerous place, not because of those who do evil, but because of those who look on and do nothing. - Albert Einstein

\section{$\underline{\text { Introduction }}$}

The above quotes illustrate the importance of responsibility in the role of democracy. For it is as Abraham Lincoln stated in the Gettysburg Address we are a "government of the people, by the people, for the people...dedicated to the proposition that all men are created equal". Without citizen engagement in democracy, our government will fail. One way to overcome failing is to teach upcoming generations those democratic values and civic responsibilities, knowledge, and skills. Teaching those values, responsibilities, knowledge, and skills has traditionally occurred in the formal classroom. However, the level of civic engagement nationally, has continued to fall (Galston, 2007). Interpretation as informal education has the capacity to fill that void and encourage civic engagement in citizens for the continuation of our government.

\section{Statement of the Problem}

The problem of this research project is bifurcated. The first problem involves civic engagement. Civic engagement is a critical component of democracy as democracy is dependent 
upon citizen involvement in governing themselves. Without civic engagement of citizens, a democratic society does not exist and will collapse. The ailing problem involving civic engagement is that throughout the past several decades, civic engagement is rapidly declining in the United States, particularly among young people (Galston, 2007). Young people typically receive their civic lessons through formal education in K-12. So, if schools are not providing the needed spur towards civic engagement (Sax, 2000) where can civic engagement be learned and cultivated?

Amongst this sharp decline in citizen trust in national government and in other citizens, the federal government has attempted to inspire citizens to help others by pushing programs on civic education, volunteering, and national service: From President Bush's "September of Service" (Keeter, Zukin, Andolina, \& Jenkins, 2002) and National Veterans Awareness week with "Lessons of Liberty" (Westheimer \& Kahne, 2004a) to President Obama's "Call to Serve" by signing the Edward Kennedy Serve America Act in 2009 to the creation of the website serve.gov. Serve.gov lists nine federally sponsored volunteer and service websites including: NationalService.gov, AmeriCorps, Citizen Corps, Baby Boomers - Get Involved!, Learn \& Serve America, MLK Day of Service, Peace Corps, Senior Corps, and Volunteer.gov, all aimed at promoting civic engagement (serve.gov, 2010). The National Park Service (NPS) has even jumped on the bandwagon, promoting civic engagement as part of its educational and interpretive mission, as illustrated in the NPS interpretation and education program logic model (NPS Conservation Study Institute [NPS-CSI], 2006; NPS, 2006a) in attempts to bolster civic engagement and ensure our democratic society (see Figure 1 below). 
Figure 1

NPS Interpretation and Education Program Logic Model

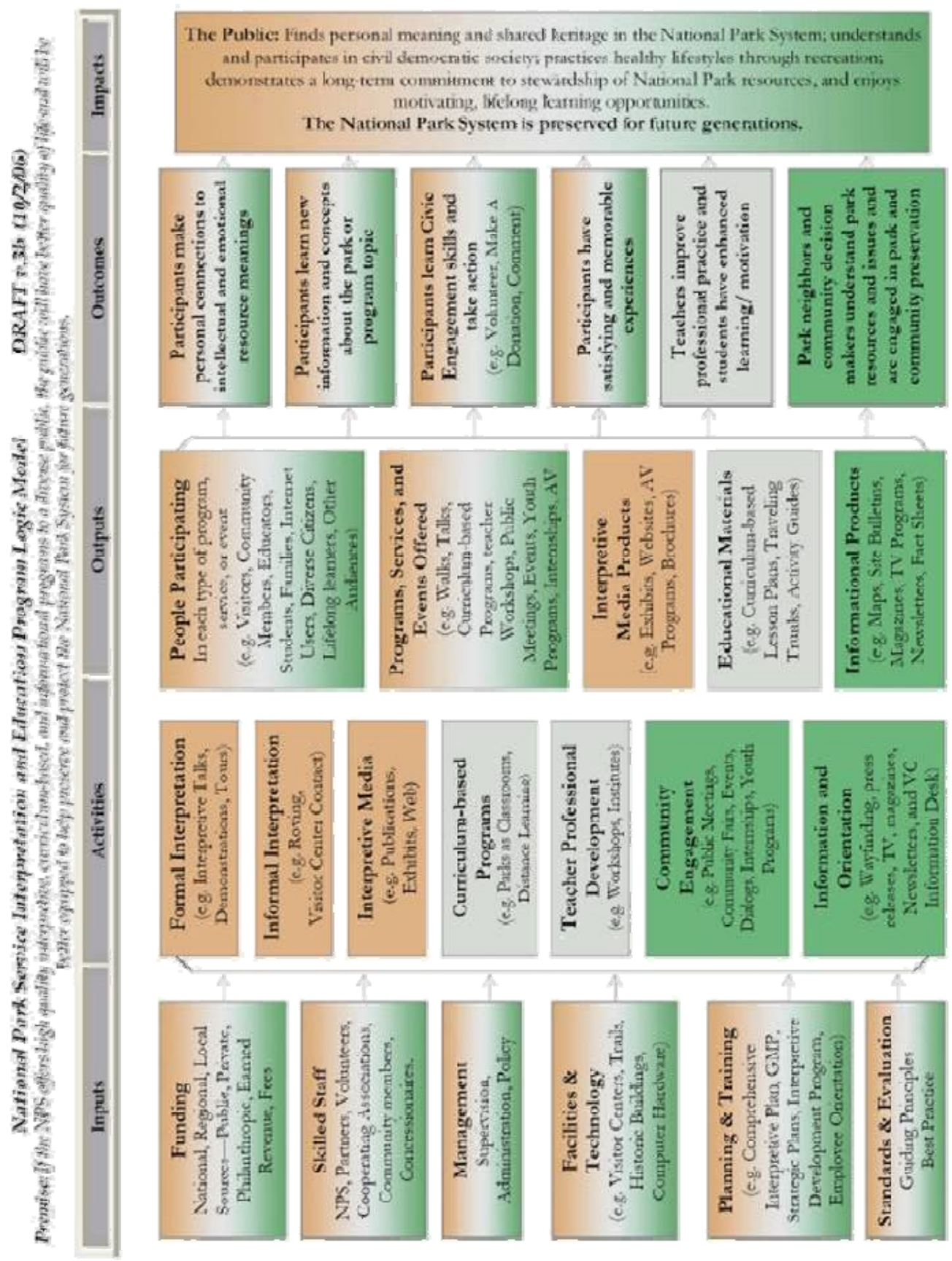

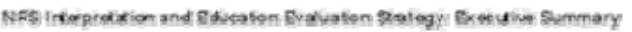


The reasons the NPS created the Interpretive Development Program (IDP) are twofold. First, it provides a model for effective interpretation. It imparts that interpretation provide opportunities for visitors to make both intellectual and emotional connections to the resource through meaning making. Second, the IDP provides a framework for NPS interpreters to submit interpretive programs and media for evaluation based on a rubric. Both personal interpretive programs (those presented by a person), and non-personal interpretive products (such as brochures, exhibits, or signs) may be submitted and evaluated through the IDP process. Nonpersonal interpretive products may be designed either by the NPS design team at Harpers Ferry, WV, or "in-house" at each park unit. Regardless of whether it is a personal or non-personal interpretive product, the IDP model does not necessarily address or evaluate the visitors. Are visitors actually making meaningful connections to the resource? What meanings are they making? How are the meanings made? When appropriate, are meanings made related to civic responsibility, civic knowledge, or civic skills? Do visitors who engage in civic meaningmaking become more civically engaged than those who are less engaged in civic meaning making? These are the questions that this research proposes to address.

\section{Study Locale}

The place in which these questions might be best addressed is Little Rock Central High School National Historic Site (CHSNHS) in Little Rock, Arkansas. Central High School is the site where the event of the "Little Rock Nine" took place in the late 1950s. Following the landmark Brown v Board of Education in 1954, nine Black students were integrated into an all White high school in 1957 with dire repercussions. Hatred was rampant, violence ensued, and the National Guard was called in to restore order. The school was closed the next school year to 
prevent further integration. Central High School was the beginning the civil rights movement, and was also a place where federal and state's rights clashed. As such, to preserve the history associated with the site, Little Rock Central High School National Historic Site was added as a unit within the National Park Service. In 2007 a new visitor center was built, complete with new interpretive exhibits (National Park Service, 2006b; National Park Service: Little Rock Central High School National Historic Site, 2002). This locale provides a unique opportunity to study non-personal interpretive products, the meanings visitors ascribe when touring the center, and if those meanings facilitate civic engagement.

The author visited the site in January 2011, and provides the following thick description of her experiences and the site:

I had timed my arrival perfectly. I should get to Central High School National Historic Site by $2 \mathrm{pm}$, giving me 3 hours to look around and take great notes $\&$ photos before heading back out on the road on my 28 hour drive from Texas to West Virginia. However, on my drive to Central I ran out of gas on the side of the interstate near Arkadelphia, about a mile and a half from the nearest gas station. My plans were thwarted, and I was running very late. When I arrived in Little Rock, I had apparently forgotten to bookmark where the VC was in my GPS. I would have sworn it was in there. Needless to say, it is NOT an easy site to find, located within a residential neighborhood. Signage was a bit lacking and it took me 15 minutes of driving around the neighborhood to find it. So, when I pulled into the concrete parking lot, there were few cars in lot, primarily in the back. The door stated the visitor center closed at 4:30PM, not 5:00 as I had anticipated. It was 4:25. There went the time I thought I had. I rushed to the door as Ranger Joni, a short, middle-aged woman was approaching to lock the door. I gushed my dilemma, "I am writing my dissertation on this site for my Ph.D. I ran out of gas on the way 
here. I work for the NPS during the summer. I just need to write some notes on the exhibits; I'll hurry." Apparently my rambling plea fell on sympathetic ears, as Ranger Joni welcomed me in. Seeing my NP passport book, she pointed to the where the stamp was on the counter. She was training a young Hispanic boy how to close the VC. I thanked her profusely and proceeded on my way.

I entered the solid glass door onto a light colored hard floor that appeared to be either tile or stone, cut into very large squares. Straight ahead of me is the restroom area. I turn left and walk into a gift shop/bookstore area. Ahead of me is an open doorway of brick and I can hear sounds of people talking, which I later discover to be videos, as there are no other visitors in the museum. I have the place all to myself. As I walk through the open doorway, I am confronted by three curvilinear blue pillars, the center one containing the video I heard. The pillars on the left and right contain words. There is a slight breeze blowing and I look up. There are lights above shining on the pillars and the pillars are connected like a mantle. The floor is still the big $\tan , 2 \times 2$ stone. It is hard and looks noisy. I am wearing tennis shoes that make no sound. I proceed to the left onto blue and white speckled carpet. As I do, I hear change being counted and sirens. Is this from another video or outside? I do not know. I do know I must hurry. I don't stop to look at my watch.

To the left is a display about the constitution. A big sign says "We the people". There is a touch screen with a stool to sit at. As I continue, the display is an open door with a picture of a girl peeking through the open screen door. There is another video screen, this time with a telephone receiver to pick up and listen to. I do not. I must hurry. There is a stool beneath the screen, and above it reads, "Right granted and denied". There are four push buttons. I hear 
sounds of the video again. Is it on a loop? I wave it out of my mind and continue to the next exhibit.

The entire museum seems to have a circular flow and I am proceeding clockwise. However, there is an opening behind the pillars, so I turn right and explore. There are five pillars here; did I miss two when I entered? There is a display case with a green metal pot/helmet above and a rifle below. I turn 180 and there are four other white pillars now in front of me, with the one of the words Ambition, Personality, Opportunity, and Preparation on each column. Between the first and second there is a panel that reads "Why step forward?" with a telephone receiver and push button, with a stool for sitting. I do not stop to listen. The center has lots of text and nothing else. Between the third and fourth columns is another touch screen with a stool below. I turn to my left and I am again facing the exhibit with the screen door and touch screen. I continue my clockwise journey.

The next exhibit is three panels with lots of text. In the center below the three panels is yet another video touch screen and a stool. The caption above reads "Taking it to courts". The background consists of neutral colors.

To the right of this display, behind the four white pillars, I hear sounds of a video and see a picture of three rifles. The exhibit is about the media's impact and the newspapers. There is a photo of a White female student yelling at a Black female student. The anger and disgust is very evident on the White student's face. The picture captures me for a moment and I briefly stop to take it in. It is very powerful and it saddens me. There is also a telephone, a case containing shoes, a stamp, and a schedule card. There is something about electors (school board) describing the lost school year. (The school was closed for a year to prevent the Black students from 
attending.) I have spent a bit of time at this display and must move along quickly, so I continue back to my left.

This display is pink, cream and orange and the title reads, "The south resists integration". I half chuckle, half snort and think, "No joke. It still does." My sound is amplified in the otherwise quiet area. There is a big book open under a case hanging on the wall. There is LOTS of text and my eyes don't even focus to read it. I briefly recall visitors stating there was a lot of text. I had forgotten. I wonder how this got made \& who designed it. Apparently someone not familiar with interp principles. In the corner there is an exit sign and a door. I continue my clockwise journey, drawn to the window beside the exit door.

The back wall of the museum is a huge picture window. It is almost floor to ceiling window. I can see the Mobile gas station across the street. The gas station is white plaster stucco with a bright red Spanish tile roof. It is bright red, not terra-cotta, Spanish tile. There is a portico protruding from the gas station and has a gable roof with an arch below. On the gable is the word Magnolia in all capital black letters. You can drive under the portico, but not really because it has been barricaded with white concrete pillars on each entrance. There are two garage bays on the left hand side and the words Mobile Gas Mobile Lubrication are above. To the left of the gas station is a NPS sign and additional parking. There is a privacy fence surrounding the small lot. On the gas station, there is a red stripe painted along the foundation of the building. There are three old style gas pumps; the center one is white, and the two end ones are red. On the corner is a blue metal sign with a red flying horse hanging from a pole. Beyond the sign, the school can be seen. The school is caddy-corner to the VC and across the street from the gas station. The school is shorter than I remember, but still huge. It is a massive tan brick building with ornate brickwork and art-nuevo detailing. It looks like it was built in the 
1920s. There is a large staircase in front. The whole building is very castle-like and I find it quite beautiful.

Still looking outside, but closer to the museum, there are large tan brick flower boxes directly outside the picture window, between three white concrete pillars supporting the building. There is a kind of arbor overhanging the flowerbeds too. Beyond the plantings is the sidewalk and then the road. Cars go by and stop at the four-way intersection.

Back inside, there is a small wayside sign with a picture on it near the windows. The sounds of the video lessen but the HVAC becomes more prevalent. The wall behind the windows is curvilinear and there are reddish wooden benches on which to sit and gaze out the windows. There are two phone stations on each end of a very open space. I continue my clockwise exploration.

To the left is an exhibit titled "Beyond Central-individuals who make a difference". There is lots of small text again on 3-4 panels. The wall juts out a bit at the end of the panels, to separate the space. On this wall panel that juts out is a photo of an Indian Chief and a quote. In the corner, there is something I cannot identify quickly. It is silver and black and I think it is the bus ticket machine from Rosa Parks' bus. As I skimmed through this section, I remembered that when I first visited CHSNHS that this section is the one I felt did not fit. It was completely confusing when I visited in 2008, and I had no idea what it had to do with the events in Little Rock at Central. As I go through it this time, I can understand how visitors I surveyed interpreted it.

Behind the wall that pokes out, there are four photos with four more panels. They are blue text on a pinkish background. I find the color scheme odd and look around at other colors. The ceiling is black with duct work. I also see dark blue exhibits with white text. I continue. 
To the right of the four panels, near the corner is another stool, with 2 touch screens. There is also a desk with a notebook to write in. In the corner is a full length window. To the right of the window on the wall is a painting of Black students and a soldier. It is bright and colorful, and has a small description tag to the right of the painting. I am once again back to the big tan tile stones. I stop to breathe and find no real smells. I look up to feel lights shining from above. Ranger Joni has not closed up shop completely.

I again thank her and as I go to walk out, she asks if I have a brochure. I tell her I have one, but change my mind and grab one anyway. I am a sucker for NPS brochures. I return to my car and begin adding detail to my notes. As I do, a dark-haired White girl and a bushy haired Black kid, both who look between 23-25 and in ranger uniforms walk out the front door. It is 4:45-4:50 and I write until 5:15. I feel rushed and would have liked to have gotten notes on the actual text of the displays but I am resigned that I did not.

\section{Rationale for Study/ Purpose/ Study Objectives}

The purpose of this research project is to investigate interpretation, meaning making, and civic engagement in a NPS historical site setting. While the NPS has discussed civic engagement in various publications, there have been no studies that addressed civic engagement at NPS sites, and therefore this study seeks to add to the field by tackling this nuanced concept. In exploring the aforementioned questions, the goal is to determine if visitors are in fact making connections through interpretive materials, what meanings visitors are deriving from interpretive materials, how visitors are connecting to resources, and if this connection leads to civic engagement. Management at Central High School National Historic Site wanted to assess if visitors were engaged in meaning-making and if meanings were related to civic engagement. 
NPS interpretive managers can use the results to enhance existing programs, develop interpretive materials that allow for more meaningful visitor connections, and potentially encourage civic engagement among visitors.

\section{Research Questions}

R1: What memories do visitors recall from their visit to CHSNHS? (Investigating interpretive media products, participants have satisfying and memorable experiences, and participants learn new information and concepts about the parks or program topic components of NPS Interpretation and Education Program Logic Model)

R2: What kind of knowledge do visitors remember? (Interpretive media products; participants have satisfying and memorable experiences, and participants learn new information and concepts about the parks or program topic)

R3: Are visitors making meaningful connections to the resource? (Participants make personal connections to intellectual and emotional resource meanings; and participants learn new information and concepts about the parks or program topic)

R4: What meanings are visitors making? (Participants make personal connections to intellectual and emotional resource meanings; and participants learn new information and concepts about the parks or program topic)

R5: How are the meanings made? (Participants make personal connections to intellectual and emotional resource meanings; and participants learn new information and concepts about the parks or program topic)

R6: Are these meanings connected to civic engagement? (Participants learn civic engagement skills and take action) 
R7: What types of citizens are visitors to Central High School NHS? (Participants learn civic engagement skills and take action)

\section{R8: Are there changes over time in types of knowledge, meaningful connections, and/or how meanings are made, and if so, what are those changes? (Interpretive media products; participants make personal connections to intellectual and emotional resource meanings; and participants learn new information and concepts about the parks or program topic) Assumptions}

The previous research questions are based on the assumption that visitors interviewed will have cognitive function of memory recall regarding their visit to Central High School NHS.

\section{$\underline{\text { Definitions }}$}

The following terms are used throughout this paper.

Learning - the process of permanently storing new information into long-term memory by finding connections with prior experience

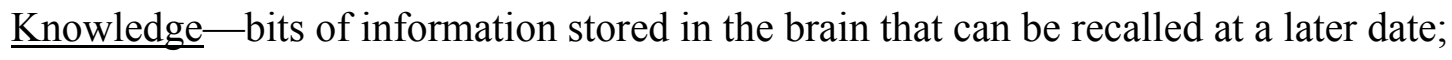

knowledge is the "what" of learning

Memory - the storage and retrieval of knowledge; memory is the "how" of learning

Formal learning-learning which occurs in a classroom, where motivation is extrinsic, content is sequential, attendance mandatory, and communication typically constrained Informal learning - learning that takes place through free choice of the participant, where motivation is internal, attendance is voluntary, there is no time limit, and is characterized as learning in museums, zoos, aquaria, and other interpretive arenas 
Interpretation - as a type of informal learning, is a communication process with a non-captive audience that helps them create emotional and cognitive connections to the resource

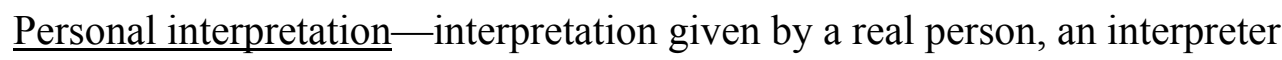
Non-personal interpretation-interpretation other than that presented by a person; typically includes such media as signs, brochures, wayside exhibits, and museum displays

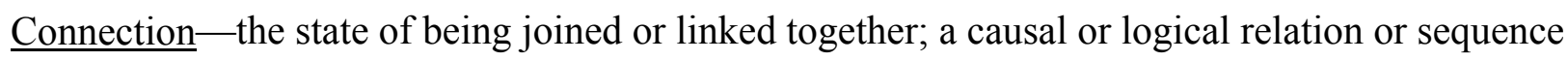
Meaning - that which one intends or aims to convey through language including hidden, special significance Meaning making - how we make sense of the world around us; it is the construction of understanding based upon what is conveyed through language or otherwise Civic responsibility — the duties of a citizen Civic engagement- the commitment, involvement, or binding of a citizen in participation in those duties and burdens laid on each one as members of a democracy Civic knowledge - bits of information regarding civic duties of a citizen stored in the brain that can be recalled at a later date; knowledge regarding civic responsibilities

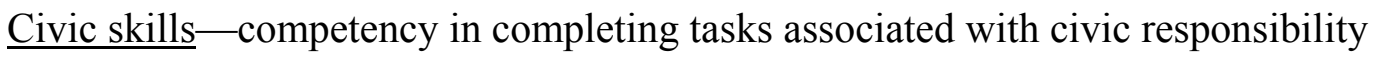




\section{CHAPTER 2: LITERATURE REVIEW}

\section{Introduction}

This literature review provides an in-depth examination of written material investigating interpretation and civic engagement. Beginning with origins in communication and the transactional model of communication, and continuing to the foundation rooted in constructivist learning theory, an image of what constitutes learning will begin to appear. Interpretation is discussed next, and is categorized as a specific style of learning that promotes active engagement and provocation through meaning making. Civic engagement is then explored, followed by an integration of interpretation, meaning making, and civic engagement.

\section{Communication}

This section defines communication and describes three models of communication; the linear model, the interactional model, and the transactional model. The transactional model is most applicable to interpretation and this study.

Communication is "the social process in which individuals employ symbols to establish and interpret meaning in their environment" (West \& Turner, 2007, p. 5). West and Turner provide three models of communication: 1) a linear model, where there is a sender, the message, and a receiver; 2) an interactional model, with a sender, message, receiver, and feedback; and 3) the transactional model of communication, which contains two or more communicators, messages, feedback, and experiences.

The linear model of communication linear in nature, where the sender provides a message to a receiver, who receives the message. The linear model is one-directional. 
The interactional model builds upon the linear model, providing a more circular flow of information, where the sender sends the message to the receiver, the receiver receives the message, and then provides feedback to the sender. This process emphasizes two-way communication between individuals, and understanding is achieved through feedback. In the interactional model, each person brings their own field of experiences-including culture, personal experiences, and heredity — to the communication setting, and this field of experiences influence the communication between the two individuals.

The transactional model of communication builds upon the interactional model, with two communicators who are concurrently both sender and receiver providing simultaneous messages and feedback. Each communicator has brought to the communication episode their own field of experiences, but understanding is achieved through a shared field of experience. As West and Turner noted, "In the transactional model, people build shared meanings...In a sense, communicators negotiate meaning. Further, what people say during a transaction is greatly influenced by their past experience. [F]or communication to take place, individuals must build shared meaning" (2007, p. 13-14).

In summary, there are three models of communication: linear, interactional, and transactional models. Beginning with a simple one-directional line, the interactional model builds upon the linear model forming a bidirectional system. The transactional model builds upon the interactional model allowing for simultaneous meaning making.

\section{Constructivist Learning Theory}

Constructivist learning theory is a learning theory based upon the transactional model of 
communication, allowing for the learner to construct his/her own meaning. This section encompasses an integration of constructivist learning theory.

Constructivist learning theory integrates meaning making as a part of learning (Hein, n.d., 1991, 1995, 1998, 1999). Meaning making is how we make sense of the world around us; it is the construction of understanding based upon what is conveyed through objects, symbols, language, or non-verbal communication (Hein, 1991; Vygotsky, 1978). Constructivist learning theory asserts that individuals learn not in a linear process of teacher transferring of meaning to student, and then the student regurgitating said meaning and knowledge as their own (Fosnot, 2005), but rather in a complex and non-linear fashion (Fosnot \& Perry, 2005), not unlike transactional communication. The individual is engaged in a continuous interaction with the environment which leads to new perceptions and knowledge (Orams, 1996). Understanding is internally and actively constructed by the learner (Hein, n.d., 1991, 1995, 1998, 1999; Vygotsky, 1978). Knowledge is a product of learner activity and the context and culture in which it happens (Tobias \& Duffy, 2009; Vygotsky, 1978). Beliefs about how the world works are formed around meanings we build from our experiences (Julyan \& Duckworth, 2005; Vygotsky, 1978). Constructivist learning theory approaches education as providing "learners the opportunity for concrete, contextually meaningful experience through which they can search for patterns; raise questions; and model, interpret, and defend their strategies and ideas" (Fosnot, 2005, p. ix). Fosnot and Perry further explain:

"We may not understand in the same way as other human beings who have had different experiences, but by using language, stories, and metaphors and models, we can listen to and probe each other's understanding, thereby negotiating and constructing 'taken-asshared' meanings (Blumer, 1969; Mead, 1934)...[W]e attempt to generalize meaning across experiences..." (p. 30-31). 
This is what West and Turner (2007) describe as the shared field of experiences in the transactional communication model. Fosnot and Perry describe constructivist learning as a nonlinear process having a transactional nature of interplay, and note that "striving for symbolic representation and coherent meaning-making with other humans is a spiraling dynamic 'dance' of interaction...” (p. 33).

People learn actively by negotiating meaning, and their background and prior experiences influence how and what they learn (Benton, 2008; Falk \& Dierking, 1992; Hein, n.d., 1991, 1998; Vygotsky, 1978). Von Glasersfeld (2005) elaborates that a scrutiny of meaning leads to individual experience and the social aspect of integrating the links between language and that experience.

The goal of instruction in constructivist learning theory is deep understanding and cognitive development instead of repetitive skills (Fosnot \& Perry, 2005). The role of the educator, then, is not one of knowledge dispenser, but rather to provide students with opportunities and incentives to build upon past experiences and construct new knowledge (von Glasersfeld, 2005; Knapp \& Benton, 2004). Building understanding requires that the individuals have opportunities to voice their ideas, to examine those ideas through experimentation or conversation with others, and to reflect on the links between the phenomena they are exploring and other relevant aspects of their lives (Julyan \& Duckworth, 2005). It is important to note that while constructivist learning is driven through learner inquiry, exploration of the surrounding environment, and occurs as the learner builds new knowledge from previous experience, it is not without guidance (Herman \& Gomez, 2009; Knapp \& Benton, 2004). Wise and O'Neill (2009) point out that guided constructivist learning results in better long-term retention. 
In summary, based upon the transactional model of communication, constructivist learning theory is a learning theory where the learner constructs his/her own meaning regarding the world around him/her. The learner builds new knowledge based upon prior personal experiences, and guided constructivist learning provides for long-term retention of information.

\section{Learning}

To begin this section, a definition of learning is provided. Learning is composed of two concepts: knowledge and memory, each discussed in further detail in subsequent sections. Formal and informal learning as types of learning are addressed, how learning occurs, and shortcomings of learning research follow. The exploration of 10 factors influencing learning wrap up this section on learning.

What is learning? Learning is "the application of prior knowledge and experience to new circumstances...with the expectation that th[e] (sic) new knowledge and experience will be useful in completing similar tasks in the future" (Falk \& Dierking, 2000, p. 19). Learning is the process of permanently storing new information, created by finding connections with prior experience and making meaning, into long-term memory (Baddeley, 1998; Beck \& Cable, 2002; Falk \& Dierking, 1992, 2000; Jonassen, 2009; Tulving, 2007; Walls, 2004). Thus, a critical element in learning is time. Learning takes time (Baddeley, 1998; Falk \& Dierking, 2000; Hein, 1991, 1998), and "to understand learning requires a longer view" (Falk \& Dierking, 2000, p. 10).

There are two important factors to consider within learning: how learning occurs, and what is learned (Baddeley, 1998; Jonassen, 2009). How learning occurs is understood through the concept of memory, and what is learned is termed knowledge. Knowledge and memory are discussed in further detail in subsequent sections. 


\section{Types of learning}

There are two types of learning: formal and informal. Formal learning typically occurs in a structured classroom setting. K-12 and higher education within the U.S. is indicative of formal learning. Informal learning or free-choice learning occurs outside a classroom setting, and can occur during a visit to a museum or nature center, when reading a newspaper or book, when on a hike, or attending an interpretive program (Falk \& Dierking, 2000; Ham, 1992; Hein, 1998;

Koran, Willems, \& Camp, 2000; Wright, Hammitt, \& Machnik, n.d.). A key difference between formal and informal learning is that participants in formal learning settings are a captive audience, in that they must attend typically for an external reward such as a grade. Informal learning entices a voluntary, non-captive audience who is free to leave any time they wish - they are attending because they want to (Ham, 1992; Hein, 1998; Koran, et, al., 2000; Kuo, 2002). Interpretation, as a form of informal learning, will be discussed in great detail in later sections.

Falk and Dierking (2000) use the term free choice learning rather than the more commonly used term, informal learning, because the term free choice better captures the structural nature and underlying motivation of the learning that occurs. Free choice learning is that which is intrinsically motivated, and thus is based upon the choice of the learner as to what, when, and where to learn. This study however, uses the more commonly used term of informal learning when describing free choice learning.

\section{Documenting learning}

Learning for most people involves the process of reaffirmation and assimilation of knowledge rather than accommodating new knowledge. Assimilation is the process of interpreting a context, building additional understanding, and reinforcing known matter, whereas 
accommodation involves changing existing knowledge structures to adapt to the current experience. This is important to note, as nearly all research methods for assessing both formal and informal learning assess changes in knowledge structure, rather than the subtle reinforcement of existing knowledge. "Thus, much, if not most, of learning, has remained effectively undocumented" (Falk \& Dierking, 2000, p. 29).

Factors in learning

Building upon the theoretical framework of constructivist learning theory, there are several factors to consider when investigating learning (Falk \& Dierking, 1992, 2000; Hein, 1991). As interpretation is a type of informal learning, the following factors should be considered and integrated into interpretive materials and programs.

1. learning is active process

2. constructing meaning is mental

3. learning involves language

4. learning is social activity

5. learning is contextual

6. knowledge is essential for learning

7. learning takes time

8. motivation is key

9. interest influences learning

10. organized information is better

As constructivist learning takes place through experience, active participation is essential (Hein, 1991, 1998; Kintsch, 2009; Wright, et al., n.d.). Having physical touchable artifacts to explore facilitates learning more so than just reading about the item (Alberti, 2005). "The 
experience of seeing tangible examples of previously learned verbal or pictorial material obviously plays a major role in facilitating long-term learning” (Falk \& Dierking, 2000, p. 27). Hein (1998) states "there can be no learning (or meaning making) if there's been no interaction" (p. 136).

While experience is critical, so is the mental process, as constructing meaning is a mental process. A person must have cognitive function in order to be able to learn. Thinking about the activity is important for complete comprehension and construction of meaning (Hein, 1991, 1998; Fosnot \& Perry, 2005). All interpretation research studies have focused on individuals who can control cognitive function and communicate (for obvious reasons). This is one of the assumptions of this study as well.

Learning is also a social activity. It is through common and shared experiences and interaction and conversations with others that knowledge is created and shared. Knowledge is shared and thus learned through communicating with others (Hein, 1991, 1998; Falk \& Dierking, 1992; Fosnot \& Perry, 2005; Wright, et al., n.d.). In an investigation of an art and a history museum, Silverman (1991) discovered visitors who went to these museums in pairs learned more as a result of the social interaction and discussion of their visit.

All learning stems from within a series of contexts, in relationship to what we know. Learning is both the process and product of interactions between personal, physical, and sociocultural contexts (Falk \& Dierking, 1992, 2000; Fosnot \& Perry, 2005; Hein, 1991, 1998; Machnik, Wright, \& Hammitt, 2006; Wright, et al., n.d.). "All learning is contextual...one cannot talk about learning except in relationship to some place and situation" (Falk \& Dierking, 2000, p. xi). Learning can therefore be viewed as a never-ending interaction and integration of the personal, physical, and socio-cultural contexts over time in order to make meaning (Falk \& 
Dierking, 1992, 2000; Fosnot \& Perry, 2005). Because learning is contextual to place and situation, interpretation studies have focused on learning in relationship to the formation of episodic memories (place and situation) (Knapp \& Benton, 2005, 2006). Episodic memories will be discussed in more detail later.

If learning is the process of creating and storing new information created by finding connections with prior experience, then it is intuitive that one must have knowledge in order to learn. "It is not possible to assimilate new knowledge without having some structure developed from previous knowledge to build on. The more we know, the more we can learn" (Hein, 1991, p. 3). Knowledge is therefore also fundamental for learning (Falk \& Dierking, 1992).

In addition, learning takes practice and experience, and hence time. While simple mindless repetition is not the premise behind constructivist learning, learning takes practice. A child cannot learn to ride a bicycle by reading a book; it takes practice. Thus, learning takes time, practice, and experience (Baddeley, 1998; Falk \& Dierking, 2000; Hein, 1991, 1998; Kintsch, 2009). For this reason Farmer and Knapp (2008) focused on longitudinal assessment and Knapp $(2006,2007)$ addresses long-term memories that assess learning over time.

The next factor influencing learning is motivation. Intrinsic motivation is essential in free-choice learning (Ham, 1992; Hein, 1991, 1998; Falk \& Dierking, 2000). When individuals are engaged in meaningful activities, are in a supportive environment, have control over their learning, and the challenges of the tasks meet their skill, they are highly motivated to learn (Falk \& Dierking, 2000). Learning is more likely to be optimized with learners who are intrinsically motivated versus motivated by external rewards, as in formal instruction (Herman \& Gomez, 2009). Personal interests develop slowly over time but have enduring effects on a person's knowledge. Personal interests also influence motivation. One is not motivated to learn if one is 
not interested in the subject. People have a tendency to follow up interest with action, including learning, and as such, usually have more knowledge on topics of interest (Baddeley, 1998; Falk \& Dierking, 2000). Also, visitors who are interested in a subject pay closer attention because they are motivated, and remember the information longer (Kuo, 2002).

Finally, organized material is easier to learn than material that has no association (Baddeley, 1998; Ham, 1992; Walls, 2004). Random information without context is more difficult to process than that which with a person can associate and form connections. Thus, information that is organized is learned quicker than unorganized material. Organized material is a critical component of interpretation and will be discussed in further detail in a subsequent section.

To summarize, this section on learning provided a definition of the term, differentiated between formal and informal learning, described how learning occurs, and addressed a measurement concern. The remainder of the section concludes with an elaboration on 10 factors influencing learning.

\section{Knowledge}

To understand learning, knowledge must be addressed. There are three main types of knowledge as described by Jonassen (2009): ontological, epistemological, and phenomenological. An organizational outline will help visualize the relationship between the various types of knowledge to be discussed below.

1) Ontological
a) Declarative, aka Propositional
2) Epistemological
i) Semantic
a) Procedural
b) Situational
3) Phenomenological
b) Structural
c) Strategic
a) Tacit aka Implicit
b) Socio-cultural
c) Episodic \& Experiential 

i) Episodic
ii) Experienti
al

\section{Ontological}

Ontological knowledge describes what exists through the properties and structure of object, and the relationship of object to its surroundings. Ontological knowledge describes the content of knowledge (Hein, 1998; Jonassen, 2009). Two types of ontological knowledge are declarative and structural.

Declarative knowledge is basic knowledge that something exists and includes knowledge about facts, principles, and concepts (Clark, 2009; Jonassen, 2009; Walls, 2004). Declarative knowledge is the most commonly researched type of knowledge in learning and interpretation (Julyan \& Duckworth, 2005; Knapp, 2007; Knapp \& Barrie, 2001). Semantic knowledge is a type of declarative or propositional knowledge and is knowledge independent of a person's past or identity. (Tulving, 2007; Walls, 2004). Within declarative semantic knowledge, Tulving and Walls include knowledge on words, language, symbols, the meanings of these concepts, as well as relationships between the ideas and how to manipulate them (structural knowledge). Other researchers separate out structural knowledge (Beck \& Cable, 2002; Jonassen, 2009), which is addressed next.

Structural knowledge is the awareness and understanding of how concepts relate together. Cognitive structure or cognitive mapping are other terms for structural knowledge which describe the organization of conceptual relationships within long-term memory (Beck \& Cable, 2002; Jonassen, 2009). The way in which learners organize conceptual relationships determines how he/she connects with the environment (Jonassen, 2009). Thus, while the idea of structural knowledge is universal between individuals, each person's cognitive map is unique (Beck \& Cable, 2002). This is the foundation of constructivist learning theory; each person constructs 
meaning differently because each person's cognitive map is distinctive.

\section{Epistemological}

Epistemological knowledge types are used to describe knowledge of procedural tasks and results from the application of declarative knowledge. Discussed in detail later, civic knowledge is equivalent to declarative knowledge and civic skills fall under epistemological knowledge. There are three main types of epistemological knowledge: procedural, situational, and strategic (Jonassen, 2009).

"Procedural knowledge is the knowledge required to perform a task" notes Jonassen (2009, p. 21). Procedural knowledge consists of cognitive and psychomotor knowledge (Tulving, 2007; Walls, 2004). Cognitive procedural knowledge is how to add $1+2+3=x$; psychomotor procedural knowledge consists of how to ride a bicycle (Clark, 2009; Tulving, 2007; Walls, 2004). Declarative knowledge is the knowledge of what ingredients are used to make bread; procedural knowledge is knowing actually how to make bread.

Situational knowledge is knowledge about situations used for problem-solving, and includes knowledge about the type of problem, context, and a solution process. This type of knowledge is normally associated with practice, so experts in a field are generally able to recognize problem types and present solutions more efficiently than novices (Jonassen, 2009).

Strategic knowledge is another type of epistemological knowledge, and involves knowing what strategies and activities to apply to perform a task. It is also known as metacognitive knowledge (Jonassen, 2009).

\section{Phenomenological}

Phenomenological knowledge is that knowledge which a learner gains through experiences. From phenomenological view, what is known about the world is filtered through 
the lens of experience. Thus, what is known represents perceptions of experiences, and not what "really" is (Falk \& Dierking, 2000; Jonessen, 2009). Phenomenological knowledge is most closely associated with constructivist learning theory and interpretation. While similar to structural knowledge, these two concepts are different. Structural knowledge contains the cognitive map used to assimilate information. Phenomenological knowledge is that gained through experience. Thus, both influence how and what a person learns. Constructivist learning theory and interpretation are built upon the premise that individuals build their own meaning based on their experiences and their unique cognitive map. Jonessen (2009) discusses three main phenomenological knowledge types: tacit or implicit knowledge, socio-cultural, and experiential or episodic knowledge.

Tacit or implicit knowledge is that which is known, but cannot be readily explained as it is not readily available to the conscious mind (Baddeley, 1998; Jonassen, 2009; Walls, 2004). Socio-cultural knowledge consists of the socially shared knowledge among a culture of people.

Knowledge in the form of episodes can be either experiential or episodic knowledge. Experiential knowledge is used to recognize similar situations and address issues or solve problems based on similar previous experiences. If the new situation differs from the previous case, individuals will adapt experiential knowledge to include the new case. As explained by Jonassen (2009), experiential knowledge is a vibrant form of memory that changes over time as an individual incorporates new experiences into what he or she has already experienced and knows. Episodic or autobiographical knowledge involves personal happenings and doings (Tulving, 2007; Walls, 2004). Tulving and Walls categorize episodic knowledge as a type of declarative knowledge rather than procedural, as these are the only two main classifications each identifies. 
As noted earlier, in studies of knowledge and learning Falk and Dierking $(1992,2000)$ emphasize the important roles that prior knowledge, personal interest, the experience, and subsequent experiences play in constructing new knowledge. Knowledge is based in the activity of the learner and is a result of that activity and the culture and context in which it takes place (Tobias \& Duffy, 2009).

In summary, this section details three main categories of knowledge: ontological, epistemological, and phenomenological. Ontological knowledge can be further subdivided into declarative and structural knowledge. Procedural, situational, and strategic all compose epistemological knowledge, which is most closely associated with civic skills, discussed later. Phenomenological knowledge consists of tacit or implicit knowledge, socio-cultural, and episodic and experiential. Episodic and experiential are most closely aligned with interpretation.

\section{Memory}

This section begins by explaining the concept of memory and the relationship to knowledge, and concludes with factors influencing memory. If learning is the continual processing of knowledge, how does this occur? Learning is the registering and storing of information, which must be efficiently accessed in the right form at the right time (Baddeley, 1998; Falk \& Dierking, 1992, 2000; Jonassen, 2009). The storage and efficient retrieval of information is the scope of memory (Baddeley, 1998). Thus, human memory is the information structure system used to learn.

Different types of knowledge result in different types of memories. Semantic knowledge can be categorized as propositional or declarative knowledge and procedural knowledge consists of cognitive and psychomotor knowledge (Clark, 2009; Tulving, 2007; Walls, 2004). From 
phenomenological episodic and declarative semantic knowledge flows episodic or semantic memories, and procedural knowledge about skills and tasks builds procedural memory. Episodic memory is the system that stores and retrieves episodic knowledge about episodes of life experiences or the stories about oneself (Clark, 2009; Schank, 1990; Tulving, 2007; Walls, 2004). This type of memory is most commonly studied in long-term interpretation research (Knapp, 2007; Knapp \& Benton, 2005, 2006).

\section{Factors influencing memory}

There are several factors that influence memory retention and recall. First is preexisting knowledge, as the more knowledge the more connections that can be readily made. Context also influences memory, as does repeated exposure, personal relevance, and active delivery of concepts. Emotion plays a key role in memory and learning, too. As noted by Falk \& Dierking (2000), “At the core of all learning are memories, and memories are not permanent entities but rather the creation of new patterns from preexisting patterns. Learning has no real beginning and no real end" (p. 31). As such, memory is an ever-changing, ephemeral process. The more prior knowledge an individual has in his/her existing memory structure about a topic or procedure (semantic or procedural), the easier and quicker it is to learn and store new information, because there are more ways to make connections (Falk \& Dierking, 1992; Walls, 2004).

Memory, as part of learning, is also context dependent. While learning occurs within a context, memory, too is enhanced through context. Knowledge learned within one environment is more readily retrieved in the same environment and may be very difficult to recall in a dramatically different context (Baddeley, 1998; Koran, et al., 2000; Walls, 2004). Koran, et al. propose that museums and other informal learning settings are vastly different than formal classrooms and as such, they should be richly described to illustrate their differences. Also, 
visitors may have difficulty recalling knowledge about a setting when not in the same locale, or may have a hard time transferring knowledge learned in one setting to the other. Thus, it may be difficult to visitors to a museum or interpretive program to recall knowledge gained when not in a museum or at interpretive program. Visitors may also find it difficult to transfer knowledge acquired through an interpretive program or media to another context, such as everyday life. An addition to environmental context, the mood context of the learner affects memory. An experience, either positive or negative, will be remembered easier when in that mood again. This is termed mood-state dependence. Mood congruency is when happy, happy events are recalled easier and when sad, sad events are recalled more readily (Baddeley, 1998; Walls, 2004). The relationship between emotion, memory, and learning is discussed in more detail in the next section.

When an individual is exposed to a particular idea more than once, recall is better and actual knowledge of the subject is strengthened (Knapp, 2006, 2007; Tulving, 2007; Walls, 2004). It is advantageous then, for visitors to be repeatedly exposed to consistent messages during a visit or an interpretive program.

Another variable influencing memory recall is personal relevance. The more personally relevant a topic, the easier it is to remember (Knapp, 2006, 2007; Webb, 2000). Webb explains there are things that are relevant to all people, such as clean air, food, and family, which are also known as universal concepts (an interpretive concept to be described in more detail later). There are other things, such as Mountaineer football, types of basil, hockey logos, or wood finishes, that are relevant to a smaller group. Webb states "anyone seeking to reach the widest audience possible must focus on those elements that are relevant to the largest number of people" (p. 18). The next element impacting memory is the active delivery of concepts. When an 
individual actively participates in the delivery of an idea, the person will remember the episodic memory better (Knapp, 2006, 2007). As with constructivist learning, visitors must actively participate and engage in a situation to learn and form episodic memories. When actively engaged, recall is better.

To summarize, learning is the process of storing and retrieving knowledge. Different types of knowledge result in corresponding memories. Episodic knowledge results in episodic memories; semantic declarative knowledge results in semantic memories. There are several factors that influence memory retention and recall including preexisting knowledge, context, repeat exposure, personal relevance, emotion, and active delivery of concepts. Each of these factors are important in interpretation as well.

\section{Emotion, Learning \& Memory}

As previously stated, mood and emotion are important factors influencing memory and learning. This section highlights this relationship.

Emotion plays a key role in memory and learning. "The more Emotional Involvement there is (especially pleasant emotions), the stronger [the memory] is for later recall" (Walls, 2004, p. 9-2, emphasis in original). The more affect or emotion associated with memories, the

better retained and recalled they are (Webb, 2000). Memories associated with strong emotional experiences may not require reinforcement for recall, whereas memories with less emotional connection require regular reinforcement for recollection (Falk \& Dierking, 1992). Recalling a memory even just once makes it stronger for remembering later as noted by Walls, when we converse with others about what happened to us, it makes the memory of the event last longer. When recounting a personal experience, the memory structure is reinforced through elaborative 
connections (Schank, 1990). "Constructivist theories of memory suggest that better elaborated memories with more extensive relational networks will lead to more reliable recall of learned material" state Wise and O'Neill (2009, p. 85). The more elaborate the memory, the easier it is to remember (Walls, 2004). Learners will develop more elaborate memories with more relational networks from more authentic experiences (Wise \& O’Neill, 2009).

Phenomenological knowledge types, particularly episodic knowledge and subsequent memories, tend to be more assembled, more easily recalled when needed, and less likely to be forgotten (Jonassen, 2009).

The interplay of emotion in learning goes as far back as Aristotle who underscored the importance of emotion in learning (Roberts, 1984). Falk and Dierking (2000) highlight that all learning involves emotion, just as affect nearly always involve cognition. The affective domain, or the attitudes, feelings, emotions, and values of a person are central to every part of learning. Emotion bridges the gap between the cognitive and the stimulus and is the basis for continued learning (Orams, 1996). Because learning, particularly informal learning, is a rich, emotion filled experience, it is lends itself to remembering more easily. "Learning is a whole-body experience, involving the emotion, and the senses, the physical as well as the mental" (Falk \& Dierking, 2000, p. 24). Orams argues that it is both emotion and knowledge that influence behavior and endorses that future research consider both cognitive and affective factors when investigating learning.

While this section highlights the importance of emotion on memory and learning, the next section, interpretation, elaborates on ways in which to make informal learning connect both emotionally and cognitively with visitors by outlining major interpretive principles. 


\section{Interpretation}

Previous sections discussed theory, learning, knowledge, memory, and the role of emotion in learning. This section elaborates on interpretation as a means of informal learning and discusses six principles set forth to actively engage visitors emotionally and cognitively with the resource. Beginning with a definition of interpretation and an explanation of components of the definition, two types of interpretation are then differentiated, and concluding this section are Tilden's six principles and their relationship to constructivist learning theory, learning, knowledge, memory, and emotion.

Freeman Tilden (1957) first defined interpretation as, "An educational activity which aims to reveal meanings and relationships through the use of original objects, by firsthand experience, and by illustrative media, rather than simply to communicate factual information" ( $p$. 8). Ham (1992) emphasizes that interpretation is an approach to communication that stresses the meanings and relationships behind ideas rather than just facts and figures. Brochu and Merriman (2002) define interpretation similar to the NPS, as "A communication process that forges emotional and intellectual connections between the interests of the audience and the inherent meanings in the resource" (p. 20). Therefore, interpretation, as a type of informal learning, is a communication process with a non-captive audience that helps them create emotional and cognitive connections to the resource (Brochu \& Merriman, 2002; Falk \& Dierking, 1992; Ham, 1992; Knapp, 2007; Knudson, Cable, \& Beck, 2003; Kuo, 2002; Morgan \& Dong, 2008;

Silverman, 1999; Smaldone, 2008; Ward \& Wilkinson, 2006; Wright, et al., n.d.).

Explicit in these definitions are several factors. One, interpretation is a communication process. Two, interpretation is informal learning. Next, interpretation is achieved through active 
experience, not passively. Finally, interpretation allows for emotional and cognitive connections to resources. These key ideas are expanded below.

As noted, interpretation is a communication process, and inherent in communication are three components: the interpreter, the visitor or learner, and the resource being interpreted, which Lewis (1980) terms the "interactive threesome". As such, meaning and understanding are achieved through a transactional communication process, as previously discussed, between interpreter and visitor, where interpreter and visitor construct meaning about the resource (Brochu \& Merriman, 2002; Knapp, 2007; Knapp \& Benton, 2004; Knudson, et al., 2003; Kuo, 2002; Machnik, et al., 2006; Silverman, 1999; Ward \& Wilkinson, 2006; West \& Turner, 2007; Wright, et al., n.d.).

Second, interpretation is informal learning (Brochu \& Merriman, 2002; Cameron, 1968; Coen, 1975; Falk \& Dierking, 1992; Ham, 1992; Knapp, 2007; Knapp \& Benton, 2004; Koran, et al., 2000; Kuo, 2002; Machnik, et al., 2006; Morgan \& Dong, 2008; Tilden, 1957; Wright, et al., n.d.). Hence, the aforementioned factors of learning apply: knowledge is essential; interest influences motivation which is key; it is an active social process that involves language over time; context is important; constructing meaning is mental; and organized information is better (Beck \& Cable, 2002; Brochu \& Merriman, 2002; Falk \& Dierking, 1992, 2000; Ham, 1992; Hein, 1991, 1998; Knapp, 2007; Knapp \& Benton, 2004; Koran, et al., 2000; Machlis \& Field, 1984; Machnik, et al., 2006). Since interpretation is a type of informal learning, audiences are free to come and go as they so desire. One distinct difference between formal and informal learning is that formal learning has an established time frame the participants are required to attend. With informal learning, the visitor is free to come and go as he/she pleases, spending as much or as little time at an exhibit or program as they chose (Ham, 1992; Koran, et al., 2000; 
Kuo, 2002; Morgan \& Dong, 2008). Thus, besides learning taking time, time is a critical element in informal learning. Thus, the socio-cultural context of time influences interpretation, as interpreter effectiveness is influenced by visitor's limited time (Machlis \& Field, 1984).

Next, interpretation is achieved through first hand experience, not by merely reading about something (Knapp, 2007; Larsen, 2003; Simon, 2010; Tilden, 1957; Ward \& Wilkinson, 2006; Wright, et al., n.d.). Consequently, interpretation is an experiential in nature, as is constructivist learning (Hein, 1998; Wright, et al., n.d.).

Finally, rather than just communicate facts and figures, the goal of interpretation is to allow for the visitor to create emotional and cognitive connections to the resource (Brochu \& Merriman, 2002; Ham, 1992; Hein, 1998; Knapp, 2007; Knapp \& Benton, 2004; Larsen, 2003; Machnik, et al., 2006; Tilden, 1957; Ward \& Wilkinson, 2006). Based on constructivist learning theory, this is achieved when the visitor finds meaning in the resource by connecting new knowledge with that which is already known. As with constructivist learning, one purpose of interpretation is deep understanding and cognitive development instead of repetitive skills (Brochu \& Merriman, 2002; Fosnot \& Perry, 2005; Hammitt, 1984; Hein, 1998; Knapp, 2007; Tilden, 1957). The role of the interpreter, then, is not to spout facts and figures, but rather to provide visitors with opportunities and incentives to build upon past experiences and construct new knowledge through a transactional communication process (Brochu \& Merriman, 2002; von Glasersfeld, 2005; Knapp, 2007; Knapp \& Benton, 2004; Machnik, et al., 2006; Morgan \& Dong, 2008; Silverman, 1999; Tilden, 1957; Ward \& Wilkinson, 2006; West \& Turner, 2007).

Based upon these aforementioned components: transactional communication, informal experiential learning, and constructing meaning and connections, interpretation is constructivist learning (Machnik, et al., 2006). Brochu and Merriman (2002) even describe interpretation in 
terms of constructivist learning, “Audiences will come with different experiences and will understand communication from personal perspectives shaped by their experiences” (pg 14). Lewis, (1980) expands, "One thing we know for sure is that every one of us sees the world uniquely...[N]one of us continues to see the world in the same way" (p. 22). As we grow older, we have different experiences, which change the way in which we see the world (Lewis, 1980). Effective interpretation, according to Beck and Cable (2002), stimulates visitors to connect with knowledge they already possess. As with the constructivist learning approach, Knapp (2007) and Knapp \& Benton (2004) state the interpreter should engage in active dialog with visitors and include the audience as much as possible into the program in a transactional style of communication. Two key publications associated with the National Park Service and embodying interpretation as constructivist learning are Larsen's (2003) Meaningful Interpretation and the National Park Service’s Interpretive Development Program (IDP) (Novey, 2008).

Now that we know the details of the composition of interpretation, the following section distinguishes between the two types of interpretation, personal and non-personal.

\section{Types of interpretation}

There are two forms of interpretation: personal and non-personal. Personal interpretation involves one person actively verbally communicating with another person or persons, such as an interpretive talk at a campfire, or a guided walk. Non-personal interpretation is a form of interpretation using printed materials such as brochures, signs, wayside exhibits, and other media that do no involve a live person (Beck \& Cable, 2002; Brochu \& Merriman, 2002; Ward \& Wilkinson, 2006). Both personal and non-personal interpretation have advantages and disadvantages. Brochu and Merriman believe that "personal interpretation is one of the most powerful approaches to interpretation because the interpreter can continually adapt to each 
audience" (p. 23). Tilden (1957) also argued that personal interpretation, when done well, is more powerful in making connections with visitors. However, personal interpretation is extremely costly, and the NPS faces numerous constraints to fulfill its educational and interpretive mission (National Park Service Education Council, 2006). Non-personal interpretation is much cheaper to produce and can reach more visitors because tourists can stop at wayside exhibits or take brochures after normal business hours. Only a small percentage of visitors actually attend a personal interpretive program; more visitors stop by visitor centers for non-personal products. Thus, non-personal products have the ability to reach more visitors than personal interpretive programs.

While the previous section differentiated between personal and non-personal interpretation and the advantages and disadvantages of both, the following section elaborates on the principles behind interpretation, as developed by the field's founding father, Freeman Tilden.

\section{Principles of interpretation}

In 1957, Freeman Tilden wrote a small book, Interpreting Our Heritage, in which he outlined six principles of interpretation. It was the first of its kind to really discuss what interpretation was, and how best to achieve effective interpretation. While subsequent scholars have elaborated, expanded upon, and reworded these initial six principles, they remain the initial and most concise foundations of interpretation. As such, other scholars work is integrated into Tilden's principles in this discussion.

Tilden's six principles of interpretation:

I. Any interpretation that does not somehow relate what is being displayed or described to something within the personality or experience of the visitor will be sterile.

II. Information, as such, is not Interpretation. Interpretation is revelation based upon information. But they are entirely different things. However, all interpretation includes information. 
III. Interpretation is an art, which combines many arts, whether the materials presented are scientific, historical or architectural. Any art in some degree is teachable.

IV. The chief aim of Interpretation is not instruction, but provocation.

V. Interpretation should aim to present a whole rather than a part, and must address itself to the whole man rather than any phase.

VI. Interpretation addresses to children (say up to the age of twelve) should not be a dilution of the presentation to adults, but should follow a fundamentally different approach. To be at its best it will require a separate program (pg. 9)

Ham (1992), another interpretive scholar, developed four guidelines leading to effective interpretation, know by the acronym EROT, standing for enjoyable, relevant, organized and thematic. Ham proposed that effective interpretation should be enjoyable, relevant, organized, and have a theme. Tilden's first principle is associated with what Ham deems as relevant, by being meaningful and personal. All interpretation should relate to the visitor, otherwise there will be no connection. As with constructivist learning, Tilden stated that visitors attend interpretive programs because their chief interest lies in their experiences (factors of learning: interest influences learning \& learning is based on context and experience). Additionally, Tilden promoted transactional communication when he stated a visitor "does not so much wish to be talked at as to be talked with" (p. 12, emphasis in original). In communicating with visitors, foremost in interpretation is to relate to the experience of the visitor so that the individual can build knowledge based on prior experiences (Ham, 1992; Tilden, 1957). "The visitor is unlikely to respond unless what you have to tell, or to show, touches his [sic] personal experiences...if you cannot connect, he may not quit you physically, but you have lost his interest" (Tilden, p. 13). Without this personal and meaningful connection to visitors, interpretation is fruitless (Ham, 1992, Tilden, 1957; Ward \& Wilkinson, 2006). In studying successful interpretation at five national parks, Knapp and Benton (2004) found that the most common concept related to success was that the interpretive program must relate to the visitor. 
Tilden's second principle illuminates the difference between information and interpretation, just as there is a difference between knowledge and learning. Tilden (1957) referred to information as the raw materials and interpretation the product. Similarly, knowledge and memory are the raw materials essential for the product of learning.

In elaborating upon "interpretation is an art" principle, Tilden (1957) proposed that interpreters "tell a story rather than recite an inventory...We cannot forget that people are with us mainly seeking enjoyment, not instruction" (p. 29). Ham (1992) and Ward and Wilkinson (2006) agree, stating that an essential quality of interpretation is that it must be entertaining and pleasurable. Enjoyable interpretation holds an audience's attention.

Principle number four is that the purpose of interpretation is not instruction, but rather provocation (Tilden, 1957). Provocation, Tilden stated is where "the visitor...search[es] out meanings for himself (sic)...eager for guidance... toward wisdom...from a natural world...that 'make sense'" (p. 36). This principle falls directly in line with constructivist learning where visitors discover meaning, not without guidance, for themselves. Tilden quoted a message from Chief Naturalist of the National Park Service, Ansel F. Hall. Written in 1928, it epitomizes constructivist learning:

In most Park educational activities it is best to give the visitor a broad, general idea of the Park in which he finds himself, allowing him to supplement the general but inclusive story with details according to his personal impressions of the facts which he himself gathers out-of-doors. He may gather these perhaps with your assistance, but he must be stimulated first to want to discover things for himself, and second, to see and understand the things at which he looks...Remember always that visitors come to see the Park itself and its superb natural phenomena, and that the museums, lectures, and guided trips afield are but means of helping the visitor to understand and enjoy these phenomena more thoroughly....[I] feel that it is more important that the visitor carry away with him an intense enjoyment of what he has seen, even though he has not accumulated many facts (p. 33). 
Principle number five entails presenting a whole rather than parts (Tilden, 1957). In elaborating on what "a whole" is, Tilden described what Ham (1992) meant as being thematic. Tilden stated "It is far better that the visitor to a preserved area, natural, historic, or prehistoric, should leave with one or more whole pictures in his mind, than with a mélange of information that leaves him in doubt as to the essence of the place, and even in doubt as to why the area has been preserved at all” (p. 41). Beck and Cable (2002) refer to this whole as the story, and according to Tilden, "The story's the thing" (p. 26). This whole picture is the central message, or theme of an interpretive program or product according to Ham and Ward and Wilkinson (2006). Ward and Wilkinson also note that the theme addresses the purpose of communication with the audience. "At the completion of any interpretive presentation, the audience should be able to tell you what was said by summarizing it in one sentence" (Lewis, 1980, p. 37). Themes are vital to interpretation, as research has shown that when an audience knows the theme beforehand, they are more likely to pay attention during the program, and remember more of it later (Ham, 1992). Repeating and reinforcing the theme at the beginning and end of a program is a strategy used to enhance recall (Knapp, 2006). Knapp also states, "interpreters [should] offer strongly themed experiences that focus on a primary topic that is reiterated throughout the program" (p. 33) because "people remember themes, they forget facts" (Ham, p. 38).

"Used properly, it [the theme] can be the key to effective organization" (Lewis, 1980, p. 37). Thus presenting the whole also includes Ham's (1992) principle that interpretation should be thematically organized and what Ward and Wilkinson (2006) refer to as structured, in that messages follow a logical sequence of ideas. Lewis suggests that interpretive programs should consist of: an introduction, theme, theme development, and conclusion. In developing the theme, it is suggested that there be only five or fewer subthemes, or main ideas supporting the theme, as 
this is the maximum number of ideas that some people can remember (Brochu \& Merriman, 2002; Ham, 1992; Miller, 1956). "If you have more than five subthemes, most will not be retained by your audience, and you may find that they leave with a different sense of your message or overall theme than you intended" (Brochu \& Merriman, p. 49).

Thus, it is critical that the audience understand the theme. "[I]n interpretation it's important that everyone in the audience comprehends the theme" (Ham, 1992, p. 39). Knapp (2007) stresses the importance of connecting the theme or message with the visitor's own life. Larsen (2003) and the NPS IDP model propose that this is best done by linking tangible and intangibles with universal concepts. Tangibles are those physical items or resources being interpreted. Intangibles are the concepts and hidden meanings being revealed, and universal concepts are intangibles that appeal to all humankind. Universal concepts include, but are not limited to, ideas such as death, family, love, work, friendship, change, and beauty. "If you can continually bring the stories you share from the tangible artifacts, places, and circumstances to the intangible and universal ideas, you are likely to connect with any audience" (Brochu \& Merriman, 2002, p. 46). Orams (1996) also upholds that universal concepts are emotional topics for people and should be the focus of interpretive programs in order to engage visitors. "With regard to nature-based interpretive programmes, issues which involve humans' affective domain are likely to be those issues that are central to all life. Topics such as reproduction, birth, death, competition and conflict, sickness, and social relationships are emotional areas for most humans" (p. 89). Therefore, the themes that are understood by and connect with the audience best are those that connect tangible artifacts with emotional universal concepts (Benton, 2008).

Tilden's (1957) final principle of interpretation concentrates on interpretation for children. Tilden proposes that interpretation for children under the age of 12 include more 
factual information than for adults, as young children are eager for factual knowledge. It is also important to reference superlatives when presenting interpretive programs to children, although Tilden points out that this intrigue continues to adulthood. Tilden also promotes interpretive programs for children should also involve the senses, particularly smell, as it is recalled better than any other sense. With adults, sense of smell can evoke an odor memory. Lastly, Tilden suggests when interpreting to children, the interpreter should provide a sense of companionship rather than direct instruction, as the story and firsthand adventure are paramount.

In conclusion, this section elaborated on a definition of interpretation, explaining each component. Differences between personal and non-personal interpretation were addressed. Tilden (1957) presented six principles of interpretation that are still relevant and applicable to interpretation today. These principles share much with constructivist learning theory, and their relationship to learning, emotion, and memory were discussed. The following section addresses meaning making and its relationship to constructivist learning theory, learning, and interpretation.

\section{$\underline{\text { Studies in Interpretation }}$}

There are several studies in interpretation relevant to learning, meaning making, emotion, and behavior, which are discussed in the following section.

There are three main areas of focus for interpretation research involving visitors: emotion, cognition, and behavior. Most studies investigate a combination of these elements. The link between elements has also been investigated and the connection between knowledge and behavior is weak (Fishbein \& Azjein, 1975; Orams, 1996). While Orams (1996) proposes 
that interpretation should prompt behavior change Hammitt (1984) and Knapp (2007) support that a goal of interpretation is to gain a broader depth of understanding and knowledge.

As most studies are either qualitative or quantitative in nature, a mixed methods short and long term study investigating knowledge gain by Farmer and Knapp (2008) is the first of its kind. Surprisingly, too, although it has been illustrated that learning takes time, it there are very few interpretive studies that assess learning longitudinally. Farmer and Knapp (2008) is the only such study and analyzed both immediate knowledge and long term recollections of an interpretive program at a historic hotel in Indiana. Multiple triangulations involved observations, document analysis and administrator interviews, along with quantitative pre and post test questionnaires, and qualitative interviews six months later. Results showed that significant information retention by the visitors as indicated through the quantitative portion of the study. The qualitative interviews produced rich data that illuminated the importance of personal relevant connections to the resource. Those individuals who made a personal connection to the hotel were much more likely to recall vivid details of the interpretive experience. Although personal relevancy is a critical component of interpretation, "it has rarely been explored or studied in regard to long-term impact of an interpretive experience" (p. 356).

Similar to longitudinal studies, another method of addressing long-term learning is to investigate long-term memories and recall, where a visitor is asked in a point-in-time to recall memories. However, there is no "immediate" knowledge to which to compare the long-term memories as there are in a true longitudinal study such as Farmer and Knapp (2008). In a qualitative study focusing on long-term recollection of interpretive programs, Knapp and Benton (2005) discovered four areas which were recalled most readily when visitors were interviewed two years after an interpretive program. Visitors remembered images, novel experiences of 
touching artifacts, aspects of the interpreter, and participating in activities. "The richest description of recalled memories related to active involvement" (p. 53), thus highlighting the importance of experience in learning and interpretation.

In a look at emotion in informal learning settings, Webb (2000) states that that one source of affect or emotion is personal relevance. Affect also motivates individuals to become involved in and identify with programs deemed personally relevant. As such, "exhibits that show and are about people will be better attended and more involving than others will" (p. 20) because it allows visitors to put themselves "in the picture". When visitors are involved with personally relevant stories, they remember better and have a much deeper experience than by simply reading about it. Webb suggests "because of the affect content of an environment...is controlling much of the learning that goes on there, measuring that element can be quite informative" ( $p$. 27).

In an investigation of feelings of visitor satisfaction of an interpretive program aboard Amtrak trains in the Missouri and Illinois, Morgan and Dong (2008) looked at the characteristics of the interpreter, the quality of the program, and benefits of the program and found based on a 5 point Likert scale, visitors felt highly satisfied in all three categories. If audience members are not satisfied, they may leave a program and potential not participate in future interpretive opportunities. Also, dissatisfied visitors may result in negative word-of-mouth publicity for the program or park.

Knapp (2006) explored visitors' recollections of interpretive experiences six months after the initial program in a qualitative study and found both cognitive and emotional components to memories about an interpretive program. Four areas dominated memories. Connections visitors made to their own personal experiences (i.e. learning) stood out the most. Visitors were also 
able to recall specific information from the program. Respondents also had positive feelings and emotions toward the program and conveyed positive recollections of the interpretive program. The last area that was readily remembered were attributes of the ranger, including communication skills, passion, excitement, interest, stimulating interest, knowledge, and providing visual aides.

Wright, et al., (n.d.) investigated both short and long term recollections of visitors to interpretive programs and discovered both intellectual and emotional connections developed. Also, visitors took direct action as a result of the interpretive program, including discussion of the program with another person, attending other talks at a national park, recommending the talk to someone else, and seeking additional information about the topic. In accordance with Walls (2004) and Schank (1990), Wright, et al., found that discussing the interpretive program with someone else, recommending the talk to someone, or speaking about the interpretive topic in another informal learning situation, resulted in a significantly higher likelihood of a memorable experience being reported eight months after the program.

In a study at Gettysburg National Military Park, PA, Machnik, et al., (2006) investigated visitors' cognitive and affective responses to an interpretive program and compared those results with responses of NPS peer reviewers. Based on Shaver's six emotion categories, the authors used a semi-structured qualitative approach finding that visitors' affective responses corresponded with the emotion categories of love, joy, surprise, anger, sadness, and fear. Both joy and sadness were reported most frequently. In analyzing cognitive responses, the six areas where visitors illustrated knowledge were: Lincoln and the Gettysburg address; the establishment history of Gettysburg National Cemetery; the vastness of death, sacrifice, and casualties as a result of the battle; identifying soldiers; the battle scene and surroundings, and the need to honor 
and respect the fallen soldiers. These responses illustrate that while both cognitive and affective responses result from interpretive programs, they are site specific as these particular cognitive responses would not be found at a different location or program.

Wiles and Hall (2005) investigated cognitive and affective interpretive messages on visitors' knowledge and attitudes regarding wildland fire at Mesa Verde National Park. Using a 7 point unipolar scale, they found that the interpretive programs changed the mean knowledge and attitude scores for both cognitive and affective treatment groups, confirming that interpretation can result in positive changes in knowledge. Wiles and Hall point out that knowledge is more easily influenced than attitude and that programs with emotional components resulted in the greatest change. They also found surprising results in that personal relevance was not related to changes in knowledge or attitude. Also, prior knowledge had an affect on gains in knowledge in that visitors with the lowest levels of prior knowledge learned the most. This can be explained by Falk and Dierking (2000) in that learning for most people involves reinforcing known matter rather than creating new knowledge. Wiles and Hall assessed changes in knowledge structure, rather than the subtle reinforcement of existing knowledge, and thus the true scope of learning was actually not documented.

Knapp's (2007) Applied Interpretation provides rich data using qualitative methods on multiple national park sites over many years. From these studies, he found that interpretive programs can produce changes in affect and a variety of long-term recollections. Interpretive techniques that resulted in best memory recall included novel settings, subject matter, interpreter traits, and hands-on engaging opportunities.

In 1998, 2001, Knapp and Barrie conducted a study investigating all three components of cognition, behavior, and emotion, of school children participating in an environmental education 
program at Indiana Dunes National Lakeshore and found mixed results. Using quantitative methods, they found that students who participated in the program during the fall term versus those who did not (the control group) had significant gains in knowledge, but not affect. The inverse was true for the spring participants: participants showed significant changes in emotion but not cognition verses the control group. However, in analyzing within subjects, Knapp and Barrie found that from pre- to posttests, there was a significant change in cognition, but not emotion. There were also no gains among any group in regards to changes in behavior. As a result of the interpretive programs, students were no more likely to increase their environmental behavior such as picking up trash in their own neighborhood.

Hungerford and Volk (2001) suggest that behavior change is the ultimate goal of education and learning. For changes in environmental behavior to occur these several factors must be addressed first (Hungerford, 1996; Hungerford \& Volk, 2001; Knapp, 2007; Knapp \& Barrie, 1998, 2001). Hungerford and Hungerford and Volk propose three categories of variables including: entry-level, ownership, and empowerment variables, that lead to a change in environmental behavior. Entry-level variables include a general awareness of a resource site (Knapp, 2007; Knapp \& Barrie, 1998, 2001) and basic environmental sensitivity (Hungerford \& Volk, 2001). Environmental sensitivity is a result of a person's contact with a pristine environment (versus a damaged one), either with friends and family or alone. Important to note is that environmental sensitivity was built over a long period of time (Hungerford \& Volk, 2001). The variables impacting behavior change are ownership and empowerment factors. Elements of ownership include the ability to understand issues surrounding the site and having the skills necessary to investigate these issues (Knapp, 2007; Knapp \& Barrie, 1998, 2001). Empowerment variables include the knowledge and skills for appropriate action to tackle the 
issue (Knapp, 2007; Knapp \& Barrie, 1998; 2001). This perceived skill in applying environmental action strategies is the best predictor of behavior (Hungerford, 1996; Hungerford \& Volk, 2001). Kuo (2002) clarifies that because the immediate benefits of interpretation are difficult to measure, the change of visitor behavior may not be the direct result from the interpretive program, but rather a culmination of factors. Also, Knapp found little evidence of changes in environmental behavior, particularly long-term, and attributed results to the difficult nature in changing people's behavior and to the short term nature of programs. As such, Knapp promotes focusing interpretive programs on entry level variables. However, there are several factors that contribute long-term to an attitude of responsible environmental behavior including: education, adult role models, environmental organizations, positive experiences in natural areas, and first hand negative experiences with environmental degradation. The most influential variable was experiences with others outdoors at an early age for long periods of time, emphasizing the importance of family recreation (Knapp, 2007).

This section illustrates the similarities in research findings in studies in interpretation and the lack of both long-term memory studies and longitudinal investigations. While visitors may make intellectual connections, these do not always convert to emotional ones nor to a change in behavior.

\section{Meaning-Making}

Silverman (1999) described how meaning is defined in numerous ways and the lack of a singular definition presents a difficult concept to grasp. Meaning can be used to describe a person's intention, a particular understanding, or even an individual's subjective value of importance. Meaning making as used in this study refers to how we make sense of the world 
around us, it is the construction of meaning and understanding (Ansbacher, 1999; Falk \& Dierking, 2000; Gutwill-Wise \& Allen, 2002a, 2002b; Hein, n.d., 1991, 1999; Rounds, 1999; Silverman, 1999; Spock, 1999). Meaning making is the result of being human; it is inevitable. As humans, we strive to make sense and derive meaning and understanding from interactions with the environment (Hein, n.d., 1999; Falk \& Dierking, 2000). The meanings people find regarding natural and cultural resources are shaped by cultural, ethnic, and life experiences (Rounds, 1999; Silverman, 1999; Tardona, 2005). On a fundamental level, Rounds presents that humans are not simply concerned with avoiding pain and gaining pleasure, but rather to see meaning in life. The age old question is "what is the meaning of my life?". It is the intent of interpretation to help visitors answer that question by helping them make meaning of their experiences. "Personal interest was the most frequent reason given for selecting an interpretive experience as most meaningful" (Beck \& Cable, 2002, p. 15). It is essential for interpretation to understand what drives people to connect and create personal meaning with natural and cultural resources (Tardona, 2005). The most meaningful interpretive programs resonate with peoples' most deeply held concerns (Spock, 1999) and in interpretation is addressed through themes and universal concepts (Ham, 2004; Larsen, 2003). "The interpretive process encourages an internalization of meaning through the use of themes that contain universal concepts that may be comprehended by the greatest number of people" (Benton, 2008, p. 299).

As noted earlier, constructivism includes meaning making as part of learning. Constructivism or constructivist learning theory not only acknowledges personal meaning making, meaning making is the central component of learning and education in constructivist learning theory (Hein, n.d., 1999; Spock, 1999). Constructivist theory entails that all meanings are constructed by the learner from the environment in context to the learner's past experiences 
and cognitive framework (Spock, 1999). "Regardless of whether we call it 'construct new knowledge' or 'make meaning', learning consists of meaning making” (Hein, n.d., p. 7; Hein, 1999, p. 16). All learning entails meaning making and all meaning making is also learning. Because humans have experiences, learning occurs, and consequently, construct meaning (Hein, n.d., 1999). Constructivist learning posits that the goal of an interpretive or education program is to facilitate meaning making (Hein, n.d.). Ham (2004) even states "Interpretation is 'meaning making"” (p. 1).

As interpretation is meaning making, and interpretation is also a transactional communication process, then, it follows that meaning making is also a transactional communication process (Goldman, Chen, \& Larsen, 2001; Beck \& Cable, 2002). No longer is communication considered a linear sender-receiver process. Rather meaning-making envisions communication as a negotiation process between individuals where knowledge and meaning is created rather than transmitted. A person receiving information forms meaning based on his/her accumulation of past knowledge and experiences. As with the transactional communication model, meaning making is a collective process. Goldman, et al., (2001) elaborate, "It is an exchange of symbolic resources through a give-and-take interaction that requires significant effort" (p. 22).

Similar to learning and interpretation, within meaning making there are key considerations. First is that "'Meaning' is always about something. Thus to understand visitor meaning making, we need to ask what is it they are making meaning about" (Rounds, 1999, p. 7, emphasis in original). Silverman (1999) found that the visitors she studied constructed meaning about themselves including their identity, their place in the world, and the meaning of their lives, thus emphasizing the importance that interpretive programs be relevant. 
Second, meaning making is a social process, as is learning. While individuals construct meaning in their own minds, the meanings they create are shaped by social and cultural influences (Rounds, 1999; Silverman, 1999; Tardona, 2005).

Spock (1999) illustrates that meaning making takes time. In his examples, visitors made connections a long as 50 years after the initial program; it sometimes takes awhile for the broad meaning-making potential of an exhibit experience to come to fruition. This is a result of new knowledge being acquired long after the program is over. Meaning making therefore also includes post-site experiences as well. Because it may take many years for an experience to reveal the full meaning, longitudinal studies are critical.

Because personal meaning making is inevitable, it is critical to know what prior knowledge including experiences, connections, and memories, visitors bring with them to a site or interpretive program. Since audiences are diverse and no two recreation sites or interpretive programs identical, this must be assessed at each site or program (Hein, 1999).

Hein (1998) states "there can be no learning (or meaning making) if there's been no interaction" (p. 136). Thus, visitor interaction with the resource and interpreter or interpretive media is essential in meaning making, interpretation, and learning. Illustrating the importance of engaging interaction, Ham (2004) also emphasizes the value of emotion when he states that the most profound and meaningful experiences at natural and cultural sites happen when visitors engage their minds and emotions with what they've been seeing and doing.

When information also has an emotional component, there is an increase in retention, understanding, and recall (Rupp, 1999). The more emotional the experience, the more likely someone is to remember and the more able to find meaning in what he/she has encountered. The connection between experience and creating new understanding is reinforced by emotional 
connections, thus making the experience memorable. Rupp (1999) noted, "When things are remembered they become part of our human ability to make connections between the present, the past and the future. These connections are what give experiences and information meaning in the larger context of our lives" (p. 43).

Just like constructivist learning discussed earlier, visitors create their own personal meanings in conjunction with the meanings presented by interpreters. "Expert interpretation matters" (Silverman, 1999, p. 13). The fact that people make their own meanings does not indicate meaning making cannot be without guidance. An interpreter facilitating the experience does not diminish the meaning that the visitor makes, (Ansbacher, 1999) and in fact, can enhance it.

\section{How meaning is made}

Silverman (1999) suggests there are several ways to constructing meaning. One is to establish or determine what something is. For example, a visitor can determine that there is a high school letterman jacket in front of him/her. Second is evaluation, where visitors express an opinion or judgment about something. For example, the visitor can associate the color of the jacket with a rival team leading to express a negative judgment about the jacket. There is also an absolute object description, which Silverman (1999) describes as solely describing what is before the visitor. Here, a visitor would only give a description of the jacket; i.e. there is a jacket with sleeves a differing color than the body, with a letter on the right breast area. Visitors may also relate special knowledge about what is something is. An example of relating special knowledge would be if the visitor stated that in order to possess a letterman jacket, a student had to participate in a varsity sport for three years. Last, visitors relate personal experience by connecting to the something. A visitor talking about when he/she first received his/her letterman 
jacket would be an example of relating personal experience. Visitors usually make meaning through a combination of these structures.

While the previous section discussed the how of meaning making, the following section talks about categories as what type of meanings visitors are making. Types of meaning

In a study of paired museum goers, Silverman (1991) found visitors made three types of meaning. First was objective meaning, which entailed the meaning intended by the exhibit designers. Second was subjective meaning associated with personal experience, and the third was a combination of both objective and subjective. Visitors with less formal education were more likely to make subjective meanings than those with higher education. More educated visitors were more likely to make objective or combination type meanings. However, even more influential on meaning than education was the nature of the visitor pair relationship, specifically gender configuration, and how long the two people knew each other. Silverman's findings emphasize the social nature of learning and meaning making.

Benton (2008) examined interpretive programs and meaning making at Grand Canyon National Park using qualitative methods. Because visitors make meaning through a constant process of remembering and connecting, Benton investigated long-term recollection six months after the program. He found that visitors created meanings emotionally, intellectually, socially, and across time. Chen (2003) found similar results in her unpublished dissertation exploring the National Park Service's Interpretive Development Program's (IDP) opportunities for intellectual and emotional connections between visitor and resource meanings. She found that interpretive programs submitted for IDP review provided many more intellectual connections than emotional ones even though strong emotional attachments contribute to a sense of ownership and 
conservation. Both studies illustrate that meaning can be construed not just intellectually, but emotionally as well. Benton highlighted the importance of meaning-making, informal learning, and memory, "The study found that long-term memory of a museum experience - the kind that contributes to new knowledge-is constructed from elements brought forth from the meaningmaking process" (p. 309).

In summary, this section discussed meaning making, how it occurs, and what types of meanings visitors make during informal education. The next section moves to civic responsibility and engagement, including the components of civic knowledge and civic skills.

\section{Civic Responsibility/Engagement}

While the preceding sections discuss learning, knowledge, memory, informal learning, interpretation, and meaning making, it may not be readily apparent how they connect to civic engagement. The connection is based on that fact that civic education rests on civic knowledge and skills. In this section, civic engagement and responsibility are first defined. Distinctions are then made between civic engagement and public participation. Types of citizenry are also discussed as are factors influencing civic engagement and barriers to civic engagement.

What are civic responsibility and civic engagement? According to Sevcenko and Russell-Ciardi (2008) there is no consensus about the terms, but they note that the National Park Service (NPS) defines civic engagement as "“a continuous, dynamic conversation with the public on many levels and a commitment to building sustainable relationships with communities of interest"” (p. 10). The NPS also characterizes civic engagement as "'a focus of current efforts at partnering with communities, expanding our educational agenda, and working with communities and partners"” (Linenthal, 2008, p. 5). Linenthal continues "Civic engagement for the NPS 
means a focus on an inclusive process: 'stakeholder' involvement in park planning, for example, from programming to land acquisition issues, as well as partnerships with educational and professional organizations" (p. 6; 2006, p. 124). Even scholars at the forum for the National Park Service and Civic Reflection note in the NPS, civic engagement "means one thing, a focus on an inclusive process and the word stakeholder often comes up" (NPS-CSI, 2006, p. 14). In one of the few published instances in which the NPS addressed civic engagement, the NPS Scholar's Forum on Civic Engagement, participants used the term civic engagement when discussing public inclusion.

This "inclusion" mindset is not, however, the way most scholars define civic engagement, but rather public participation, according to the recreation, planning, and policy fields. Public participation is the process of including the public, and was first mandated by the National Environmental Policy Act (NEPA) in 1972. Rowe and Frewer (2000) provide the most concise portrayal of public participation: it "encompasses a group of procedures designed to consult, involve, and inform the public to allow those affected by a decision to have input into that decision" (p. 6). Public participation methods include referenda, public hearings or inquiries, public opinion surveys, negotiated rule making, consensus conference, citizens panel, public advisory committee, or focus groups (Rowe \& Frewer, 2000).

Therefore it appears that the NPS is using the phrase civic engagement in ways that are different than other fields. Thus, we return to the question, what is civic responsibility and civic engagement? The term civic actually stems from the Latin civicus, or civis, meaning citizen, and Merriam-Webster defines civic as "of or relating to citizen, citizenship, or community affairs" (Merriam-Webster, 2010). Responsibility is "moral, legal, or mental accountability; burden" and engagement is defined as "emotional involvement or commitment; the state of being engaged" 
which is "to offer (as one's word) as security for a debt or cause; to pledge oneself; promise; to bind (as oneself) to do something; to take part, participate; to give attention to something; to come together and interlock"(Merriam-Webster, 2010). Thus, most simply, civic responsibility is the duty of a citizen (Dictionary.com, 2010; thefreedictionary.com, 2010); and civic engagement is the commitment, involvement, or binding of a citizen in participation in those duties and burdens laid on each one of us because we are members of the democracy of the United States. Not only is each citizen bound to those duties and responsibilities, through participation, we become bound to each other, forming civil society and our communities. From the public works field, Boyte (2000) said, “"Civic engagement should be seen as catalyzing citizen work, not simply doing things for people"' (p. 8). In 1929, Mary Mims wrote in her widely read book, The Awakening Community, “'We've been too much inclined to depend on beginning at the top in our efforts at reform. So-called "social workers" cannot hammer a community into shape. If a community is grows, it must do so from the inside"' (Boyte, 2000, p.

3). Ehrilch (2000), a noted scholar on democracy and public policy, elaborates,

Civic engagement means working to make a difference in the civic life of our communities and developing the combination of knowledge, skills, values, and motivations to make that difference. It means promoting the quality of life in a community, through both political and non-political processes (p. vi). A morally and civically responsible individual recognizes himself or herself as a member of a larger social fabric and therefore considers social problems to be at least partly his or her own; such an individual is willing to see the moral and civic dimensions of issues, to make and justify moral and civic judgments, and to take action when appropriate (p. xxiv).

In the U. S., civic responsibility and engagement roots itself in democracy through the Constitution, which declares, "We the people of the United States, in order to form a more perfect union, establish justice, insure domestic tranquility, provide for the common defense, promote the general welfare, and secure the blessings of liberty to ourselves and our prosperity, do ordain and establish this Constitution for the United States". By engaging in civic 
responsibility, citizens uphold democratic values written into the Constitution. Those democratic values and duties include: authority, diversity, due process, equality, freedom, human rights, justice, mutual assistance, participation, patriotism, privacy, property, rule of law, self respect, self restraint, tolerance, and truth.

There are three seminal works regarding civic engagement and the NPS. First, is the Scholars Forum which took place in 2006 (NPS-CSI, 2006). While the report is somewhat incoherent in that it blocks texts from each speaker, with little fluidity between, it begins with the premise that civic engagement hinges on the values of democracy mentioned above. It notes that civic education is declining, but integral to civic engagement. These premises (which have also been noted in other fields) are discussed in much greater detail in the following subsections. However, the various talks appear to morph civic engagement into something very different. One scholar remarked, "Civic engagement has always been a way of doing business, although it was not always done with great sensitivity" (p. 14). However, civic engagement is not a way in which the NPS does business. If we rely upon the earlier noted definition from other fields, civic engagement is actually not a way in which anybody other than a citizen strives to improve the democratic society in which he/she lives--therefore federal agencies like the NPS cannot really "do" civic engagement.

Linenthal $(2006,2008)$ contributes the second work, an op-ed article on the NPS and civic engagement. Similar to the first piece, Linenthal recounts stories of public participation and collaborative planning under the guise of calling it civic engagement. The definition he uses contains similar language to that of public participation, "partnering with communities... working with communities and partners..." (2008, p. 5). Again, civic engagement and public participation or collaboration are two different concepts. 
The third work is the NPS and civic engagement is the Interpretation and Education Program Logic Model (NPS, 2006a), displayed below (See Figure 2).

Figure 2

Interpretation and Education Program Logic Model

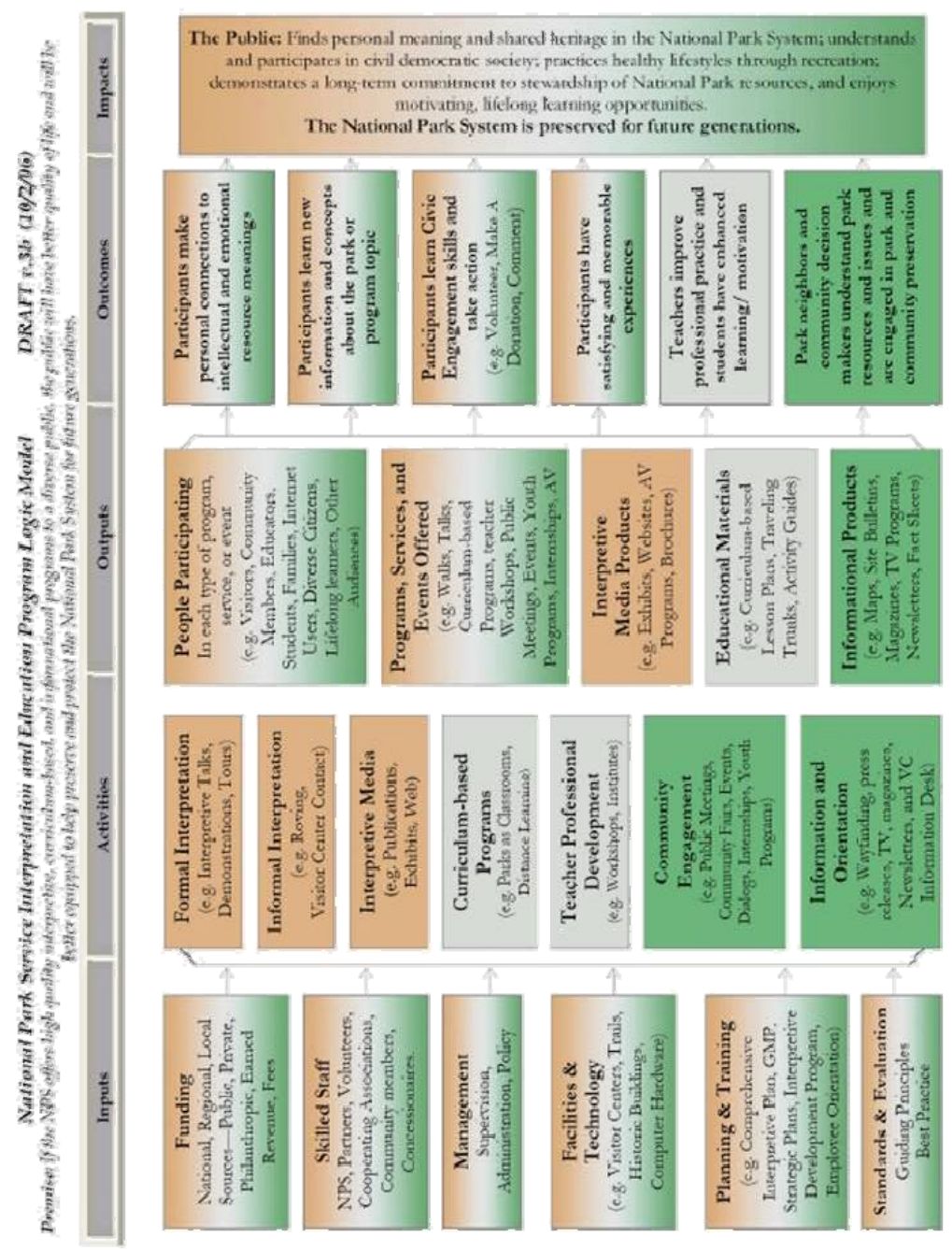

As illustrated, the model accurately describes opportunities for public involvement as areas for community engagement. Community engagement involves participation by and for the community, focusing on an inclusive scale versus the individual citizen. Activities described include those of public participation. The second aspect of the model is that of civic engagement 
skills. While the actions described are not skills per say, they are civic behaviors (Brady, Verba, \& Schlozman, 1995) and are addressed as actions in the model. Civic skills may be developed at work, church, or other structured social event (Kirlin, 2003) so this is an applicable use of the term by the NPS and a realistic outcome.

The only critical work regarding civic engagement and museums (one type of informal learning venue) is the book Mastering Civic Engagement: A Challenge to Museums, written by the American Association of Museums (2002). This work is much like the first paper dealing with the NPS; while using the term civic engagement, the concept being discussed is public participation. On several occasions, contributors even use the terms collaboration or collaborative leadership. While similar to public participation, still neither of these is civic engagement. Thus, while on face value this book appears useful, in reality it contributes little to the field of civic engagement and museums.

There is a distinct difference between civic engagement and public participation. Just as a grassroots movement begins at an individual local level and by definition cannot come from the top, neither can civic engagement. Civic engagement by definition begins with the individual citizen and cannot be initiated from a ruling body. That which is initiated by the ruling body to involve the public in the decision making process is called public participation. To reiterate, civic engagement is the involvement of a citizen in the civic duties placed on us as members of a democracy. Public participation is a process an agency adheres to in order to ensure the public has input into agency decisions. While civic duty may compel a citizen to sit on an advisory committee (for a governmental agency), the act of involvement is civic engagement, and the process of the citizen becoming involved in the committee is public participation. They are two 
different and distinct ideas; one from the viewpoint of the individual, the other from the agency; one is a state of being or action, (Ehlrich, 2000) the other a process (Rowe \& Frewer, 2000).

\section{Civic Education/Civic Knowledge}

One issue surrounding civic responsibility and engagement is teaching children and the current generation the value of civic engagement and the duties involved in becoming a member of society in the U.S. It is critical for the continuance and advancement of democracy that society be informed by the mistakes of the past (Masango, 2008; Sevcenko \& Russell-Ciardi, 2008). As the old adage goes, those who cannot remember the past are condemned to repeat it. Civic knowledge is essential as Hanson (2008) elaborates, "Education for citizenship [is] seen as essential to the development of a well-formed and critically thinking society" (p. 3). "If we forget the lessons of the past, we lack any models to live by in the present. We find ourselves as inactive as our ancestors were proactive. For this country to continue, a majority of it's citizens each generation must believe not that it is perfect, but rather it is far better than the alternative, and therefore worth investing one's loyalty and talents in its preservation". Thus, civic education and knowledge are critical for the future of America (Sax, 2000).

\section{Civic Skills}

Is knowledge about democracy and how to be a good citizen enough? What constitutes an engaged citizen? If we go back to Ehrilch's (2000) definition, we see that there are four components to a citizen must possess in order to be civically engaged: knowledge, skills, values, and motivation to make a difference.

While knowledge is important, knowledge in and of itself does not equate to civic engagement. Kirlin (2003) describes this combination of requirements, "Civic skills do not exist in a vacuum; they are part of a larger set of ideas about what is believed to be necessary for 
citizens to be engaged in public life. Civic skills are part of a larger package including knowledge, motivation or interest, connections to networks of engaged people, and resources (time and money)" (p. 3-4). Communication and organizational abilities are essential to civic engagement; those individuals who can speak or write well or who are comfortable organizing a meeting are likely to be more effective when engaged in politics. Brady, et al., (1995) differentiate between civic behaviors (the action of writing a letter to a congressman) and the civic skills necessary to actually write the letter. Thus, they outline several civic skills including: competency in English, writing letters, vocabulary, going to meetings, planning or chairing a meeting, or giving a presentation or speech. Contrary to other research, Brady, et al., (1995) also discovered that job level, organizational affiliation, religious attendance, and free time were not significant indicators of civic engagement, but civic skills, education level, vocabulary, and citizenship status were significant predictors of civic engagement.

\section{Types of Citizenry}

Ehrlich (2000) also elaborates that civic engagement takes place in both the political and non-political arenas, and that citizens must take ownership of social problems and take action when appropriate. Parker (1996) discusses various types of citizens as "traditional", "progressive", and "advanced". Traditional citizens emphasize core democratic values such as freedom of speech. Progressives share a similar commitment to civic knowledge with traditionalists, but place a greater emphasis on civic participation. Advanced citizens are ones who build on the progressive perspective. Westheimer and Kahne (2004a, 2004b) propose three types of citizens with varying degrees of ownership of problems and levels of action. First, is the personally responsible citizen who "acts responsibly in his/her community by, for example, picking up litter, giving blood, recycling, volunteering, and staying out of debt” (2004 b, p. 242). 
The personally responsible citizen is similar to Parker's (1996) traditional citizen. The participatory citizen actively participates in the social life and civic affairs of the community at a local, state, or national level, similar to the progressive citizen of Parker (1996). And finally, the justice oriented citizen calls attention to matters of injustice and pursues social justice goals. While Parker (1996) does not detail actions taken by advanced citizen, perhaps this citizen aligns with the justice oriented citizen of Westheimer and Kahne (2004a \& 2004b).

Westheimer and Kahne (2004a \& 2004b) use an example of a food drive to illustrate the three types of citizens: "if the participatory citizens are organizing the food drive and personally responsible citizens are donating food, justice oriented citizens are asking why people are hungry and acting on what they discover" (2004b, p. 243). The authors (2004a) warn though, of limits of personal responsibility, pointing out that "the emphasis placed on individual character and behavior obscures the need for collective and public sector initiatives; that volunteerism and kindness are put forward as ways of avoiding politics and policy" (p. 243). Westheimer and Kahne (2004b) also caution that desirable character traits and goals of honesty, respect, good neighborliness, etc, are not inherently about democracy. "These are desirable traits for people living in a community. But they are not about democratic citizenship. In a very real sense, youth seem to be 'learning' that citizenship does not require democratic governments, politics, or even endeavors" (p. 244).

Nie, Junn, and Stehlik-Barry (1996) also discuss citizen types, and propose two types of citizens: enlightened and engaged. The enlightened citizen has relevant and adequate knowledge about democracy and democratic values such as tolerance, similar to Parker's (1996) traditional citizen. It is the engaged citizen who actually participates in the political processes and activities that require an additional commitment of time and energy. The engaged citizen aligns with 
Parker's progressive and advanced citizen and Westheimer and Kahne's (2004a \& 2004b) participatory citizen. The engaged citizen could potentially be a justice oriented citizen (Westheimer \& Kahne, 2004a \& 2004b), but not necessarily. Both the enlightened and engaged citizen require education, but the engaged citizen also has a social network surrounding their involvement in public life, which Brady et., al, (1995) suggests helps civic skill development.

To summarize, various authors have proposed different terms for the level of involvement of a citizen. While most are similar, it seems that each author proposes a gradient of sort for citizenry, with little to no participation on one end, and the other end composed of the most actively involved citizen. What then influences whether or not a citizen becomes engaged? The next section will discuss factors influencing civic engagement.

Factors influencing civic engagement

Sax (2000) noted, "'If there is a crisis in education in the United States today, it is less that test scores have declined than it is that we have failed to provide the education for citizenship that is still the most important responsibility of the nation's schools and colleges"' (quoting Carnegie Foundation Report, p. 3). "What good citizenship is and what good citizens do" should be embodied by education programs on democracy nationwide (Westheimer \& Kahne, 2004a, p. 241). Based on this, in the U.S., citizenship is taught in formal education curriculum. As such, the majority of research on civic engagement deals with studying formal education programs that instill democratic values in students and teach them about civic duty. The reason for including civic education in formal education is that formal education (K-12) is not optional, thus all students receive some form of civic education about democratic values so that the current generation becomes proactive in our democratic society now, and in the future. 
In a statewide assessment of senior California students, the California Survey of Civic Education presented eight conclusions about its future citizens (N.A., 2005). First, high school seniors in California care about those in need and are willing to help, with $84 \%$ reporting they volunteered. Second, students are not well prepared for citizenship, with the majority indicating they were not well informed enough to vote. Also, these students express little trust in government and government officials. Galston (2007) also noted this decline in American's trust in the national government, as well as trust in one another as citizens. These last two findings were consistent with Syvertsen, Flanagan, and Stout's (2007) assessment of nearly 2000 students aged 12-18 nationwide, where they found that students who took field trips to government offices to gain a first hand experience of the political process were less likely to trust public officials or express an interest in civic engagement and had lower political self efficacy regarding voting. However, the authors found that watching a presidential debate was a significant and positive predictor of students' self efficacy in casting an informed vote.

Next, for the California seniors, volunteering did not necessarily translate to other forms of civic engagement. This is contrary to Gallant, Smale, and Arai (2010) who found that community service led to civic engagement. Sixty-four percent of the California students stated that they volunteered more than once during high school, which is consistent with national findings demonstrating that volunteer rates are up dramatically from previous decades, but apparently this increased volunteerism has not translated to other forms of civic engagement in California (N.A., 2005). Colby, Ehrilch, Beaumont, and Stephens, (2003), Galston (2007), and Sax (2000) concur, also finding that although there has been a decline in civic engagement, there has been an increase in young people volunteering. Colby, et al. (2003) stated, "These students understand that their communities face real needs that they can help meet...[but] this 
involvement does not seem to foster a broader or deeper forms of civic or political engagement among them" (p. 8). Sax found that while students' volunteerism has increased, interest in politics has waned. This was explained as "students today are unlikely to view politics as an effective vehicle for change. As a result, many see no particular benefit to getting involved in the larger political system. Instead...students are trying to make a difference by taking action in their local communities" through volunteering (p. 7).

This is also supported by the Individual and Campus Assessment Tools (N.A., n.d.) which suggests that volunteering may not predict concern about the community as a whole, but rather only the portion of the community to which the volunteer can relate. This type of volunteering is deemed as social bonding and not considered a measure of increased civicmindedness. Westheimer and Kahne (2004a) offer a different explanation, that while most school-based civic education focuses on promoting service through service learning and community service programs, this does not in itself foster democracy. Service type programs promote individual acts like volunteerism and service, but not democratic values, social justice, or systematic social change.

In California, the study recommended that students need to be exposed to civic lessons in the classroom and then practice those civic skills. Practicing civic skills led to students' more realistic evaluation of their ability to communicate their political voice with others and critically analyze political information (Kirlin, 2003). The skills of communication and critical thinking were two of the four categories Kirlin found in her analysis of civic skills fostering civic engagement. The other two categories were organization and collective decision-making.

Also, for California students, extracurricular activities play an important role in fostering students' connection with society and their civic responsibilities. Those students who 
participated in activities such as student government or the school newspaper were $24 \%$ more likely to agree that being involved in state and local politics was their responsibility versus students who did not report extracurricular activities. Gallant et, al., (2005) found similar results among college students who had participated in mandatory "volunteering" during high school. Extracurricular activities were significantly related to students' attitudes of social responsibility. In an analysis of the role of civic skills in fostering civic engagement, Kirlin (2003) stresses, "the repeated correlation between adolescent extracurricular participation and adult civic engagement" (p.12) with extracurricular activities including service learning, community service, and other youth development programs. Participating in organized groups during adolescence allows youth to encounter the basic roles and processes required for civic engagement as an adult. When youth are involved in extracurricular activities, they encounter projects and governance over their own organizations which foster leadership and civic skills useful for civic engagement later in life. They are also more likely to encounter adults who can serve as role models (Kirlin, 2003). Kirlin also notes the relationship between church participation (occasionally viewed as an extracurricular activity) and civic engagement, as church also fosters relationships with adults who serve as role models. The church environment also provides exposure to organizational structure and opportunities for participation, teaching civic skills. Sax (2000) found that among college freshman, attending religious services promoted postcollege volunteerism as well as commitment to social activism while in college. Gallant et al., (2007) also determined that religion and gender (being female) significantly affected ongoing volunteering.

The second to last findings in California public schools was that multiple opportunities for civic engagement were important. As with learning, memory, and interpretation, students 
need to be exposed to repeated messages regarding civic engagement; a single shot of civics was not enough to develop participatory citizens (N.A., 2005). This is consistent with prior research illustrating that for students to become civically engaged as participatory citizens, the educational process must develop both the civic knowledge and civic skills (Kirlin, 2003).

Finally, the California Survey of Civic Education found that there was unequal access to opportunities to develop civic knowledge and skills. Kirlin (2003) notes that urban youth have even fewer opportunities to develop civic competence than their suburban peers. Those students who expected to continue on to post-secondary education had more opportunities in the classroom than those who either had no aspirations beyond high school or planned on vocational education after high school (N.A., 2005). This is important to note because education and parental education is highly correlated with civic participation and engagement (Kirlin, 2003). Similarly, Brady, et al., (1995) found that adults who never finished high school received little opportunity elsewhere to develop civic skills.

In studying students, Flanagan, Syvertsen, and Stout (2007) discovered that "a good way to gauge an adolescent's interest in politics and current events is to ask whether s/he discusses these issue with others" (p. 22). Galston (2007) suggests that a classroom climate conducive to open discussion helps foster civic engagement, as well as frequent discussion. The frequency that current civic events were discussed in class effected civic education and knowledge. Discussion with others has not been addressed elsewhere in the civic engagement literature, but may play an important role in civic engagement, because discussion as a form of social interaction is critical for learning.

The prior passages address factors that influence civic engagement, in relationship to formal education. While civic engagement is down, volunteering has increased, and various 
explanations were given for this anomaly. Students expressed little trust in government officials and were also not well informed enough to vote, emphasizing the need for civic education. Practicing civic skills produced more realistic evaluations from students, and extracurricular activities played an important role in fostering civic knowledge regarding civic engagement. Multiple opportunities for exposure to civic engagement was important but there was unequal access to those opportunities. Lastly, students who discuss issues with others foster a greater interest in social issues. With these factors influencing civic engagement, what obstacles might exist to prevent a citizen from becoming engaged in the community?

\section{Obstacles to Civic Engagement}

While taken from a perspective relating to the university setting, Boyte (2000) found five obstacles to civic engagement that are applicable to American society today. First was the erosion of broad public purpose. Boyte noted, “"Every time something goes wrong, we create a dozen rules"'( p. 11), and this causes increased bureaucracy and over-regulation, which has resulted in drawing back from a larger connection to the whole. Common vision and sense of direction has greatly weakened. Second, as a result, there is a loss of community and sense of collective efficacy. The culture in the U.S. is increasingly competitive, individualistic, and characterized by personal achievement rather than a collective action that can bring about change. Third, within the academic community, restrictive theories of knowledge are obstacles to civic engagement, "Scholarly bias has long slighted what the Greeks called phronesis, or knowledge gained through engagement with the public world, and privileged sophia, or the ideal of the detached and isolated scholar" (Boyte, 2000, p. 12). Next, Boyte warns of historical amnesia of the civic mission of public universities, paralleling Hanson's (2008) observation of historical amnesia of civic duty in the U.S. The last obstacle discussed is the flawed theoretical 
map of civic engagement. Boyte warns that "public service is a one-directional effort to 'help' or enlighten, rather than a partnership in which members of the university and community work together to create things of public usefulness" (p. 12).

Mettler (2007) goes even further by suggesting that government should be brought back into civic engagement: In her analysis of federal assistance programs, those who partook of federal programs were more civically engaged than those who did not. When citizens participate in well known federal social programs like the G.I Bill, they became more civically engaged than non-beneficiaries, partially out of gratitude, partially out of civic duty to repay, and partially from the increase in education they received. Citizens also derive important civic skills in negotiating federal agencies for benefits and become more active politically as they seek to change the system. Mettler argues that service is a two way street, with the responsibility of government to help citizens and citizens becoming civically engaged. But,

with the government's role in promoting social opportunity so well hidden, might we be relinquishing means of conveying to citizens a sense of public life and our common bonds to one another as citizens? ...We are separate individuals, workers, and competitors in the market, rather than citizens joined through government into a shared project of democracy. Such policy approaches are likely to destroy further our fragile sense of social trust and fading willingness to engage in civic organizations and political activities (p. 648-649).

\section{Civic Engagement and Constructivist Learning}

Kirlin (2002) proposes a change in teaching civic knowledge and skills to students to enhance long-term effects of civic engagement. While not explicitly stating as such, it seems that Kirlin calls for civic engagement to be taught based on constructivist learning theory. She suggests "that students have as much latitude as possible to learn and practice civic skills through the process of designing and organizing their activities themselves." Kirlin notes that this does not mean that the teacher disengage from the classroom, but rather facilitate learning: "It means 
facilitating students' discovery of what problems exist, whom they need to contact to address the issues, and what types of projects they will undertake. Adults should facilitate learning by asking questions, and providing support and encouragement, but not prepackaged experiences" (p. 573-574).

Galston (2007) hints at constructivist learning as well when he states that "unless citizens possess a basic level of civic knowledge... it is difficult for them to understand political events or to integrate new information into an existing framework" (p. 637). The author also addresses the social component of learning in discussing civic knowledge, education, and engagement. The social aspect of learning is fostered two ways: first through the classroom environment, and second, through frequent discussion. An encouraging classroom climate versus a hostile environment, promotes respectful discussions of political issues fostering both civic knowledge and engagement. And as noted, the frequency that current civic events were discussed in class effected civic education and knowledge.

\section{Civic Education, Civic Engagement and their Relationship to Interpretation}

The formal education setting has been found to provide an effective means of teaching civic knowledge (Galston, 2007). But what of informal education? Can informal education also provide an effective way to relay civic knowledge and skills, promoting civic engagement?

Civic education typically occurs in formal education from school, colleges, and universities but "consists of a set of complex formal and informal educational processes that attempt to instill appropriate knowledge, skills, values, and behaviors in people so they become good citizens of the country" (Masango, 2008, p. 67). As such, interpretation is informal education--but does it have the prospect to provide opportunities for civic education, and based on the NPS 
Interpretation and Education Program Logic Model, the potential for civic skill building as well? As we have seen, while in general the NPS discusses civic engagement as something akin to public participation, within their logic model above, there is an avenue to address it in a way that other fields have. Currently, there has been no research studying this relationship between civic engagement and interpretation, even though the NPS as included it in their Interpretation and Education Program Logic Model. This project aims to span this gap of knowledge. 


\section{CHAPTER 3: METHODS}

\section{Introduction}

This project is a portion of a much larger research project involving Little Rock Central High School National Historic Site, in Little Rock, AR. The larger project consisted of evaluation of the exhibits at the new visitor center museum at Little Rock Central High School National Historic Site. The larger project used both qualitative and quantitative approaches to investigate the intellectual and emotional connections visitors made to resources. Data collection techniques for the project involved conversation analysis, observations, focus groups, exit interviews, and this portion of the study, follow-up interviews.

\section{Methods}

As this study explores relationships between constructs that have not previously been investigated, the most appropriate method is to use a qualitative approach (Patton, 2002).

Qualitative methods provide for the study of issues in depth and detail and are particularly useful when little is known about a topic. Qualitative methodology allows for the exploration of a subject to understand the relationship between concepts (Patton, 2002). Because of the subjects being explored (learning, knowledge, memory, meaning making, communication, interpretation, and civic engagement) this study is based on a phenomenological perspective. With phenomenology, the underlying question is, what is the meaning or essence of this phenomenon for this person? Patton elaborates on phenomenology, "Thus, phenomenologists focus on how we put together the phenomenon we experience in such a way as to make sense of the world...thus the focus on meaning making as the essence of human experience" (p.106). 


\section{Study Area Selection/Project Background}

Little Rock Central High School National Historic Site was selected as the study area for various reasons. A new visitor center was built in 2007 including a museum area with new nonpersonal interpretive exhibits (NPS, 2006b). Park management was interested in an evaluation of exhibits to determine if visitors were making connections to the resource, what those meanings were, and if visitors were becoming more civically engaged as a result, thus fulfilling the NPS education mission of fostering civic engagement.

Little Rock Central High School National Historic Site uniquely affords opportunities for fostering civic engagement due to the site it protects and subject matter interpreted. Central High School was at the heart of desegregation in the late 1950s when the "Little Rock Nine" were marched in by armed National Guard to attend a then, all White school. The hatred and racism that ensued with the treatment of the nine Black students, the closing of the school, the eventual graduation of those students, and their successes, along with the relationship of these events in the larger civil rights movement are all stories portrayed within the visitor center museum exhibits. Little Rock Central High School National Historic Site is unique in its connection to those who stood up for injustice, were directly involved in the civil rights movement, and who were civically engaged with those political events. Thus Little Rock Central High School National Historic Site offers the perfect setting for investigating the relationship between interpretation and potential civic engagement.

\section{Research Questions}

The research questions addressed in this study are:

R1: What memories do visitors recall from their visit to CHSNHS? 
R2: What kind of knowledge do visitors remember?

R3: Are visitors making meaningful connections to the resource, as assessed using the NPS IDP rubric?

R4: What meanings are visitors making?

R5: How are the meanings made?

R6: Are these meanings connected to civic engagement?

R7: What types of citizens are visitors to Central High School NHS?

R8: Are there changes over time in types of knowledge, meaningful connections, and/or how meanings are made, and if so, what are those changes?

\section{Study Population/Sampling Procedures \& Problems}

As previously stated, this project is part of a much larger study evaluating the

effectiveness of the visitor center museum. As such, it is constrained by the parameters of larger project.

The study population of the larger project consisted of visitor who visited the Little Rock Central High School National Historic Site visitor center museum in July 2009. Visitors were contacted as they exited the museum for a brief exit interview and asked if they would be willing to participate in a follow-up telephone interview 6-12 months later. The study sample for this research project is limited to those individuals who, after initial contact during the exit interview, agreed to participate in the follow-up interviews and provided their contact information.

Of the initial 76 visitors exiting the museum, 49 consented to follow-up interviews. All 49 were contacted a minimum of three times, using a combination of either email or telephone calls. If no one was available to take the phone call, a voice mail message was left along with a 
phone number for the subject to call back. The population was contacted on various days of the week and at various times of the day to maximize contact and potential participation.

\section{Data Collection}

Due to the long-term nature of learning, and to better understand the intellectual and emotional connections visitors are making with the museum exhibits, a longitudinal study was essential. Knapp (2007) discovered both intellectual and emotional connections years after visitors had attended interpretive programs. Following Knapp's (2007) example, this study used follow-up telephone interviews as a means of data collection to discover if and what meanings visitors ascribe to resources. Interviews took place 12 months after participants visited the visitor center museum at Little Rock Central High School National Historic Site.

The telephone interviews were semi-structured in format (Patton, 2002), allowing the interviewer to deviate from a script to probe a subject matter with a respondent. Questions were open-ended in format providing the respondent the opportunity to answer in his/her own words. The interviews were digitally recorded and transcribed verbatim, providing linguistic accuracy (Oliver, Serovich, \& Mason, 2005). Two transcriptionists provided reliability in the accuracy of transcription.

\section{Instrumentation}

As data were collected through telephone interviews, the instrument used was an interview script, allowing for open-ended responses from participants and guiding the interviewer through the semi-structured process. The beginning of the script identified the interviewer to the participant, asked if the current time was appropriate to conduct the interview, 
or if not, when would be a better time to conduct the interview. The beginning also included a reminder that the participant already signed an informed consent to participate in research form when initially contacted at Central High School NHS visitor center. Participants were asked for their permission to audio record the interview to accurately capture their ideas. Once permission was given, they were identified by their respondent number in order to keep answers as confidential as possible (Patton, 2002). Interview questions began general and broad, then focused in on specifics (Knapp, 2007). The interview structure and questions are listed below:

1.) Do you remember visiting CHS NHS?

2.) What do you remember about your visit/ the $\mathrm{VC}$ ?

- Over the past months, have you thought about or reflected on, your visit to Central HS NHS since your visit last summer? What topics or ideas have you reflected on?

3.) What do you think the main idea of the exhibits was? Did anything stand out to you? 3a.) the theme? most important point? Key point?

4.) When exploring the exhibits, did you learn anything you didn't know before or did it reinforce something you already knew? Did you understand anything better or think about something differently?

4a.) Can you give me an example? what did you learn/ what was reinforced?

4b.) any exhibit element stand out to you?

5.) Did the exhibits trigger any emotions or feelings in you? Did you feel anything emotionally when you went through the exhibits?

5 a.) were they positive or negative?

5b.) what kind of emotion?

5c.) Which exhibit made you feel that way?

5d.) Have any emotions lingered? Or Changed?

6.) Was anything in the exhibits personally relevant to you?

6a.) Have you had any life experiences that you saw reflected in the exhibits? 7.) What do the exhibits tell us about civil rights then \& now?

8.) Since your visit, have you participated in any activities or projects for the betterment or improvement of your community/state/nation? Same level or more (increase commitment)? Are any of these things new (ones that you were not participating in before)? Did your visit motivate you to participate in these things?

8a.) done anything that promotes any democratic values?

- Justice

- Freedom

- Equality

- Diversity

- Authority

- Privacy

- Due process 
- Property

- Participation

- Truth

- Patriotism

- Human rights

- Rule of law

- Tolerance

- Mutual assistance

- Self restraint

- Self respect

8b.) done anything that falls under civic responsibilities such as donate $\$$ to charity, serve on jury duty, or volunteered at some place you haven't before?

- Form a more perfect union

- Establish justice

- Insure domestic tranquility

- Provide for common defense

- Promote general welfare

- Secure blessings of liberty for ourselves \& our posterity

8c.) Why did you do those activities/things? (If a friend asked you why you did those things, what would you tell them?)

9.) While you were onsite in July 2009, did you buy anything at the Visitor Center, or take any materials home with you? If so, did you interact/reflect, etc. on those items?

10.) Have you visited CHS since your visit in July 2009?

9a) if yes, how many times

9b) what made/ why did you return/ come back?

9c) what was purpose of the visit? (did your visit motivate you to bring them?)

9d) who with?

11.) If you were to drive by the school and site today, what thoughts (or feelings) would be going through your mind? (Looking for main idea again)

Now for some demographic questions...

12.) What category best describes your age?

$\begin{array}{lllll}18-25 & 26-35 & 36-45 & 46-55 & 56-65\end{array}$

over 75

13.) What is your highest level of education?

Less than high school High school Some college Bachelor's

Masters/graduate degree Doctorate/post graduate

14.) What best describes your employment status:

Employed : what field

Homemaker Student Retired

Unemployed Other:

15.) Is there anything else you would like to share about your visit to Central High

School National Historical Site?

\section{Data Analysis/Treatment of Data}

Analysis in qualitative research is an ongoing process that typically begins during data collection. During data collection, the researcher records ideas and thoughts regarding the 
collection process. Formal data analysis occurs after collection is complete and is guided by both the ideas that emerged during collection and the questions that were generated when designing the study (Patton, 2002). As standard questions were used during the interviews, it logically follows that data were organized around the questions, versus processes or issues. Content analysis is the process of scrutinizing data for patterns and themes to identify consistencies, anomalies, and meanings (Patton, 2002). Data collected during the follow-up interviews were open coded according to the most dominate idea (Strauss \& Corbin, 1998), creating a coding scheme or classification system. Codes were determined based on two criteria: internal homogeneity and external heterogeneity. Internal homogeneity is the extent to which data belong together in a certain category. External heterogeneity describes the way in which differences between categories are clear and distinct (Patton, 2002). This initial process analyzes for convergence, or how things fit together (Patton, 2002).

The second portion of analysis involves divergence, which is what Patton (2002) defines as fleshing out patterns or categories. Divergence can be achieved in three ways: by extension, bridging, and surfacing. Extension is "building upon items of information already known"; bridging is "making connections among different items", and surfacing is "proposing new information that ought to fit and then verifying its existence" (Patton, 2002, p. 466). For this study, analysis for divergence was achieved through extension and bridging, when the data were recoded according to the themes that emerge from the coding scheme (Patton, 2002). This inductive analysis process "involves discovering patterns, themes, and categories in one's data" versus "deductive analysis where the data are analyzed according to an existing framework (Patton, 2002, p. 453). 
To ensure reliable coding both convergently and divergently, a secondary coder provided analysis to collaborate what was stated by interviewees as well as the accuracy of coding. The follow-up interviews were digitally recorded and then transcribed. As this study is interested in the content of the interviews, denaturalized transcriptions will be produced (Oliver, et al., 2005). Two transcribers provided reliability for accurate transcription of the vernacular colloquialism allowing the speaker's emic voice to prevail (Patton, 2002; Oliver, et al., 2005). Coding was conducted both by hand providing reliability through much deeper involvement with the data (Patton, 2002).

Visitor demographics were analyzed quantitatively. Demographics collected were sex, age category, education level, and employment status. As education level and income are highly correlated, income was not asked. Basic frequency statistics were used to analyze demographic data.

\section{Validity \& Reliability}

Patton (2002) discussed four main opportunities for triangulation, a means of increasing accuracy and credibility of findings. They are: methods, data collection, analysis, and theory. Triangulation using methods includes using both qualitative and quantitative methods. The larger evaluation project uses both qualitative and quantitative methods, but this portion of the project relies solely on qualitative analysis. While both can present the same results, often there are divergences and it is those differences that can provide insightful revelations.

Data collection triangulation within qualitative methods includes using interviews, document analysis, and observation. While observations were used in the larger project, interviews and document analysis were used in this portion of the research project. Interviewing 
participants a number of months after their visit provided for interview data collection. Document analysis on the content of the exhibit and background literature allowed for comparison of what was stated by interviewees.

Analysis triangulation was achieved through participant feedback, having a second person code a portion of the data, and expert reviewers. Participant feedback allowed for the interviewees to read the analysis to ensure that the meanings are accurately represented, and if not, to provide ways to correct the analysis. A second coder provided the opportunity to make sure that the researcher accurately coded the data without bias. Expert reviewers provided through my committee members made certain that I had accurately analyzed the data.

For this study, triangulation was therefore achieved through data and analysis triangulation. Data collection triangulation was achieved through interviews and document analysis. Expert reviewers, a second coder, and participant feedback assured analysis triangulation.

\section{Delimitations}

One constraint of this project is the small study population and resulting very small sample size. Due to both the limited number of interviewees and the evaluation of a specific site and exhibits, the results of this project are not generalizeable to other locations. Also, as there are no visitor statistics for CHSNHS, the representativeness of the sample is undeterminable. 


\section{CHAPTER 4: RESULTS}

\section{Introduction}

When analyzing the data collected from the follow-up telephone interviews one year later, there were many interesting themes that emerged. The data were analyzed based on the research questions asked. During analysis, not only were the research questions addressed, but other key findings resulted. These additional results are addressed in detail in the subsequent portion of this chapter.

The research questions addressed were:

R1: What memories do visitors recall from their visit to CHSNHS?

R2: What kind of knowledge do visitors remember?

R3: Are visitors making meaningful connections to the resource?

R4: What meanings are visitors making?

R5: How are the meanings made?

R6: Are these meanings connected to civic engagement?

R7: What types of citizens are visitors to Central High School NHS?

R8: Are there changes over time in types of knowledge, meaningful connections, and/or how meanings are made, and if so, what are those changes?

A brief summary of the findings is presented first in the following paragraph, and then the complete results are discussed in detail. Visitors recalled a variety of memories from their visit to CHSNHS including episodic and declarative memories, which were the most prevalent. Emotion and people also played a role in what visitors recalled. Socio-cultural, declarative, and episodic knowledge were the most common types of knowledge visitors remembered. Participants made meaningful connections to the resource through both intellectual and emotional connects and these meanings were made by a combination of establishment, evaluation, personal experience, and special knowledge. These meanings were connected primarily to civil rights, and thus, civic engagement. Citizenry was best described as a sliding 
scale, and visitors to Central High School NHS ranged all along the scale of citizenry, from passive to active to engaged citizens. Additional findings not related to the research questions were that souvenirs were important, that visiting CHSNHS opens the doors of communication with others, that the visit and exhibits at Central High School NHS provided encouragement for visitors to continuing to do public works, and that participants are truly altruistic, believing in democratic values of helping others and doing the "right" thing, but they do not seek recognition for what they do. These results are fleshed out in the following sections, but first, the demographics of the respondents are addressed.

\section{Demographics}

Of the 17 usable interviews, 10 participants were male, seven female. Two respondents did not provide demographic data. Respondents' age ranged from $18-25$ to over 75 , with the median age 46-55. All respondents had at least some college, nine of which either had or were working on a graduate degree. Eight were employed full time in the education field, four were retired, and three employed in other fields. Three individuals indicated they had returned to Central after their July 2009 visit. While race was not asked during the interviews, several participants offered this information freely during their responses. It was determined that there were six Whites, six Blacks, and one Hispanic participant.

\section{Research Question \#1: Memories}

The first research question addressed "What memories do visitors recall from their visit to CHSNHS?" There were two major findings that emerged from analysis of the data. The first 
finding related to the types of memories that visitors recalled. Four types of memories were prevalent: declarative, structural, experiential, and episodic.

Declarative memories were the most commonly recounted, noted by 15 of 17 participants. For example, visitors mentioned a number of things associated with the visitor center, including the gift shop, the school, the gas station, the museum, difference types of exhibits, etc. (See Table 1). In total, there were 92 items recalled by the 15 participants. These items were open coded into 8 categories: Exhibits, people, women, larger world events, the school, the Little Rock Nine, the museum-bookstore-gift shop, and the gas station and window. An item could fall into more than one category based upon what it included. For example, the mention of discrimination against women was grouped into exhibits (there was an exhibit on discrimination against women), larger world events, and women.

Table 1

Types of Declarative Memories by Number of Remarks and Respondents

\begin{tabular}{lcc} 
Declarative Memories & $\begin{array}{c}\# \\
\text { remarks }\end{array}$ & \# respondents \\
\hline 1. Exhibits & 43 & 15 \\
A. Artifacts & 16 & 12 \\
$\quad$ a. Photos & 10 & 10 \\
b. Clothes & 4 & 4 \\
B. Interactive Displays & 14 & 9 \\
$\quad$ a. Videos & 4 & 4 \\
2. People (other than LR9) & 16 & 11 \\
A. People behind LR9 & 9 & 8 \\
B. National Guard & 3 & 3 \\
C. Other visitors & 2 & 2 \\
3. Little Rock 9 & 12 & 12 \\
4. The School & 12 & 9 \\
A. Size & 4 & 4 \\
5. Museum/bookstore/gift shop & 6 & 5 \\
6. Gas station / window & 5 & 5 \\
7. Women & 4 & 4 \\
8. Larger World Events & 4 & 3
\end{tabular}


The most frequently mentioned category in declarative memories was exhibits, with fifteen of seventeen respondents mentioning something about the exhibits a total of 42 times. The most commonly mentioned exhibit items were artifacts, with 10 individuals making remarks about photos, and four participants mentioning clothing. Interactive displays were also prevalent with four individuals mentioning the videos.

The next most common category recalled were people other than the Little Rock Nine. Other people, including people behind the Little Rock Nine, such as family or teachers, the National Guard troops, and other visitors were mentioned 16 times. Eight participants mentioned these people behind the Little Rock Nine a total of nine times. Three visitors mentioned the National Guard, and two visitors talked about other visitors.

The Little Rock Nine were brought up by twelve different participants. The school was mentioned twelve times by nine participants. The museum/bookstore/gift shop was talked about six times by five visitors, and the gas station and picture window (through which you can see the gas station) was brought up by five visitors. Women were discussed by four participants and larger world events were mentioned four different times by three participants.

Experiential memories and episodic memories were also common, mentioned by 5 and 4 respondents respectfully. (See Table 2). Experiential memories are those related to experiential knowledge, which is based on previous experience, and includes the ability to relate to similar or current situations (Jonassen, 2009). Episodic memories are those relating to personal happenings or doings (Tulving, 2007; Walls, 2004). An example of an experiential memory is revealed in this example from a male visitor over age 75 as he related his previous experience with the events as a young boy to his visit, "I was...a young man when the school was under siege so 
many years ago and it made an impression on me. I have a newspaper background, and the visuals in the exhibit were just great. The photographs, and the video clips, that's really what I remember most."

A female participant aged 26-35 described her experience with this episode:

I remember coming in and there's a gift shop and then I remember going to and looking at all the pictures and interactive displays that you had and that you could see the school right across the street from the visitor's center. Well I, it was a picture like that was right by the window that looks onto the school and it was like uh, kinda ironic that whoever was standing there took the picture. But that's what I think I remember the most. I was like WOW!. Yes, and that's what I said. And when we were there, I was like, 'oooo', this school is huge. I had uh, my family members laughing 'cause I was like 'Who would go here?' 'cause I wasn't gonna walk through one side to the other!

Two visitors recalled how concepts related, which falls under the realm of structural memories.

For example, a female participant aged 56-65 recounted:

Well, I think what I...one of the things that I liked most and remember most about the exhibit was that it treated prejudice, and bigotry, and racism in general by showing a connection between the Central High School Incident and racial incidents all over the United States and all over the world. Prejudice against color, gender, ethnicity, so I liked the way it put it into the larger picture.

Table 2

Frequency of Types of Memories

\begin{tabular}{lc} 
Types of Memories & Visitor Frequency \\
\hline Declarative & 15 \\
Experiential & 5 \\
Episodic & 4 \\
Structural & 2
\end{tabular}

The second major finding regarding what memories participants recalled about their visit to CHS dealt with the factors influencing their memories. Twelve participants recalled memories associated with emotion, and ten mentioned people, either family members, other visitors they encountered, a ranger, or the Little Rock Nine and those associated with the events. The 
following example from a female participant aged 36-45 captured both when she spoke of emotion and people:

Oh, it's a, it's a...it's a wonderful experience. You know, seeing all the information they collected, you know, for people to use and to see just what happened back then is just awesome. I remember the pictures of...Minnijean Trickey there waiting for someone there to help her out after the kids had taunted her when she was waiting for someone...on, I guess, the bench. And I remember, you know, those pictures of the White students, you know, just screaming out things to the students you know at they were walking in, and the look of fear that was on their faces you know and even in the face of fear, they had the courage to walk through it. You know, it's just an awesome, awesome display and it's even more awesome to know that all of the Little Rock Nine are successful and doing well.

\section{Research Question \#2: Types of Knowledge}

Research question \#2 addressed what kind of knowledge visitors remembered. As types of memories stem from different types of knowledge, results similar to findings from RQ1 were uncovered — visitors remembered declarative, experiential, episodic, and structural knowledge. However, another type of knowledge also emerged from the data: socio-cultural. Socio-cultural knowledge is knowledge that is inherent to a specific culture, and is a type of phenomenological knowledge shared among a culture of people. A female respondent aged 45-55 illustrates sociocultural knowledge:

I would basically say that the main idea to get across was that American history was like that with the Jim Crow laws and things like that and how the kids...particularly at Central High and other schools took a chance, took a huge risk with their lives and their parents' lives to stand up for what is right against what is established back when we established this country.

\section{Research Question \#3 \& \#4: Meaningful Connections}

Question three asks if visitors are making meaningful connections to the resource. The straightforward answer is yes. All 17 participants made some meaningful connection to Central High School NHS. (See Table 3). Question four delved into what meanings were made. Several 
interesting findings emerged in analysis of the meanings. First, all but two participants connected on both an emotional and cognitive level. These two participants connected emotionally but not cognitively. Interestingly, these two participants, both male, were actually there during the events of the Little Rock Nine. One was a student, whose sister was not able to graduate due to the school closing, and the other was a National Guardsman during the event. Table 3

Frequency of Types of Meanings Made

\begin{tabular}{lc} 
Types of Meaning Made & \# Respondents \\
\hline Cognitive Connections & 15 \\
Emotional Connections & 17
\end{tabular}

When connecting cognitively, visitors learned by either gaining new information or the site reinforced what they already knew. The 15 respondents provided 107 responses that were divided into 11 different categories of cognitive meaningful connections. Again, as with categories of memory, the 107 responses were open-coded and thus may have fallen into multiple categories based on to what the item referred. The categories from descending order of most common to least prevalent were: exhibits, other people, the Little Rock Nine, the school, history, conceptual ideas, the museum-bookstore/gift shop, the window and gas station, women, larger world events, and details. (See Table 4).

Table 4

Categories of Meaningful Cognitive Connections by Frequency of Remarks and Respondents

\begin{tabular}{lcc} 
Categories of Cognitive Connections & $\begin{array}{l}\# \\
\text { remarks }\end{array}$ & \# respondents \\
\hline 1. Exhibits & 43 & 15 \\
A. Artifacts & 16 & 12 \\
a. Photos & 10 & 10 \\
b. Clothes & 4 & 4 \\
B. Interactive Displays & 14 & 9
\end{tabular}




$\begin{array}{lcc}\quad \text { a. Videos } & 4 & 4 \\ \text { 2. People (other than LR9) } & 16 & 11 \\ \text { A. People behind LR9 } & 9 & 8 \\ \text { B. National Guard } & 3 & 3 \\ \text { C. Other visitors } & 2 & 2 \\ \text { 3. Little Rock 9 } & 12 & 12 \\ \text { 4. The School } & 12 & 9 \\ \text { A. Size } & 4 & 4 \\ \text { B. Closed } & 2 & 2 \\ \text { 5. History } & 7 & 7 \\ \text { 6. Universal Concepts-Ideas } & 6 & 5 \\ \text { 7. Museum/bookstore/gift shop } & 6 & 5 \\ \text { 8. Gas station / window } & 5 & 5 \\ \text { 9. Women } & 4 & 4 \\ \text { 10. Larger World Events } & 4 & 3 \\ \text { 11. Details } & 3 & 3\end{array}$

Exhibits--including artifacts of photos (mentioned by 10 participants), clothing (discussed by 4 participants), and interactive displays such as videos (mentioned by 4 participants)--were discussed most often regarding cognitive connections to the resource. Recordings and audio were also mentioned two times each, but recordings was not grouped with video or audio as respondents did not provide further detail as to what types of recordings to which they were referring.

People were the second most common cognitive connection with eight participants talking about the people behind the Little Rock Nine nine times. The National Guard was mentioned by three visitors, and two visitors talked about other visitors. These two individuals held a personal conversation on the steps of Central High School. One participant actually participated in the events of desegregation at Central High School providing a first-hand account to the other participant, of black heritage, whose son was just accepted into law school. This interaction provided a very personal cognitive and emotional connection to the resource. As the Black gentleman recalled his encounter with the National Guard soldier: 
It became a very personal experience, right. Mhhmm and then my son is enrolled in that law school there in Little Rock and so and we had seen there and we was in town to get him situated in school and we run into Mr. [Jones] and that was the thing that Mr. [Jones] was you know...interesting because he was...had it not been for him and his...duty... encouraged my son he wouldn't have gone to the law school there in Little Rock.

The Little Rock Nine were discussed by 12 different respondents, and the school was mentioned 12 times by nine respondents. Specifically, the size of the school was talked about on four occasions, and the fact that the school was closed during the desegregation was mentioned twice. Seven respondents mentioned the "history" surrounding Central High School, and conceptual ideas were brought up six times by five visitors. Ideas included such universal concepts as duty, importance, education, and working together. Five participants pointed out the museum bookstore/ gift shop six times, and five visitors talked about the window and gas station (which can be seen through the window). Women were discussed by four different visitors and larger world events were talked about four times by three participants. Larger world events included the American's with Disabilities Act, discrimination against women and women's rights, and desegregation events occurring at other schools within Arkansas. Finally, three visitors mentioned that they connected cognitively to the resource through the details they did not know previously. For example, when asked if she felt she learned anything, a female participant age 18-25 mentioned four categories (history, school, people, and details) when she stated:

Probably the history that I really didn't know about. Mainly like, they had to close down the school for a year and how many people were just involved in that. History books don't really, they don't focus on a lot of 20th century history unfortunately. So, you don't get all the details of everything.

A male visitor aged 56-65 stated:

Well it did both, it certainly reinforced what I already knew about the significance of the Central High and integration but, also there were a number of things I saw, I can't think 
of anything in particular but there was some personal history on some of the participants, having an opportunity to visit, to the see the location across the street, the gas station where the press corps was centralized and that's something you never get to see, and it made it much more, much more personal, probably much more in to the experience of what was going on, to walk where Elizabeth Eckford walked and to walk where Melba Beils walked was fantastic and then we had the opportunity to go inside the high school and see some of the classrooms and hallways and what have you, so it was very moving experience.

The gentleman continues in discussing the emotions he felt when visiting:

For me, it was the size of the high school. I had no idea that it was as large a school physically, as it is, and the fact that it is still in operation today and it is still doing business and that, that was very impressive...I think the emotions that always strike me is having been a high school student myself during that, a junior high and high school student myself during that period, I was only, peripherally aware of the particular incidents, I would see them in news stories so again...being a US history teacher and anytime I am at a historic site, I try to think about what the people who were there and how they would have felt and how those incidents would have been impacting their personal lives and the contributions that made to what we all enjoy in terms of freedoms today....Well, certainly empathy would be with the students themselves but also with the parents of the students who were willing to have their children take the risks of having to integrate the school and the courage that took on the part of the parents and the students themselves and to understand the impact on the White students and white population of Little Rock and their cultural and historic background that put them in the position that they were in. I certainly empathized, I had a deeper empathy I would say with all the participants.

Analysis revealed that when visitors made meaning emotionally, those emotions were both positive and negative. While the above quote highlights the empathy many visitors felt, several visitors expressed feeling both positive and negative emotions when exploring the exhibits. Positive emotions ranged from pride to admiration to encouragement and negative emotions included sadness, empathy, anger, and frustration. The 17 respondents provided 101 counts of emotional connection to the resource. These 101 responses were open-coded into 10 categories, from descending frequency: feelings of affinity, awe, discouragement, moving, empathy, courage, genuine, encouragement, and outliers. (See Table 5). 
Table 5

Categories of Meaningful Emotional Connections by Frequency of Respondents and Remarks

\begin{tabular}{|c|c|c|}
\hline $\begin{array}{c}\text { Categories of } \\
\text { Emotional Connections } \\
\end{array}$ & $\begin{array}{c}\# \\
\text { remarks } \\
\end{array}$ & \# respondents \\
\hline Feelings of Affinity & 24 & 13 \\
\hline Interest & 5 & 5 \\
\hline Pride & 4 & 4 \\
\hline Admiration & 2 & 2 \\
\hline Appreciation & 2 & 2 \\
\hline Beauty & 2 & 2 \\
\hline Awe & 14 & 10 \\
\hline Impressive & 5 & 5 \\
\hline Surprise & 2 & 2 \\
\hline Discouragement & 12 & 9 \\
\hline Difficulty & 4 & 4 \\
\hline Disappointment & 2 & 2 \\
\hline Frustration & 2 & 2 \\
\hline Pain & 2 & 2 \\
\hline Disdain & 12 & 8 \\
\hline Anger & 2 & 2 \\
\hline Shock & 2 & 2 \\
\hline Moving & 10 & 7 \\
\hline Intensity & 2 & 2 \\
\hline Powerful & 2 & 2 \\
\hline Empathy & 8 & 7 \\
\hline Courage & 6 & 5 \\
\hline Encouragement & 4 & 4 \\
\hline Genuineness & 4 & 4 \\
\hline Outliers & 5 & 5 \\
\hline
\end{tabular}

Feelings of affinity were talked about 24 times by 13 respondents and included interest (mentioned by five respondents), pride (four respondents), admiration (2), appreciation (2), beauty (2), enjoyment, fondness, rewarding, etc.

Feelings of awe were mentioned 14 times by 10 visitors and included the terms impressive (mentioned by five respondents), surprise (2), eye-opening, amazing, overwhelming, awesome, etc. 
The third most common emotional response were feelings of discouragement expressed 12 times by nine visitors. The category discouragement included words feelings such as difficulty (mentioned by four respondents), disappointment (2), frustration (2), pain (2), sadness, etc.

Disdain was categorized as a more intense negative feeling than discouragement, and was expressed 12 times by eight visitors. Disdain included anger (mentioned by two visitors), shock (2), fear, hatred, scary, etc.

Seven participants expressed their visit in terms of a moving experience a total of 10 times. Intensity and powerful were discussed by two visitors, and the category "moving" included additional terms of touching, significant, hit my heart, and struck a chord, among others.

The sixth most prevalent category was empathy, expressed eight times by seven participants. Visitors used the term almost exclusively. Next was courage, mentioned six times by five visitors, and again, the term courage was used almost exclusively by respondents.

The next two emotional categories were encouragement and genuineness, mentioned four times each by four different participants. Encouragement was explicitly stated by each of the four respondents, but genuineness was composed of feelings of realness, personal, and as male respondent stated, "It brings some realization to it. All of this happened, it happened right here."

The last category includes five feelings that did not lie within any of the other categories. The responses included abnormal, confusion, strange, fairness, and responsible, and each was expressed by a different visitor. One visitor mentioned how she felt it was abnormal the way in which the Little Rock Nine had to behave. The next visitor expressed confusion as to the organization of the interpretive displays. Another visitor communicated that he had a strange 
feeling when visiting the Central High School and hinted at a spiritual aspect to his feelings. The next visitor expressed feelings of fairness regarding the actions of the principle of the high school during that time. And the last participant stated that the displays on women's rights made her feel responsible for doing something about the issue.

A female respondent aged 46-55 broached the categories of emotions well when she stated:

I guess pride you know, because we have come as far as we have and empathy for those people who went through those situations, and admiration for everyone, for sure, who worked to make that happen. And, I guess, still frustration that we don't have total equality in our society for all of our citizens.

A Black male participant aged 36-45 noted:

I can say pride, but...it made me want to not stop in spite of everything around me that appears to be...it, it might appear to be hard, it might feel hard but in the long run, when you look back over it, it was worth it.

Perhaps a male visitor aged 56-65 summed up the emotional connection best with:

It's...a wave of emotions, some anger, a great deal of pride, and... at the same time, some I guess I would use the word, tenderness; it just touches you to see what people had to go through and what they did. ...I think the...the first day of school....was, the great animosity was shown towards these children, that's probably the most memorable.

\section{Research Question \#5: How Meanings were Made}

How meanings were made was the focus of research question \#5. Based on Silverman's (1999) work, five categories were used as a framework for evaluation of data pertaining to question \#5. The five categories of how meanings can be made are: establish, evaluate, absolute description, special knowledge, and personal experience. Analysis revealed visitors made meaning based on all five categories, as well as through a combination of methods. (See Table 6). 
Table 6

Frequency of How Meanings Were Made by Category

\begin{tabular}{lccccc} 
& \multicolumn{5}{c}{ How Meanings were Made } \\
\cline { 2 - 6 } & Evaluation & Establishment & $\begin{array}{c}\text { Absolute } \\
\text { Description }\end{array}$ & $\begin{array}{c}\text { Personal } \\
\text { Experience }\end{array}$ & $\begin{array}{c}\text { Special } \\
\text { Knowledge }\end{array}$ \\
\cline { 2 - 6 } \# Respondents & 17 & 16 & 16 & 15 & 3
\end{tabular}

All 17 visitors evaluated the exhibits, which led them to connect on an intellectual and emotional level. A female participant aged $36-45$ best illustrates how meaning is made through evaluation:

I cannot think of one of the one girl's names that went to school there and she, her parents were divorced and how they kept their shades closed and grandma had to sleep by the door and didn't answer the phone, and that's so abnormal. That's so abnormal of the time period we live in, and I feel extreme sadness for them.

Sixteen participants made meaning by establishing what something was. This is synonymous with declarative knowledge — stating what something is. For example, one visitor, a female age 18-25 said, "There were a lot of pictures and then some recordings and stuff of the time frame and history. And then the little gift shop, bookstore area."

She continued, providing an example of absolute description of the physical aspects, "They were all black and white pictures." A male respondent over age 75 provides another absolute description of a photograph, detailing the content, "I can remember one picture where it looked like one of the White students was screaming at one of the Black students." A female participant aged 46-55 provides an example of absolute description of an exhibit by recalling the subject matter, "The Little Rock Nine, one of the girls, she had stuff thrown in the bathroom. They were lighting paper and throwing it into the bathroom stall."

Meaning was also made through personal experience for 15 participants. Some illustrative examples include: 
- "Yes, we integrated schools. I did, but it was on a very different scale. Just the fact that I was at that era when we did integrate schools, there was some personal piece that I could take away, but again, nothing near the magnitude that they went through."

- "Well you know, yea, being a young, a Black woman, you...at some point in my life, I have experienced racism and you know, being treated unfairly because of the color of my skin."

- "Certainly, well the clothing that you see the students themselves, what they were wearing, that's what I was wearing back in those days. I had, I connected with it at that level, and it just brought me into the realm of considering how I would have responded had I been there in myself in my circumstances and how I would have responded. I know where I am today, hard to say where I would have been then."

- "Yes, and one of them, especially because I'm a woman, when which made the connection with discrimination against women. Well, I have been a teacher all my life and...I've worked at schools that have problems with attitudes towards race, towards ethnicity, and toward income level.....and...sometimes I have, I felt a sense of institutional discrimination against women."

Making meaning based on special knowledge was one of the least common ways. Four visitors created meaning based on special knowledge. One respondent had actually participated in the events surrounding the Little Rock Nine as a member of the National Guard's One Hundred and First division.

And that's why I went there in the first place to see, you know, what it was. But anyway, um, we...it, it, it...At first when we got there, uh I'm talking about the federal troops, it, it, it bothered me that um, that people were, what they were doing. You know, they were calling us names...And, it took me a little bit, but aft... after a while I realized it's not me, I'm not the one that's sick, you are. You know, I'm doing, you know, what I, what I should be doing. And you're the one that's sick. Not me.

\section{Research Question \#6: Meaning and Civic Engagement}

If visitors made meaning, were these meanings connected to civic engagement?

Research question \#6 addressed this topic. Analysis revealed that four participant's meaning making was not at all related to civic engagement. Results revealed that meaning making for the other 13 participants was at least somewhat related to civic engagement, specifically civil rights. Participants spoke of civil rights and that while progress has been made, there is still a long way 
to go for equality for all. One male respondent stated, "I think a lot of the people that have been deprived of certain rights at the time have gained some. I don't think they necessarily have gained everything they should have but we've made progress. I think we have as a society.” Other visitors related civil rights to a larger picture or context. A female participant age 36-45 said:

Even though women have rights to vote and we can own property and we can hold office, and it seems that, I still think that looking at what Arizona is doing, which closing, being able to ask if you are an illegal immigrant in my neck of the woods, guys came in and raided the cattle industry of all of the migrant workers, there's still a huge, there is a serious class system in this county.

Participants were asked if their level of participation in community activities had remained the same or increased after their visit to CHSNHS, and if so, if they attributed the change to their visit. Seven participants stated their participation and activity level increased and also attributed this increase to their visit to CHSNHS. Seven visitors stated that their participation levels had not changed or it remained the same after their visit. Three participants did not answer the question. Interestingly, of the four participants who did not make meaning regarding civic engagement (via civil rights) one was a no answer and the other three had participation levels that remained the same. All those who professed their commitment levels increased also made meaning related to civic engagement via civil rights. One female respondent aged 36-45 elaborated on her increased commitment, "I went to the Brown versus Board of Education Museum, based upon my experience at Central High School.” Many of those whose commitment to participation in community activities remained the same stated that their visit "heightened awareness" or "informed decisions". When asked about his participation activities, a male participant aged 56-65 stated he participated at "the same level that I have participated in all of my adult life but I wouldn't say it has motivated me to go out and seek 
something more to do, but it certainly informed my participation in the things that I do." Thus it appears that Central High School NHS provides opportunities for visitors to connect emotionally and cognitively to civil rights and motivates their participation in community activities.

However, do meaningful emotional and cognitive connections and motivation and participation in community activities translate into civic engagement? The final research question addressed the types of citizens based on levels of civic activities.

\section{Research Question \#7: Types of Citizens}

The final research question investigated the types of citizens participants were. This research question was analyzed inductively, rather than using established categories and several groups emerged when analyzing the types of citizenry. First, participants were asked if they had participated in any activities or projects for the betterment of their community/state/or nation; if participation was the same or an increased commitment; if any activities were new; and if their visit motivated them to participate. They were also asked if they had done anything that promoted democratic values such as justice, freedom, equality, patriotism, etc. And finally, participants were asked if they had done anything that fell under civic responsibility such as donate to charity, serve on jury duty, or volunteer.

First, five main categories emerged: volunteering, speaking with others, donating to charity, jury duty, and voting. Volunteering was reported by 14 participants, 10 indicated conversations with others, nine visitors donated to charity and served on jury duty and only three stated they voted. (See Table 7). 
Table 7

Frequency of Participation in Civic Activities

\begin{tabular}{lc}
\multicolumn{1}{c}{ Activity } & $\begin{array}{c}\# \text { of } \\
\text { Respondents }\end{array}$ \\
\hline Volunteer & 14 \\
Conversations with others & 10 \\
Donate to charity & 9 \\
Jury Duty & 9 \\
Vote & 3
\end{tabular}

After analyzing the data, a spectrum or continuum of engagement was developed, and one key factor for placing people along this spectrum dealt with how passively or actively the respondents had participated in the various activities. For example, activities such as volunteering and donating to charity, while these are good things to do and improve people's lives, are not essential to a democracy, and thus were grouped as "passive participation". Examples such as speaking with others about CHSNHS or democratic values within the confines of job duties or participating in a rally were categorized as "active participation". Two additional actions/activities that were included in "active participation" were serving on jury duty and voting, and as these items are essential in a democracy, no other factors were needed for participants who had done these to be labeled "active". A participant would be labeled "active" if he/she voted or served on jury duty but did not give to charity or volunteer. In order for speaking with others to count as "active" both items for "passive participation" also had to be met. Thus, if an individual only volunteered at a nursing home and talked with others about civil rights, participation was deemed "passive". However, if a person volunteered, donated to charity, and taught students about tolerance and acceptance, participation was judged "active". The highest level of participation was termed "engaged participation". In order to reach this level, respondents must have also mentioned political discourse of democratic values outside of 
their job, contacting Legislators, or any activity that required a civic skill to complete. (See Table 8). As discussed in Chapter 2, literature review, a civic skill differs from a civic behavior in that a civic behavior is an action a citizen takes, such as attending a rally. A civic skill requires the in-depth civic knowledge to perform an action, such as actually organizing a political rally, "Civic skills are part of a larger package including knowledge, motivation or interest, connections to networks of engaged people, and resources (time and money)" (Kirlin, 2003, p. 3-4).

Table 8

Coding Scheme for Types of Citizenry Based on Activities

\begin{tabular}{|c|c|c|c|c|c|c|c|c|c|}
\hline \multirow[b]{2}{*}{ Continuum } & \multicolumn{9}{|c|}{ Activities } \\
\hline & $\begin{array}{c}\text { Donate } \\
\text { to } \\
\text { charity }\end{array}$ & Volunteer & $\begin{array}{l}\text { Attend } \\
\text { rally }\end{array}$ & $\begin{array}{c}\text { Speak } \\
\text { w/in } \\
\text { confines } \\
\text { of job }\end{array}$ & Vote & $\begin{array}{l}\text { Jury } \\
\text { duty }\end{array}$ & $\begin{array}{c}\text { Speak } \\
\text { outside } \\
\text { job }\end{array}$ & $\begin{array}{c}\text { Write } \\
\text { congress }\end{array}$ & $\begin{array}{l}\text { Other } \\
\text { civic } \\
\text { skills }\end{array}$ \\
\hline Passive & $\mathrm{x}$ & $\mathrm{x}$ & & & & & & & \\
\hline Active & $\mathrm{R}$ & $\mathrm{R}$ & I & $\mathrm{C}$ & I & I & & & \\
\hline Engaged & $\mathrm{R}$ & $\mathrm{R}$ & I & $\mathrm{C}$ & I & $\mathrm{R}$ & $\mathrm{C}$ & I & I \\
\hline & $\begin{array}{l}\mathrm{R}=\text { Requi } \\
\mathrm{C}=\text { Contir } \\
\mathrm{I}=\text { Indepe }\end{array}$ & $\begin{array}{l}\text { action for } 1 \\
\text { ent upon pre } \\
\text { ent of either }\end{array}$ & $\begin{array}{l}\text { xt step } \\
\text { ous step } \\
\text { rior step }\end{array}$ & & & & & & \\
\hline
\end{tabular}

Based on this framework, there were six passive participants, seven active, and four engaged. Of the four engaged individuals, one had won a state award for being an equality leader, one contacted a legislator to voice his disapproval regarding her vote and lack of representation in Congress, and the last two participants were a married couple who started a community outreach program/center to teach civic responsibility. The wife actually quit her career in finance to become the director of the project.

One interesting finding in analysis of types of citizenry was that in designing the interview, voting was intentionally not mentioned (i.e., participants were not initially asked or 
prompted about voting) in order to see if respondents would make the connection between civic engagement and voting. Only three of the participants mentioned, without prompting, that they voted.

During the questions related to the types of citizenry, participants were asked if their participation remained the same or increased and if their visit contributed to their civic participation. Seven respondents stated that their level of participation increased and they directly attributed this to their visit to Central High School NHS. For example, when asked about her participation and commitment, a female participant aged 46-55, stated:

Oh, it was increased, absolutely....what I am saying to you, when I do visit these places, it always goes back into my classroom. So yes, definitely increase, and just the idea that, even in our world today, a lot of these kids today don't understand tolerance and compassion and you can't just say go be compassionate, go be nice to other people, you can't do that. You have to teach them and show them. But yeah, it's increased.

Another female respondent age 36-45 noted:

Oh, absolutely, I see that the bottom line to that is yes, seeing how this country evolved and being able to speak to somebody with that perspective, I never ever would have gone to that museum, and ever gotten in to this. It lead me in to Memphis and I think that it is not something that our curriculum necessarily is designed to do but I don't think that I ever would have been aware and had been as involved if I didn't have that background knowledge, so I would say yes. So, huge.

Seven said they participated in community activities at the same level that they did prior to their visit, and some also mentioned that their visit informed their current participation. A male, age 56-65 stated: "The same level that I have participated in all of my adult life. But I wouldn't say it has motivated me to go out and seek something more to do, but it certainly informed my participation in the things that I do."

Finally, when looking at commitment and meanings related to civic engagement, all participants who increased their participation in civic activities made meanings related to civic 
engagement. However, all those who did not make meanings regarding civic engagement remained at the same participatory level prior their visit.

\section{Research Question \#8: Longitudinal Results}

As previously described, this study was part of a larger research project evaluating the exhibits at Central High School NHS. Part of the larger research project involved exit interviews with visitors, conducted approximately one year prior to the phone calls. Certain questions were asked both during the exit interviews and the follow-up telephone interviews, allowing for longitudinal comparisons. Using the exit interviews, there were 12 individuals who had both portions of an exit interview and a follow-up telephone interview. There were four research questions that could be answered with the exit interview data. The applicable research questions were: what types of knowledge visitors recall; are visitors making meaningful connections; if so, what are the meanings visitors are making; and how are those meanings made (See Table 9).

During the exit interviews, 12 visitors recalled five types of knowledge. Eight recounted declarative knowledge, five episodic, three structural, and two each for socio-cultural and experiential. As with the follow-up data, declarative knowledge was the most widespread. However, during the follow-up interviews, socio-cultural was the second most common, whereas in the exit interviews episodic was second. This could be due to the fact that a question that specifically targeted socio-cultural knowledge was asked during the follow-up interviews.

Excluding socio-cultural knowledge, then, episodic was the most second most prevailing type of knowledge in both the exit and follow-up interviews. Structural knowledge was more common during the exit interviews than during the follow-up interviews with 3 out of 12 versus 2 of 17 
respondents recalling how concepts related. This might be explained in that the concepts were fresh on visitors' minds as they exited the museum.

Table 9

Differences and Similarities in Longitudinal Assessment of Exit Interviews and One-year Followup

\begin{tabular}{|c|c|}
\hline Exit Interviews & One-year Follow-up \\
\hline \multicolumn{2}{|c|}{ Types of Knowledge } \\
\hline Declarative & Declarative \\
\hline Episodic & Socio-cultural \\
\hline Structural & Episodic \\
\hline Socio-cultural & Experiential \\
\hline Experiential & Structural \\
\hline \multicolumn{2}{|c|}{ Categories of Cognitive Connections } \\
\hline Exhibits & Exhibits \\
\hline Perspectives & People \\
\hline Little Rock Nine & Little Rock Nine \\
\hline School & School \\
\hline People & History \\
\hline Constitution & Ideas/Concepts \\
\hline History & Museum/Bookstore \\
\hline Women & Gas Station/Window \\
\hline & Women \\
\hline & Larger world events \\
\hline & Details \\
\hline \multicolumn{2}{|c|}{ Categories of Emotional Connections } \\
\hline Affinity & Affinity \\
\hline Discouragement & Awe \\
\hline Disdain & Discouragement \\
\hline Genuine & Disdain \\
\hline Courage & Moving \\
\hline Moving & Empathy \\
\hline Empathy & Courage \\
\hline \multirow[t]{3}{*}{ Encouragement } & Genuine \\
\hline & Encouragement \\
\hline & Outliers \\
\hline
\end{tabular}

As with the follow-up interviews, visitors during the exit interviews made meaningful connections to the resource. Similar to the follow-up interviews, participants made meaningful 
connections to the resource both emotionally and cognitively. The details of these meanings were similar and yet different.

During the exit interviews, six visitors mentioned parts of exhibits 11 times, with mentions of photos by three people, and two people mentioning the constitution. As with the follow-up, the exit interview exhibit category included such artifacts as a book and telephone, and displays of videos, visuals, and media. Clothing was not mentioned in the exit interviews as it was in the follow-up interviews; nor were videos as prevailing. The second most prevalent category during the exit interviews was that of perspectives. Four visitors made mention four times of the various perspectives presented or not within the museum. This was not mentioned during the follow-up interviews. The third most common category was the Little Rock Nine, mentioned by four visitors. This was consistent with the follow-up interviews. Three people spoke about the school making the school the fourth category for the exit interviews as well during the follow-up. Other people were mentioned three times by two individuals during the exit interviews--this was very different than findings from the follow-up interviews. While the category of other people was the second most frequently reported in the follow up, it ranked fifth in the exit interviews. Next, two respondents mentioned the constitution in exit interviews, whereas the constitution was not mentioned during the follow-up. During the exit interviews, history tied with the constitution with two mentions by two visitors, while seven people mentioned history during the follow up telephone interviews. Finally, during the telephone interviews women were discussed by four participants, but only once during the exit interviews.

Emotional connections during the exit interviews presented similar but different results as the follow-up interviews. Feelings of affinity were most common during both, with five participants mentioning affinity eight times during the exit interviews. Affinity included the 
terms good, gratitude, happy, interesting, pride, respect, and welcoming during the exit interviews. Awe was the second most frequently mentioned category during the follow-up interviews, but was not present at all in the exit interviews. Excluding awe, feelings of discouragement and disdain were next for both the exit interviews and follow-ups.

Discouragement during exit interviews included difficulty, frustration, sacrifice, struggle, and suffering, and was mentioned six times by four people. Disdain was also talked about six times by four people during the exit interviews, and as with the follow-ups included feelings of anger, wrongness, horribleness, being bad, or not good. Three out of 11 participants talked about genuine experience in the course of the exit interviews. This is similar to the follow-up interviews when four of 17 participants mentioned it, but moved feelings of genuineness up four places on the exit interview list compared to the follow-up. During the exit interviews courage was the fifth most common category and was discussed three times by two people. This is similar to the follow-up interview data, where five participants mentioned courage six times. Having a moving experience was next on the list during exit interviews, mentioned by two people. While the numbers were greater during the follow-ups with 10 mentions by 7 participants, the ranking were similar. Finally, empathy and encouragement were only brought up once each during the exit interviews compared with eight times by seven participants and four of 17 participants, respectively, during the follow-up calls.

How meanings were made was also analyzed from the exit interview data. Analysis revealed that the 12 respondents made meanings in all five ways. The categories were not mutually exclusive, and all but two participants made meaning in some combination of the five types: establish, evaluate, absolute description, personal experience, and special knowledge. Eleven of 12 made meaning through evaluation; eight of 12 established what something was; six 
made meaning through personal experience, four gave absolute descriptions, and two through special knowledge. This corresponds with the follow up, where evaluation was most common, followed by establishment. One difference is personal experience and absolute description with 6/12 and 4/12 in the exit interviews respectfully, whereas the follow-up interviews resulted in 16/17 respondents making meaning through personal experience and 15/17 using absolute description. Special knowledge was least common in both exit and follow-up interviews.

\section{Additional Findings}

There were several additional key findings that emerged from the data that were not directly related to the research questions. First was the importance of souvenirs. Visitors were asked if they took any promotional materials home with them or purchased anything at the gift shop. Fifteen participants took something with them and interacted with it later. "Lets see, one of the things I brought home was the...the Little Rock Nine Foundation baseball cap that I wear on a regular basis, and it even stimulates some questions so I get a chance to talk about it with friends and acquaintances", stated a male participant age 56-65.

This quote also illustrates the second finding, that visiting Central High School NHS opens the doors of communication with others, whether it is a conversation started from a souvenir baseball hat or speaking with family, as a female participant age 46-55 recalled:

I actually went home and talked to my mom about going to Little Rock and different things like that and we actually got into a conversation about the Ku Klux Klan, and my parents have never spoke to me about anything, but come to find out, my great grandfather was in the Klan. When we lived in Hollow, Michigan, our Catholic church had been repeatedly attacked with graffiti from the Klan and it was just, sorta hit home. It opened a door for my parents to talk about this in their experiences with prejudice and things. 
The next finding was that the visit and exhibits at Central High School NHS provided encouragement for continuing to do public works. A Black male, age 36-45 embodied this finding:

It made me want to not stop in spite of everything around me that appears to be...it, it might appear to be hard, it might feel hard but in the long run, when you look back over it, it was worth it, and I remember, in my wall in college, there was a paddle, 'Don't Quit.' And...that right there, those seven or those six [sic] didn't quit.

The last additional themes that emerged were that people still believe in the democratic values put forth in our Constitution of providing for the general welfare, and doing the "right" thing by helping others. Participants were also humble about what they do, not seeking any recognition for their deeds. When asked why they participate in the civic activities they do, respondents overwhelming responded by saying something about providing for the general welfare and establishing justice.

In response to the interview question, "If a friend asked you why you did those things, what would you tell them?", the following responses were illustrative:

- "I would tell my friends that it was my civic responsibility."

- "It is important to us as a people and to the betterment of our characters and our community, you know, the most important thing is you want to be able to say you've done everything you can and you don't ever want to be caught in the situation where you say, you know, if you are asked, have you done anything to help and you say, 'no not really.' You don't want to be put in that position, and you do everything that you can and you tell people that the reason why you do things is because, you know, you want the best for others, and that's what it is all about. And if you come out of a community that has done good for you, then you want to see it grow for others also so it takes a personal investment."

- "Well, there's really two different levels but they do intersect. Of course, jury service really is participation in the governmental system of country, the third branch, the judicial branch of the government, it can't function without people serving on juries so that really, literally puts you in direct contact with the Constitution and the establishment of the government, all the way back to the Revolutionary period. As far as, being an adviser for the gay-straight alliance on campus, again it's a civil rights issue, and all, not only 
students but all members of society have a right to their choices, so those are the things that I think are important for individuals."

- "I thinking we all have an obligation for a, for community service and an obligation to the common good. And, just this is how I make my contribution."

\section{$\underline{\text { Conclusion }}$}

To summarize, visitors primarily recalled episodic and declarative memories, and emotions and people were influential in what visitors recalled. Socio-cultural, declarative, and episodic knowledge were the most common types of knowledge visitors recollected. Participants made meaningful connections to the resource through both intellectual and emotional connections. These meanings were made through a combination of establishment, evaluation, personal experience, and special knowledge. Regarding connections to civic engagement, these meanings were connected primarily to civil rights, and therefore, civic engagement. Citizenry was found to fall along a gradient scale, and visitors to Central High School NHS ranged up and down the scale, from passive to active to engaged citizens. Additional findings not related to the research questions were that souvenirs were important, and that visiting CHSNHS opened the doors of communication with others about civil rights. Finally, the visit and exhibits at Central High School NHS provided encouragement for visitors in their public works efforts, and that participants believe in democratic value of providing for the general welfare by helping others and doing the "right" thing, without the need to seek recognition for their good deeds. 
This page is intentionally blank. 


\section{CHAPTER 5: DISCUSSION}

This chapter provides discussion of the previous results and sets them in relationship to previous research, and areas for future research are addressed. The chapter begins with an explanation of visitor demographics and moves through the seven research questions concluding with discussion on the serendipitous findings.

\section{Demographics}

Little Rock Central High School National Historic Site has no data on visitor demographics. The NPS Public Use Statistics Office states that there were 60,103 recreational visitors to CHSNHS, but no socio-economic data are provided. This study provides a baseline for future research at CHSNHS. When compared to national park visitors, demographics of visitors to CHSNHS that participated in this study are comparable: they are well-educated, older adults (National Park Service Social Science Program, 2001). While race was not asked during the follow-up interviews, many respondents volunteered their race in their answers. Of the 17 respondents, there were 6 Blacks, 6 Whites, and one Hispanic. This differs vastly from general national park visitors, who are overwhelmingly White . One explanation for this phenomenon could be that CHSNHS addresses an issue that at that time period, was specific to Black Americans, and Black Americans feel more welcome at CHSNHS than other National Park sites. An area for future research is to investigate demographic differences between National Park sites that interpret various situations to specific cultural heritages or races within the U.S. Such sites could include Manzanar NHS, Trail of Tears National Historic Trail, Central High School NHS, and Ellis Island National Monument. 
Despite the economic slump, as with most National Park visitors, respondents at CHSNHS were employed full-time or retired (National Park Service Social Science Program, 2001). Of those employed, majority of respondents worked in the education field. This could be the result of a teacher's conference that took place in Little Rock during the time of the initial survey, or that teachers visit Central High School NHS for the purpose of deepening their knowledge on civil rights and bringing those experiences back to the classroom. Future research at CHSNHS should target dates where educational conferences are not occurring in town.

\section{Research Question \#1: Memories}

There were two major results that emerged from analysis of the data. First were the types of memories that visitors recalled: declarative, structural, experiential, and episodic. This study found that declarative memories were the most abundant, both during the follow-up and during the longitudinal analysis, a finding that is similar to a number of past studies. In Knapp's (2007) year follow-up studies of visitor memories of various interpretive programs, he found that visitors recalled declarative and episodic memories, with episodes being quite vivid and detailed. Stevenson (1991) explored visitor recall at a science museum and divided responses into not remembered, mentioned, elaborated clear and less clear. Of those elaborated memories, $60 \%$ were declarative memories. McManus (1993) also found that declarative memories were most prevalent in her study of museum visitors, with $51 \%$ of respondents recalling memories of objects or things. Bitgood and Cleghorn (1994) found similar results, with objects or declarative memories most likely to be recalled. However, Anderson's (2003) study of long-term memories regarding the 1986 and 1988 World Expos found that declarative memories were highly deficient, in that less than $20 \%$ of participants could recall any exhibits or displays. This 
aberration might be explained in that study took place 15 and 17 years after the Expos and details on displays may have been forgotten during this time. Future research on memories may want to follow select individuals to investigate how declarative memories deteriorate over time.

Tulving (2007) states that humans recall memories based upon episodes in their lives. Thus, it is not surprising that visitors to Central High School NHS talked about their visit as a detailed episode in their life. Compared to previous research, what is surprising is that more visitors did not (only 4 participants of $17 \mathrm{did}$ ). While Knapp's (2007) studies were qualitative in nature, providing no quantitative data on recounted episodic memories, he hints that both declarative and episodic memories were pervasive and abundant. The low response found in this study could perhaps be explained in the wording of the question asked, "What do you remember" versus "Tell me about your experience". Another explanation is that Knapp's research has focused on personal interpretation, which may be seen as an episode, versus the non-personal interpretive experience of Central High School NHS. The role of people is key, as discussed later, and perhaps not having a personal interpreter at Central High School NHS leads visitors to not provide memories as episodes. Martin (1993) also offers an explanation quoting Slavin (1991), “'Episodic memories are often difficult to retrieve because most episodes in our lives are repeated so often...unless something happens during the episode to make it especially memorable"' (p. 171). Anderson and Shimizu (2007b) reveal that visitors to the 1970 World Exposition recalled vivid episodic memories, but no quantitative data accompanies the rich descriptions. But results of this study are consistent with McManus's (1993) results of an exploratory study of museum visitors where she discovered only $23 \%$ of memories were episodic. 
Structural \& experiential memories have not been specifically investigated in relationship to interpretation. However, within the field of memory research, structural and experiential memories are most closely associated with learning and cognitive learning theory, as structural memories involve the process of linking concepts together using one's cognitive map, and experiential memories involve relating previous experience to current situations. While many visitors stated that they had learned new details or concepts they already knew were reinforced, without delving into their cognitive map, what they know, based on simple recall, may be easier to determine than how well they know it. As their cognitive map reveals connections between known concepts and how concepts relate, without exploring each unique individual's linkages in the brain, knowing what constructs visitors connected together remains a mystery. Two visitors to Central High School NHS, though, related concepts together and expressed such in the interview, illustrating a deeper understanding of ideas presented at the CHSNHS visitor's center. Stevenson's (1991) research into visitors' memories of a science museum found that of the elaborated memories, $26 \%$ were categorized as "thoughts" which included structural memories. Thus it is difficult to determine if visitors to CHSNHS are similar to Stevenson's respondents as a comparable level of analysis was not provided in Stevenson's research. Each of the five respondents who provided experiential memories had either visited CHSNHS site before or were there during the events in 1957 and related their experiences with their June 2009 visit. This highlights the importance of return visits of repeat exposure in memory and learning (Falk, 2009).

The second major finding regarding what memories participants recalled about their visit to CHS related to factors influencing memories. Twelve participants recalled memories associated with emotion, and ten mentioned people. Both of these findings are consistent with 
prior research illustrating the influential factors on memory. Stevenson's (1991) research on elaborated memories revealed 14\% included an emotional component. McManus (1993) found similar results with $15 \%$ of memories involving feelings surrounding a museum visit. In a study of memories of the 1970 Japan World Exposition, Anderson and Shimizu (2007a) found that most vivid memories were closely associated with extremes of affect, both positive and negative. Positive and negative emotions will be discussed in more detail under meaning-making. McManus (1993) and Falk and Dierking (1992) highlight the important role people play in the social aspect of learning. While both address with whom we learn, they do not broach the subject of learning about people. Machnik, et al., (2006) suggest that telling individual human stories to which visitors can relate provides opportunities for personal connection. Tilden (1957) reiterates the importance of personal relevance on meaningful interpretive experiences. The more personally relevant a subject is, the easier it is to remember because of the connections made (Knapp, 2006, 2007; Webb, 2000). Wenger (1998) elaborates on learning as a social activity central to our lives and that people connect with other people to form identity. Connecting with other people can entail learning about others who have come before us, as is the case of the Little Rock Nine at Central High School NHS, to better understand ourselves and help shape our identity. Visitors may better remember details of interpretation about other people versus non-human subjects because they can relate to other human beings better (Webb, 2000). Ham's (1992) book Environmental Interpretation suggests,

a focus on people rather than nature. Most of the conservation problems our world faces are human problems. Almost all protected areas were formerly occupied by people, and their historic influences on the environment contributed to the species and landscapes that people admire today. Building support for protected areas might be best based on showing what they mean to people today (p. xv) 
An area for future interpretation research might focus on comparing visitor memories about interpretive programs on a person versus a concept, wildlife, or an inanimate object.

\section{Research Question \#2: Types of Knowledge}

Research question number two addressed what visitors know about Central High School NHS. Based upon RQ1, visitors recalled declarative, experiential, episodic, and structural knowledge. However, in addition to these types of knowledge and memories, socio-cultural knowledge emerged from the data, with 12 of 17 respondents providing some type of sociocultural knowledge, making it the second most common type of knowledge recalled. Sociocultural knowledge has not been studied specific to interpretation either. However, in a study of visitors' long-term memories about the 1986 and 1988 World Expos, Anderson (2003) found that visitors recall was strongly influenced by their socio-cultural identity. What they recalled was based on their socio-cultural affiliation. "In short, who you are largely determines what you are able to see and perceive, and what you ultimately recall after the experience" (p. 417, emphasis in original). McEachern (1998) explored socio-cultural knowledge and memories when discovering memories associated with the District Six Museum in Cape Town, South Africa. People living in the region recounted different socio-cultural memories depending upon the time period (apartheid) and their race. Not only are there varying socio-cultural memories within one area, international visitors to the museum are likely to bring a very different socio-cultural knowledge with them, providing different interpretations and meanings of the site. As Central High School NHS deals with events that specific to the United States, it is reasonable that American visitors would have socio-cultural knowledge regarding it. International visitors to Central High School NHS may lack the socio-cultural knowledge of Americans and thus recall 
very different types of memories and knowledge. The high number of respondents providing socio-cultural knowledge might be explained in that an interview question targeted this type of knowledge. The interview question asked respondents what they thought civil right meant then (during the civil rights movement) versus now. A respondent could not answer the question without socio-cultural knowledge. Future research might consider constructing interview questions to target different types of knowledge equally or establish a framework for analyzing

questions prior to asking them. Researchers may also want to target both international and native born peoples in future studies to determine socio-cultural differences in memory and knowledge recall.

\section{Research Question \#4: Meaning Making}

Question four investigated what types of meanings visitors made to the resource at Central High School NHS. The results were twofold: visitors connected both intellectually and emotionally. Based on the NPS interpretive development program model, intellectual and emotional connections are vital to the visitor's meaningful interpretive experience. All visitors connected emotionally, and all but two made meaning intellectually. Machnik, et al., (2006) in their study of visitors to an interpretive program at Gettysburg National Military Park, and Barrie (2001) in her research on visitors' meaningful interpretive experiences, found similar results, with visitors making both intellectual and emotional connections to the resource.

The two visitors who did not connect cognitively in this study had both been at Central High School during the events in 1957. When asked if he understood anything better as a result of the exhibit experience, one male aged 66-75 best summed it up with, "I don't think so because I lived it." While this makes intuitive sense that someone who actively participated in the events 
of the day would have more insight into what occurred than what could be presented in interpretive exhibits, Falk and Dierking (1992) argue otherwise, "people with greater previous experience are likely to learn more than people with less experience" (p. 125). Barrie's (2001) findings support Falk and Dierking in her analysis of visitors to the National Museum of American History and Yosemite National Park, where previous experience was a major factor in meaningful interpretive experiences for visitors.

Those who did connected cognitively made meaning regarding the exhibits. McManus (1993) also found similar results, with most visitors connecting cognitively to museum exhibits, particularly interactive videos. Barrie (2001) discovered that multiple-sensory experiences were most memorable in visitors in recalling meaningful interpretive experiences. Active participation fosters better memory and is essential for constructivist learning (Barrie, 2001; Falk \& Dierking, 1992, 2000; Hein, 1991; Knapp, 2006, 2007). Interactive displays tied with clothing for second after photographs as the most noted exhibit feature that helped in creating cognitive connections at CHSNHS. Interactive displays and personal objects are both ways in which to connect social objects with visitors in a participatory museum (Simon, 2010). Falk and Dierking (1992) warn that too many stimuli such as interactive displays may overwhelm visitors so they suffer from sensory overload.

People behind the Little Rock Nine and the Little Rock Nine themselves, were in the top three cognitive connections visitors made to the site. Machnik, et al., (2006) research also reveals the importance of people and states, "sharing stories of individuals that visitors can relate to across a variety of contexts is also an effective technique" for making meaningful connections (p. 515). Making interpretive experiences relative to the visitor is one of Tilden's (1957) six principles, and one way to do this is to tell individual human stories (Machnik, et al., 2006), 
which CHSNHS does very well. The more personally relevant a topic is, the better later recall is because of the meaningful connections (Knapp, 2006, 2007; Webb, 2000).

History was another area in which visitors cognitively connected to Central High School NHS and Machnik, et al., (2006) also found history to be important for those visitors attending an interpretive program at Gettysburg National Military Park.

Conceptual ideas were one of the ways visitors made meaning the least. This can be justified in that connecting ideas takes cognitive effort, and this is unlikely to be the focus of participants' visits (Ham, 1992). Not only does connecting conceptual ideas require a knowledge of the ideas in the first place, it also takes time and energy to connect the dots (Afonso \& Gilbert, 2006), and with informal education, most visitors are "on vacation” (Ham, 1992). As also found in Farmer and Knapp (2008), other categories of cognitive connections were site specific and were not generalizeable across studies.

All visitors made meaning emotionally to Central High School NHS and were able to recall the emotions they felt when exploring the exhibits, even one year after their initial visit. Emotional connections were both positive and negative. As with Anderson and Shimizu (2007a) vivid accounts of meaning making were closely associated with extremes of affect, both positive and negative. Machnik, et al., (2006) also discovered both positive and negative affect when investigating visitors to Gettysburg National Military Park. Because interpretive programs and exhibits are site specific, the specific emotions felt (such as courage, empathy, or the experience being moving) were particular to materials presented at Central High School NHS, and may or may not be felt at other sites. However, several categories seem to overlap with Machnik, et al., findings based on Shaver, Schwartz, Kirson, and O’Connor's (1987) six major emotion categories. Feelings of affinity correspond primarily with the category "love". While Machnik, 
et al., included empathy in love, it emerged as a separate theme in this study. The theme of discouragement corresponded with the category "sadness", and disdain included elements similar to that of “anger". Machnik, et al.,'s category "joy" overlapped with both affinity and encouragement in this study. Another finding with noteworthy interest is the idea of awe. Many visitors expressed their surprise and feelings of overwhelming at the size of the school, with such responses as, "It was the size of the high school. I had no idea that it was as large a school physically, as it is, that was very impressive." Farmer and Knapp (2008) also found that the most frequent memories regarding the West Baden Springs Hotel tour were those of awe surrounding the size and grandeur of the atrium and architecture. Machnik, et al., (2006) sixth emotional category was that of surprise which included elements of awe.

Lastly, visitors at CHSNHS expressed emotionally connections in terms of the genuineness of the experience, in being able to walk the same steps as the Little Rock Nine. Barrie (2001) also found elements similar to genuineness, which she termed "immersion experience" and "bringing the past to life" both of which were influential in visitors' meaningful interpretive experiences. The theme of genuineness also touches on the idea of personal relevance, in that visitors can relate on a personal level to the resource, a critical component of interpretation (Tilden, 1957).

Because $100 \%$ of respondents made meaning emotionally to the resources at Central High School NHS, this may at first seem to be an aberration. Investigation into the interpretive meaning making research finds that visitors in both Barrie (2001) and Machnik, et al.,'s (2006) studies made meaning both intellectually and emotionally. While neither provides any numerical frequencies for respondents, both communicate in-depth qualitative findings of respondents' cognitive and emotional connections. McManus (1993) and Stevenson's (1991) results were 
similar to each other with both finding about $15 \%$ of responses to be associated with feelings. However, in both studies, the authors categorized responses as mutually exclusive, so although visitors may have expressed emotion regarding their visit, it may have been categorized as interactive displays or an episode. This greatly limits an in-depth analysis of data because more often than not, emotion is linked to cognition and they are not mutually exclusive (Falk \& Dierking, 2000). Both Barrie and Machnik, et al., allow for responses to fall into multiple categories, and this study followed their example. Future researchers should account for the interplay between cognition and emotion and rather than confine responses into either or, allow for data to fall into congruent categories. However, with that being said, the interview outline purposefully asked about visitors' feelings, based on the NPS Interpretive Design Process rubric, so it is not surprising to find that every visitor connected to the site emotionally. Anderson and Shimizu (2007a) still purport though, that "emotional events are more likely to be recalled than more neutral events" (p. 179) and Central High School NHS provides very emotionally charged exhibits.

\section{Research Question \#5: How Meanings were Made}

When visitors made emotional and cognitive connections to the exhibits at Central High School NHS, how were these meanings made? Silverman's (1999) framework for construction of meaning was used to analyze how visitors to CHSNHS made meaning. Evaluation was most common, followed by a tie between establishment and absolute description. Personal experience followed closely with 15 respondents, and special knowledge was the least common with 3 of 17 visitors constructing meaning in this manner. Consistent with Silverman's (1991) findings, visitors to Central High School NHS constructed meaning similarly. In her analysis of visitor 
pairs to a history museum, she found that visitors used establishment $90 \%$ of the time, absolute description $78 \%$ of the time, evaluation $68 \%$, personal experience $35 \%$, and least used was special knowledge at $29 \%$ of the time when connecting with history museum exhibits. Likewise, as with Silverman's (1991) research, visitors to Central High School NHS constructed meaning through a combination of the five ways. One notable difference between Silverman's (1991) study and CHSNHS results is that of personal experience. Silverman (1991) found that personal experience was used $35 \%$ of the time, whereas personal experience was used by $88 \%$ of respondents at CHSNHS. One explanation in this difference might be that CHSNHS visitors were better able to remember things that were personally relevant to them and thus constructed meaning based upon these personal connections (Knapp, 2006, 2007; Webb 2000). A differing explanation is that the interview questions targeted personal relevance. Based on the NPS Interpretive Design Process, personal relevance is essential for meaningful connections, and thus the interview questions addressed this topic. There have been no other empirical studies that use Silverman's (1991) framework for evaluating how meaning is constructed, but these findings support Silverman's work. As there are different ways of evaluating meaning making, future researchers may want to look at different rubrics and evaluation frameworks from the beginning of the research process.

\section{Research Questions \#6 \& \#7: Meanings and Civic Engagement, Types of Citizens, and}

\section{$\underline{\text { Additional Findings }}$}

Research question six addressed if meanings made (those found in RQ4) were related to civic engagement. Respondents constructed meanings specifically about aspects of the civil rights movement and thus, indirectly, civic engagement. The majority of research on civic 
engagement (Flanagan, et al., Keeter, et al., 2002; Kirlin, 2003; 2007; McIntosh \& Munoz, 2009; Syvertsen, et al., 2007; Westheimer \& Kahne, 2004a \& 2004b) focuses on civic engagement as students volunteering, and the American Association of Museums addresses civic engagement in terms of facilitating public participation. There is little research on civic engagement and interpretation or meaning-making and this study is breaking new ground in this area.

Visitors to CHSNHS constructed meaning about the events surrounding the Little Rock Nine and the civil rights movement. This is important because it reflects a collective memory and socio-cultural knowledge. Public history is not always reflective of collective memory and oftentimes stories are marginalized (Blake, 1999; Glassberg, 1996). A White male respondent vocalized this idea, "I think it is good that we are doing those kinds of sites and not just parks and major buildings, you know? In the past, there were times when it had to have been a Civil War battle...or some pretty phenomenal scenery to qualify as a national site." With the civil rights movement present in visitors' memories and visitors connecting both emotionally and cognitively to the site, visitors constructed meaning about civil rights. These meanings and collective memories help establish personal identity and sense of self that continue to permeate a visitor's life. Because the meanings and memories may help establish identity, visitors are unlikely to forget the concept of civil rights. In a study of meaning making at three National Capital Memorials, Goldman et al., (2001) also link emotional and intellectual connections to self identity through attachments to significant places. As visitors form bonds to significant places, they cultivate a sense of place and connect to the community, and thus, themselves. Place attachment and subsequent self-identity stem from intellectual and emotional connections to a site (Goldman, et al., 2001). Thus if the democratic value of civil rights endures in the 
memories of visitors, by proxy, so will the concept of civic engagement (Blake, 1999; Falk, 2009; Glassberg, 1996; Hanson, 2008).

However, knowledge and emotion may not convert into action. Kirlin (2002) is quick to highlight, civic knowledge does not always translate into the action of civic engagement. Numerous other studies in parks and recreation, particularly, visitor behavior and environmental education substantiate this disconnect between visitor knowledge and visitor behavior. While visitors may know the right thing to do, they do not always do it, illustrating the weak link between knowledge and action (Fishbein \& Ajzen,1975; Ham, et al., 2007; Hines [Stone], Hungerford, \& Tomera, 1986-87; Hungerford \& Volk, 2001; Jacobi, 2003a, 2003b; Johnson \& Swearingen, 1992; Martin, 1992; Monroe, 2003; Orams, 1995).

What civic memory and civic knowledge do, though, is to promote support for democratic values (Galston, 2007). This was a serendipitous finding that emerged from analysis of the data: visitors to CHSNHS still believe in democratic values of establishing justice and providing for the general welfare by helping others. Along with visitors helping others, their visit to the site provided encouragement for them to continue doing public works. Of the 17 participants, 14 revealed that they volunteered in some capacity, from food drives to neighborhood associations. Volunteering was one factor that emerged in determining types of citizenry.

When assigning visitors along the civic engagement spectrum, volunteering was the most widespread factor that emerged, with 14 of 17 (82.4\%) participants stating they volunteered. This is higher than the national average of $26.3 \%$ (Bureau of Labor Statistics, 2011). Donating to charity and serving on jury duty were mentioned by nine participants $(52.9 \%)$, and speaking with others was brought up by 10 respondents. Donating to charity and serving on jury duty 
were specifically asked during the interview process, but conversations with others was not. Donating to charity was much lower than the national average of $65 \%$ (National Philanthropic Trust, 2005). Voting was the least mentioned, by only three participants (17.6\%). This is vastly different from the national statistics where $63.6 \%$ of the American population voted (File \& Crissey, 2010). Voting was intentionally excluded from the interview wording to see if visitors made the connection between civic engagement in democracy and voting. It is discouraging that so few participants made this connection.

From these categories grew a continuum of citizenry which ranged from passive to active to engaged. These categories of citizenry that emerged are similar to Westheimer and Kahne (2004a \& 2004b) and Parker's (1996) spectrum of citizens. Passive citizens align with Westheimer and Kahne's (2004a) personally responsible citizen who volunteers or donates to charity. Parker's traditional citizens, who emphasize democratic values, seem to be more participatory than the passive citizens in this study, and align more with the active citizen. The active citizen also reflects Parker's progressive citizen who place a greater emphasis on civic participation. The engaged citizen in this study corresponds with Westheimer and Kahne's participatory citizen. Nie et al.'s (1996) engaged citizen who participated in activities that require an additional commitment could be either active or engaged in this study. 
Figure 3

\section{Citizenry Continuum}

Nie, Junn, \& Stehlik-Barry (1996)

Parker (1996)

Westheimer \& Kahne (2004a \& 2004b)

CHSNHS

Visitors
Enlightened

Traditional Progressive
Engaged

Advanced?

Personally

Responsible
Participatory
Justice Oriented

Corresponding to Colby, et al., (2003), Galston (2007), and Sax (2000), just volunteering did not translate into civic engagement. Fourteen participants volunteered, but four were engaged. Because in itself, volunteering does not foster democracy or promote democratic values such as social justice or civil rights, future research should focus on broader constructs of civic engagement (Westheimer \& Kahne, 2004a).

During analysis of types of citizenry, the topic of churches emerged. Kirlin (2003) notes the relationship between church participation and civic engagement in youth, as church provides exposure to organizational structure, role models, and opportunities to learn civic skills. Of the 17 respondents, 6 mentioned their church. Of those six, three were rated as engaged, one as active, and two as passive. Correspondingly, in total, there were six passive, seven active, and four engaged citizens. In other words, $75 \%$ of the engaged respondents mentioned church, with $14 \%$ of active and $33 \%$ of passive visitors discussing their church. While there were not enough data to run statistical inferences to determine the correlation between church and citizen types, the numbers present intriguing insight for future researchers. This phenomenon hints at a relationship between church and civic engagement. Other researchers have found a relationship 
between church and volunteering (Gallant, et al., 2010; Sax, 2000), but none between volunteering and civic engagement (Colby, et al., 2003; Galston, 2007; \& Sax, 2000). Future research should focus on the relationships between all three: church, volunteering, and civic engagement.

Another interesting finding involved civic engagement and education. While visitors to CHSNHS were well educated, more so than the general public, (National Park Service Social Science Program, 2001), just four participants ranked as engaged. This appears to be contrary to Kirlin's (2003) findings that education levels and civic engagement were highly correlated.

A final area for future civic engagement research entails discussions with others. While four participants were evaluated as engaged, 10 mentioned they spoke with others either about their visit to Central High School NHS, democratic values, or general political discourse. The interview questionnaire did not specifically target conversations with others, and participants voluntarily offered this information without prompting. Galston (2007) posits that open discussion fosters civic engagement, and learning and meaning making are also enhanced through conversations with others (Hein, 1991, 1998; Falk \& Dierking, 1992; Fosnot \& Perry, 2005; Silverman, 1991; Wright, et al., n.d.). Future research should include a focus on discussion with others when exploring learning, meaning-making, and civic engagement.

The last two serendipitous findings align with conversations with others, and are in fact, communication and souvenirs. Fifteen of 17 visitors took something with them, either promotional materials or souvenirs purchased at the gift shop, and interacted with it later. These interactions help reinforce memories and strengthen meaningful cognitive and emotional connections to the resource (Falk, 2009; Knapp, 2006, 2007; Simon, 2010; Tulving, 2007; Walls, 2004). Simon (2010) even advocates that museum exhibits provide participatory content that 
visitors can take with them, fostering continued engagement long after the visitor leaves the museum. Suggestions include the simple from bookmarks visitors make themselves or picture of the visitor taking a pledge or writing and mailing a postcard to themselves, to the elaborate act of creating a personalized snap-shot video of constructing a building. In one museum, visitors were encouraged to construct a building, especially with others. During their active participation, a camera would take still photos at specific intervals. At the end of their participation, the still photos would be merged into a time-lapse video that visitors could then purchase to take with them. This elaborate activity allowed visitors a personalized connection to the museum. Serrell (1996) suggests that well designed interpretive exhibits offer visitors something to take with them, and this idea has also been noted as important in the interpretive design of non-personal products. For example, Ham (1992) and Smaldone (2008) suggest that the final conceptual level of exhibit design should include a way for visitors to act or follow up on their new awareness and knowledge, which would be helpful in maintaining connections long after the visitor has left the site.

Through subsequent interaction, these souvenirs also led to interaction with others by simulating conversations. One visitor mentioned that wearing a Little Rock Nine baseball cap allowed others to ask about it and started conversations. Another visitor said a poster of Little Rock Central High School prompted students in her classroom to ask questions about it, allowing her to discuss the events. It appears that visiting Central High School NHS opens doors of communication, as a female respondent elaborated how based on the exhibits and her visit, she went home and talked to her mother about their family history including the KKK. She attributes her visit to CHSNHS to opening the doors for her parents to discuss previously silenced family history. These examples of discussion illustrate that visiting CHSNHS and 
souvenirs promote conversations with others resulting in reinforced memories and strong meaningful connections to the site (Hein, 1991, 1995,1998; Falk \& Dierking, 1992; Fosnot \& Perry, 2005; Silverman, 1991; Wright, et al., n.d.).

\section{Research Question \#8: Longitudinal Assessment}

The longitudinal analysis of four research questions provided many similarities and a few notable differences. Analysis of knowledge type revealed a shift in knowledge type. Episodic knowledge was much more prevalent and socio-cultural knowledge less common in exit interviews than in the one-year follow-up interviews. Episodic knowledge decreased from five of twelve respondents to four of 17 or from $41.6 \%$ to $23.5 \%$. Structural knowledge also decreased from three of twelve participants to two of 17 or $25 \%$ to $11.7 \%$, but experiential knowledge increased from $2 / 12$ or $16.6 \%$ to five of 17 respondents or $29.4 \%$. While episodic knowledge was present in both exit and follow-up interviews, it was more common during the exit interviews. This seems contrary to Knapp's (2007) research which revealed wide-spread episodic knowledge during the follow-up. Conversely, Knapp (2006, 2007), Knapp and Benton (2005, 2006), and Anderson and Shimizu's (2007b) research provide a look at long-term memory and knowledge without providing insight into initial reactions for comparison. Farmer and Knapp (2008) did look at initial knowledge versus follow-up and statistically quantified differences in knowledge pre- and post an interpretive program. Farmer and Knapp studied individual respondents' gain in knowledge, and did not compare group compositional changes so it is difficult to assess similarities and differences between this study and Farmer and Knapp's research. Farmer and Knapp address this as a limitation of their study, "the use of 
pretest/posttest without a direct comparison group limits the conclusions appropriate for the study" (p. 355).

One potential explanation for the decrease in this study is that of time: visitors had just left the museum and their visit was fresh on their minds. They were able to describe their recent actions in episodes to the interviewers. The immediacy of the visit may also account for the decrease in structural knowledge as well, as the concepts may have been fresh on participants minds and they were able to make those intellectual connections, whereas one year later, the information was not as fresh and it became more difficult to make linkages between concepts. Time may also contribute to the difference in experiential knowledge as visitors had a year to think about their experience, have additional experiences, and relate those to Little Rock CHSNHS during the follow-up interviews. Learning takes time, but time can also degrade memories without rehearsal and reinforcement (Baddeley, 1998; Falk \& Dierking, 2000; Hein, 1991, 1998; Kintsch, 2009; Walls, 2004). As such, time may be an influential factor in the changes in types of knowledge from exit to follow-up interviews.

During both the exit and follow-up interviews, visitors made meaningful connections both cognitively and emotionally. Cognitively, the biggest differences were during the exit interviews, visitors made connections to the constitution and through perspectives. These two items were not present during the follow-up interviews at all. Other notable changes were increases in history from $2 / 12$ or $16.6 \%$ to $7 / 17$ or $41.2 \%$ of respondents, $1 / 12$ or $8.3 \%$ to four of 17 or $23.5 \%$ mentioning women, and respondents talking about people other than the Little Rock Nine up from $3 / 12$ or $25 \%$ to 11 of 17 or $64.7 \%$. As with types of knowledge, changes in meaningful cognitive connections might be attributable to time. The exit interviews were conducted at the entrance to the museum, where visitors might have been able to see the exhibit 
on the constitution, and thus, it was fresh on their minds. Similarly, visitors might have been thinking about the big picture during their visit, and correspondingly perspectives were brought to mind during the exit interviews. Conversely, women and people other than the Little Rock Nine may be recalled more frequently during the follow-up interviews because visitors thought about these connections after their visit. Walls (2004) describes this as the primacy/recency effect. When asked immediately about something, there is a tendency to recall the last few items, termed the recency effect. The exhibit of the constitution is close to the entrance/exit as was the exhibit illustrating civil rights from various perspectives. However, after a delay, a year in this case, the recency effect disappears and the primary items are recalled better. Based on this explanation, women and people other than the Little Rock Nine were deemed more important or meaningful as they were stored in long-term memory and recalled more frequently than the constitution or perspectives, which were recalled immediately after the visit.

There were differences among emotional connections as well. The biggest divergence was that involving awe. During the exit interviews no participants felt awe, whereas during the follow-up interviews, 10 of 17 (58.8\%) mentioned feelings of awe. Two additional changes were empathy and encouragement, both with one of 12 during the exit (8.3\%) versus the followup with seven of 17 (41.2\%) participants mentioning empathy and four of $17(23.5 \%)$ talking about encouragement. Farmer and Knapp's (2008) study of a historic preservation site found visitors primarily felt awe as an emotional connection to the site. However, emotional connections were not followed longitudinally (only differences in cognition were reported). The authors even state "Having both immediate postinterviews and long-term postinterviews would allow for the comparison of in-depth information directly following the experience and six 
months after the experience" (p. 355). This study does that and provides a valuable basis for filling this research gap.

The last research question that allowed longitudinal analysis was how meanings were made. The two prominent differences here were increases in personal experience and absolute description. During the exit interviews, six of 12 or $50 \%$ of respondents made meaning through personal experience and $4 / 12$ or $33.3 \%$ made meaning through absolute description. These numbers increased dramatically during the follow-up interviews with 15 of 17 or $88.2 \%$ using personal experience to make meaning and 16 of 17 or $94.1 \%$ connecting through absolute description. As no other research has used Silverman's (1991) categories of meaning making, it is difficult to make comparisons. There are several potential explanations for these changes, though. First, material that is personally relevant is remembered better (Knapp, 2006, 2007; Tilden, 1957; Webb, 2000), so it is reasonable to believe that visitors may have thought about their experiences and recalled those things to which they connected to on a personal level. A more likely explanation, though, is that during the follow-up interviews, a question targeted personal experience, and thus most respondents answered by providing examples of personal experiences they saw reflected in the exhibits. As for the increase in absolute description, visitors were at the site during the exit interviews and the interviewer could see and walk around the exhibits. Respondents may not have felt the need to give detailed particulars of exhibits because of proximity. However, the follow-up interviews were conducted over the telephone, so neither the interviewer nor respondents were physically at the site. Thus, respondents may have felt the need to give detailed descriptions of the exhibits to ensure the interviewer knew about which exhibit he/she was talking. This is illustrated by the numerous "you knows" respondents interjected for confirmation of the interviewer's understanding. 


\section{Conclusion}

In summary, visitors to CHSNHS recalled various types of memories with similar types of knowledge. Meanings were made both intellectually and emotionally through a variety of factors, some of which were related to civil rights. This civic knowledge about civil rights corresponded with participation in community activities, but did not translate into civic engagement. A continuum of civic engagement was developed providing for three types of citizens, of which civically engaged visitors were the least prevalent. Longitudinally, there was a shift in knowledge type which may be attributable to the lapse of time. Visitors made meanings both emotionally and cognitively, although the categories of connections varied slightly between the exit and follow-up interviews. Frequencies of connections both emotionally and cognitively increased over time. Longitudinally, visitors made meaning through all five channels, with frequencies increasing from exit to follow-up interviews. Visits to CHSNHS provide encouragement for visitors to continue their community activities, and future research should incorporate the role of churches as well as conversations with others when investigating meaning-making, interpretation, and civic engagement. 


\section{REFERENCES}

Afonso, A. S., \& Gilbert, J. K. (2006). The use of memories in understanding interactive science and technology exhibits. International Journal of Science Education, 28(13), 1523-1544.

Alberti, S. J. M. M. (2005). Objects and the museum. Isis, 96(4), 559-571.

American Association of Museums. (2002). Mastering civic engagement: A challenge to museums. Washington, D.C.: American Association of Museums.

Anderson, D. (2003). Visitors' long-term memories of world expositions. Curator, 46(4), 401420.

Anderson, D., \& Shimizu, H. (2007a). Factors shaping vividness of memory episodes: Visitors' long-term memories of the 1970 Japan World Exposition. Memory, 15(2), 177-191.

Anderson, D., \& Shimizu, H. (2007b). Recollections of Expo 70: Visitors' experiences and the retention of vivid long-term memories. Curator, 50(4), 435-454.

Ansbacher, T. (1999). Experience, inquiry, and meaning making. Exhibitionist, 118(Special issue), 22-26.

Baddeley, A. (1998). Human memory: Theory and practice (Revised edition ed.). Boston, MA: Allyn \& Bacon.

Barrie, E. R. (2001). Meaningful interpretive experiences from the participants' perspective. Unpublished Dissertation, Indiana University, United States; Indiana.

Beck, L., \& Cable, T. (2002). Interpretation for the 21st century: Fifteen guiding principles for interpreting nature and culture (2nd ed.). Champaign, IL: Sagamore Publishing.

Benton, G. M. (2008). Visitor meaning-making at Grand Canyon's Tusayan Museum and ruin. Curator, 51(3), 297-311.

Bitgood, S., \& Cleghorn, A. (1994). Memory of objects, labels, and other sensory impressions from a museum visit. Visitor Behavior, 9(2), 11-12.

Blake, C. N. (1999). The usuable past, the comfortable past, and the civic past: Memory in contemporary America. Cultural Anthropology, 14(3), 423-435.

Boyte, H. C. (2000). Public engagement in a civic mission: A case study. Washington, D.C.: Council on Public Policy Education.

Brady, H. E., Verba, S., \& Schlozman, K. L. (1995). Beyond SES: A resource model of political participation. American Political Science Review, 89(2), 271-294.

Brochu, L., \& Merriman, T. (2002). Personal interpretation: Connecting your audience to heritage resources. Singapore: InterpPress.

Bureau of Labor Statistics. (2011). Volunteering in the U.S.--2010. Retrieved April 20, 2011. from http://www.bls.gov/news.release/pdf/volun.pdf

Cameron, D. F. (1968). The museum as a communications system and implications for museum education Curator, 11(1), 33-40.

Chen, W. L. J. (2003). The craft and concepts of interpretation: A look at how National Park Service interpreters reveal and facilitate opportunities for connections. Unpublished dissertation, West Virginia University, Morgantown, WV.

Clark, R. E. (2009). How much and what type of guidance is optimal for learning from instruction? In S. Tobias \& T. M. Duffy (Eds.), Constructivist instruction: Success or failure? (pp. 158-183). New York, NY: Routledge.

Coen, L. (1975). The interpretive function in museum work. Curator, 18(4), 281-286. 
Colby, A., Ehrilch, T., Beaumont, E., \& Stephens, J. (2003). Educating citizens: Preparing America's undergraduates for lives of moral and civic responsibility. San Francisco, CA: Jossey-Bass a Wiley Imprint.

Dictionary.com. (2010). Civic, engagement, civic engagement, civic responsibility, civic duty. Retrieved October 13, 2010, from www.dictionary.com

Ehrilch, T. (2000). Civic responsibility and higher education. Phoenix, AZ: American Council on Education Oryx Press.

Falk, J. H. (2009). Identity and the Museum Visitor Experience. Walnut Creek, CA: Left Coast Press, Inc.

Falk, J. H., \& Dierking, L. D. (1992). The museum experience. Washington, DC: Whalesback Books.

Falk, J. H., \& Dierking, L. D. (2000). Learning from museums: Visitor experiences and the making of meaning. Lanham, MA: AltaMira Press, a division of Rowman \& Littlefield Publishers, Inc.

Farmer, J., \& Knapp, D. (2008). Interpretation programs at a historic preservation site: A mixed methods study of long-term impact. Journal of Mixed Methods Research, 2(4), 340-361.

File, T., \& Crissey, S. (2010). Voting and registration in the election of November 2008. Retrieved April 20, 2011, from http:/www.census.gov/prod/2010pubs/p20-562.pdf.

Fishbein, M., \& Ajzen, I. (1975). Belief, attitude, intention, and behavior: An introductions to theory and research. Reading, MA: Addison-Wesley.

Flanagan, C. A., Syvertsen, A. K., \& Stout, M. D. (2007). Civic measurement models: Tapping adolescents' civic engagement. CIRCLE working paper \#55. College Park, MD: The Center for Information \& Research on Civic Learning \& Engagement (CIRCLE).

Fosnot, C. T. (2005). In C. T. Fosnot (Ed.), Constructivism: Theory, perspectives, and practice. New York, NY: Teachers College Press.

Fosnot, C. T., \& Perry, R. S. (2005). Constructivism: A psychological theory of learning. In C. T. Fosnot (Ed.), Constructivism: Theory, perspectives, and practice (pp. 8-38). New York, NY: Teachers College Press.

Gallant, K., Smale, B., \& Arai, S. (2010). Civic engagement through mandatory community service: Implications of serious leisure. Journal of Leisure Research, 42(2), 181-201.

Galston, W. A. (2007). Civic knowledge, civic education, and civic engagement: A summary of recent research. International Journal of Public Administration, 30(6/7), 623-642.

Glassberg, D. (1996). Public history and the study of memory. Public Historian, 18(2), 7-23.

Goldman, T. L., Chen, W. J., \& Larsen, D. L. (2001). Clicking the icon: Exploring the meanings visitors attach to three national capital memorials. Journal of Interpretation Research, 6(1), 3-30.

Grinder, A.L. \& McCoy, E.S. (1985). The good guide: A sourcebook for interpreters, docents and tour guides. Scottsdale, AZ: Ironwood Press.

Gutwill-Wise, J., \& Allen, S. (2002a, May 14, 2002). Finding significance: Testing methods for encouraging meaning-making in a science museum. Paper presented at the American Association of Museums, Dallas, TX.

Gutwill-Wise, J., \& Allen, S. (2002b). Finding significance: Testing methods for encouraging meaning-making in a science museum. Current Trends in Audience Research and Evaluation, 15, 5-11.

Ham, S. H. (1986). Interpretive views evaluating interpretation in the National Park Service. Washington, DC: National Parks and Conservation Association. 
Ham, S. H. (1992). Environmental interpretation: A practical guide for people with big ideas and small budgets. Golden, CO: North American Press, Fulcrum Publishing.

Ham, S. H. (2004). Creating unforgettable event experiences-Making a difference by meaning making. Paper presented at the Tasmania XChange Conference, Country Club Resort, Launceston, Tasmania.

Ham, S. H., Brown, T. J., Curtis, J., Weiler, B., Hughes, M., \& Poll, M. (2007). Promoting persuasion in protected areas: A guide for managers: Developing strategic communication to influence visitor behaiour (No. Project SR6c: Strategic communication and visitor behaviour sub-project): Sustainable Tourism CRC.

Hammitt, W. E. (1984). Cognitive processes involved in environmental interpretation. Journal of Environmental Education, 15(4), 11-15.

Hanson, V. D. (2008, June 4, 2008). Memory and civic education: The perils of cultural America. Paper presented at the 2008 Bradley Symposium: Encounter at 10: The Power of Ideas, St. Regis Hotel, Washington, D.C.

Hein, G. E. (n.d.). Constructivism: More than meaning making. Unpublished manuscript.

Hein, G. E. (1991, October 15-22). Constructivist learning theory: The museum and the needs of the people. Paper presented at the CECA: International Committee of Museum Educators Conference, Jerusalem, Israel.

Hein, G. E. (1995). The constructivist museum. Journal of Education in Museums, 16, 21-23.

Hein, G. E. (1998). Learning in the museum. New York, NY: Routledge.

Hein, G. E. (1999). Is meaning making constructivism? Is constructivism meaning making? Exhibitionist, 118(Special issue), 15-18.

Herman, P., \& Gomez, L. M. (2009). Taking guided learning theory to school. In S. Tobias \& T. M. Duffy (Eds.), Constructivist instruction: Success or failure? New York, NY: Routledge.

Hines [Stone], J. M., Hungerford, H. R., \& Tomera, A. N. (1986-87). Analysis and synthesis of research on responsible environmental behavior: A meta-analysis. The Journal of Environmental Education, 18(2), 1-8.

Hungerford, H. R. (1996). The development of responsible environmental citizenship: A critical challenge. Journal of Interpretation Research, 1(1), 25-37.

Hungerford, H. R., \& Volk, T. L. (1998, 2001). Changing learner behavior through environmental education. In H. R. Hungerford, W. J. Bluhm, T. L. Volk \& J. M. Ramsey (Eds.), Essential readings in environmental education (pp. 289-304). Champaign, IL: Stipes Publishing.

Jacobi, C. (2003a). An experiment using signs to reduce visitor-built cairns in Acadia National Park (No. 2002-04): NPS: Acadia National Park.

Jacobi, C. (2003b). Leave the rocks for the next glacier: Low impact education in a high use national park. International Journal of Wilderness, 9(1), 30-31.

Johnson, D. R., \& Swearingen, T. C. (1992). The effectiveness of selected trailside sign texts in deterring off-trail hiking at Paradise Meadow, Mount Rainier National Park (No. Pacific Northwest Research Station General Technical Report PNW-GTR-293.): US Department of Agriculture, Forest Service.

Jonassen, D. (2009). Reconciling a human cognitive architecture. In S. Tobias \& T. M. Duffy (Eds.), Constructivist instruction: Success or failure? New York, NY: Routledge. 
Julyan, C., \& Duckworth, E. (2005). A constructivist perspective on teaching and learning science. In C. T. Fosnot (Ed.), Constructivism: Theory, perspectives, and practice. New York, NY: Teachers College Press.

Keeter, S., Zukin, C., Andolina, M., \& Jenkins, K. (2002). The civic and political health of the nation: A generational portrait. College Park, MD: Center for Information and Research on Civic Learning and Engagement (CIRLCE).

Kintsch, W. (2009). Learning and constructivism. In S. Tobias \& T. M. Duffy (Eds.), Constructivist instruction: Success or failure? (pp. 223-241). New York, NY: Routledge.

Kirlin, M. (2002). Civic skill building: The missing component in service programs? PS: Political Science and Politics, 35(3), 571-575.

Kirlin, M. (2003). The role of civic skills in fostering civic engagement. CIRCLE working paper \#6. College Park, MD: Center for Information \& Resources on Civic Learning \& Engagement (CIRCLE).

Knapp, D. (2006). The development of semantic memories through interpretation. Journal of Interpretation Research, 11(2), 21-35.

Knapp, D. (2007). Applied interpretation: Putting research into practice. Fort Collins, CO.: National Association for Interpretation.

Knapp, D., \& Barrie, E. (1998). Ecology versus issue interpretation: The analysis of two different messages. Journal of Interpretation Research, 3(1), 21-38.

Knapp, D., \& Barrie, E. (2001). Content evaluation of an environmental science field trip. Journal of Science Education and Technology, 10(4), 351-357.

Knapp, D., \& Benton, G. M. (2004). Elements to successful interpretation: A multiple case study of five National Parks. Journal of Interpretation Research, 9(2), 9-24.

Knapp, D., \& Benton, G. M. (2005). Long-term recollections of an environmental interpretive program. Journal of Interpretation Research, 10(1), 51-53.

Knapp, D., \& Benton, G. M. (2006). Episodic and semantic memories of a residential environmental education program. Environmental Education Research, 12(2), 165-177.

Knudson, D. M., Cable, T. T. \& Beck, L. (2003). Interpretation of cultural and natural resources $\left(2^{\text {nd }}\right.$ Ed.). State College, PA: Venture Publishing.

Koran, M. L., Willems, P. P., \& Camp, B. D. (2000). Situated cognition: Implications for visitor studies. Journal of Interpretation Research, 5(2), 5-13.

Kuo, I. L. (2002). The effectiveness of environmental interpretation at resource-sensitive tourism destinations. International Journal of Tourism Research, 4, 87-101.

Larsen, D. L., Ed. (2003). Meaningful interpretation: How to connect hearts and minds to places, objects, and other resources. Fort Washington, PA: Eastern National.

Lewis, W. J. (1980). Interpreting for park visitors. Philadelphia, PA: Eastern Acorn Press.

Linenthal, E. T. (2006). The National Park Service and civic engagement. The Public Historian, 28(1), 123-129.

Linenthal, E. T. (2008). The National Park Service and civic engagement. The George Wright Forum, 25(1), 5-11.

Machlis, G. E., \& Field, D. R. (1984). Introduction. In G. E. Machlis \& D. R. Field (Eds.), On interpretation: Sociology for interpreters of natural and cultural history (pp. 1-8). Corvallis, OR: Oregon State University Press.

Machnik, L. K., Wright, B. A., \& Hammitt, W. E. (2006). Perceptions and cognitions from an interpretive talk: Comparing visitor responses to expert reviews. Paper presented at the Northeastern Recreation Research Symposium, Bolton Landing, NY. 
Martin, J. (1993). Episodic memory: a neglected phenomenon in the psychology of education. Educational Psychologist, 28(2), 169-183.

Martin, S. R. (1992). The effect of three signs and a brochure on visitors' removal of pumice at Mount St. Helens (No. Pacific Northwest Research Station General Technical Report PNW-GTR-293): US Department of Agriculture, Forest Service.

Masango, R. S. (2008). Enhancing the efficacy of public participation in policy-making and implementation through civic education: A South African perspective. International Journal of Learning, 15(6), 65-71.

McEachern, C. (1998). Mapping the memories: Politics, place and identity in the district six museum, Cape Town. Social Identities, 4(3), 499-522.

McIntosh, H., \& Munoz, M. A. (2009). Predicting civic engagement in urban high school students. CIRCLE working paper \#69. College Park, MD: Center for Information and Research on Civic Learning and Engagement (CIRCLE).

McManus, P. M. (1993). Memories as indicators of the impact of museum visits. Museum Management and Curatorship, 12, 367-380.

Merriam-Webster. (2010). Connection, civic, education, civic engagement, civic responsibility, civic duty, meaning. Retrieved October 13, 2010, from m-w.com

Mettler, S. (2007). Bringing government back into civic engagement: Considering the role of public policy. International Journal of Public Administration, 30(6/7), 643-650.

Miller, G. A. (1956). The magical number seven, plus or minus two: some limits on our capacity for processing information. Psychological Review, 63(2), 81-97.

Monroe, M. C. (2003). Two avenues for encouraging conservation behaviors. Human Ecology Review, 10(2), 113-125.

Morgan, M., \& Dong, X. D. (2008). Measuring passenger satisfaction of interpretive programming on two Amtrak trains in the Midwest: Testing the expectancy disconfirmation theory. Journal of Interpretation Research, 13(2), 43-58.

N.A. (2005). Educating for democracy: California campaign for the civic mission of schools: The California survey of civic education: Constitutional Rights Foundation, Center for Civic Education, \& Alliance for Representative Democracy.

N.A. (n.d.). Individual and campus assessment tools. Unpublished manuscript.

National Park Service Education Council. (2006). Interpretation and education renaissance action plan. Washington, D.C.: Department of Interior: National Park Service.

National Park Service Social Science Program. (2001). The National Park Service comprehensive survey of the American public (Technical Report): Social Research Laboratory: Northern Arizona University.

National Park Service. (2006a). Interpretation and education program logic model (3b ed.).

National Park Service. (2006b). Visitor center design narrative. Retrieved November 9, 2010, from http:/www.nps.gov/chsc/upload/buildingdesignnewvisitorcenter.doc

National Park Service: Little Rock Central High School National Historic Site. (2002). General Management Plan. GPO report no. 2002-775-576.

National Philanthropic Trust. (2005, 2010). Philanthropy statistics. Retrieved April 20, 2011, from http://www.npt.org/philanthropy/philanthropy_stats.asp

Nie, N. H., Junn, J., \& Stehlik-Barry, K. (1996). Education and democratic citizenship in America. Chicago, IL: University of Chicago Press.

Novey, L. (2008). Why we should communicate, rather than interpret: A call to arms. Journal of Interpretation Research, 13(1), 51-58. 
NPS Conservation Study Institute. (2006, January 14). Summary report. Paper presented at the Scholars forum: The National Park Service and civic reflection, Independence National Historical Park, Philadelphia, PA.

Oliver, D. G., Serovich, J. M., \& Mason, T. L. (2005). Constraints and opportunities with interview transcription: Towards reflection in qualitative research. Social Forces, 84(2), 1273-1289.

Orams, M. B. (1995). Using interpretation to manage nature-based tourism. Journal of Sustainable Tourism, 4(2), 81-94.

Parker, W. (1996). 'Advanced' ideas about democracy: Toward a pluralist conception of citizen education. Teachers College Record, 98, 104-125.

Patton, M. Q. (2002). Qualitative research and evaluation methods (3rd ed.). Thousand Oaks, CA: Sage.

Roberts, W. R. (Trans.). (1954, 1984). The rhetoric and poetics of Aristotle. New York, NY: Modern Library.

Rounds, J. (1999). Meaning making: A new paradigm for museum exhibits? Exhibitionist, 118(Special issue), 5-8.

Rowe, G., \& Frewer, L. J. (2000). Public participation methods: A framework for evaluation. Science, Technology, \& Human Values, 25(1), 3-29.

Rupp, A. (1999). Meaning-making in children's museums: Why try? Exhibitionist, 118(Special issue), 42-44.

Sax, L. J. (2000). Citizenship development and the American college student. In T. Ehrilch (Ed.), Civic Responsibility and Higher Education (pp. 3-17). Phoenix, AZ: American Council on Education Oryx Press.

Schank, R. C. (1990). Tell me a story: Narrative and intelligence. Evanston, IL: Northwestern University Press.

Serrell, B. (1996). Exhibit Labels. Walnut Creek, CA: AltaMira Press.

Serve.gov. (2010). United we serve. Retrieved November 9, 2010, from www.serve.gov

Sevcenko, L., \& Russell-Ciardi, M. (2008). Sites of conscience: Opening sites for civic dialogue. The Public Historian, 30(1), 9-15.

Silverman, L. H. (1991). Of us and other "things": The content and functions of museum talk by adult visitor pairs in an art and a history museum. Unpublished doctoral dissertation, University of Pennsylvania.

Silverman, L. H. (1999). Meaning making matters: Communication, consequences, and exhibit design. Exhibitionist, 118(Special issue), 9-14.

Simon, N. (2010). The Participatory Museum. Santa Cruz, CA: Museum 20.

Smaldone, D. A. (2008). Class notes: RPTR 693. Unpublished course notes. West Virginia University.

Spock, M. (1999). The stories we tell about meaning making. Exhibitionist, 118(Special issue), 30-34.

Stevenson, J. (1991). The long-term impact of interactive exhibits. International Journal of Science Education, 13(5), 521-531.

Strauss, A., \& Corbin, J. (1998). Basics of Qualitative Research (2nd ed.). Thousand Oaks, CA: Sage.

Syvertsen, A. K., Flanagan, C. A., \& Stout, M. D. (2007). Best practices in civic education: Changes in students' civic outcomes. CIRCLE working paper \#57. College Park, MD: The Center for Information \& Research on Civic Learning \& Engagement (CIRCLE). 
Tardona, D. R. (2005). Exploring evolved psychological underpinnings of universal concepts and meaningful connections. Journal of Interpretation Research, 10(1), 69-74.

Thefreedictionary.com. (2010). Civic, engagement, civic engagement, civic responsibility, civic duty. Retrieved October 13, 2010, from www.thefreedictionary.com

Tilden, F. (1957). Interpreting our heritage (3rd ed.). Chapel Hill, NC: University of North Carolina Press.

Tobias, S., \& Duffy, T. M. (2009). The success or failure of constructivist instruction: An introduction. In S. Tobias \& T. M. Duffy (Eds.), Constructivist instruction: Success or failure? New York, NY: Routledge.

Tulving, E. (1983; 2007). Elements of episodic memory (Vol. 2). New York, NY: Oxford University Press.

von Glasersfeld, E. (2005). Introduction: Aspects of constructivism. In C. T. Fosnot (Ed.), Constructivism: Theory, practice, and perspectives. New York, NY: Teachers College Press.

Vygotsky, L. S. (1978). Mind in Society. Cambridge, MA: Harvard University Press.

Walls, R. T. (2004). Memory: Notes and notions. Morgantown, WV: ICDI.

Ward, C. W., \& Wilkinson, A. E. (2006). Conducting meaningful interpretation: A field guide for success. Golden, CO: Fulcrum Publishing.

Webb, R. C. (2000) The nature, role, and measurement of affect, Journal of Interpretation Research, 5(2), 15-30.

Wenger, E. (1998). Communities of Practice: Learning, Meaning, and Identity. Cambridge, UK: Cambridge University Press.

West, R., \& Turner, L. H. (2007). Introduction to communication theory. NY, NY: McGrawHill.

Westheimer, J., \& Kahne, J. (2004a). Educating the "good" citizen: Political choices and pedagogical goals. PS: Political Science and Politics, 37(2), 241-247.

Westheimer, J., \& Kahne, J. (2004b). What kind of citizen? The politics of educating for democracy. American Educational Research Journal, 41(2), 237-269.

Wiles, R., \& Hall, T. E. (2005). Can interpretive messages change park visitors' views on wildland fire? Journal of Interpretation Research, 10(2), 18-35.

Wise, A. F., \& O'Neill, K. (2009). Beyond more versus less. In S. Tobias \& T. M. Duffy (Eds.), Constructivist instruction: Success or failure? New York, NY: Routledge.

Wright, B. A., Hammitt, W. E., \& Machnik, L. K. (n.d.). Unpublished Manuscript. 


\section{ADDENDUM: INTERVIEW SCRIPT}

Phone call Script:

Hello, my name is Sandy Strickland and I am calling from West Virginia University in Morgantown, WV. I am calling to speak with about his/her experience at Central High School in Little Rock, AR last summer. Is he/she available? You visited the site in July, and participated in interview while you were there. During that interview, we asked if we could follow up with you later, and that is why I'm calling today. Do you have time right now for the follow-up interview? NO: When would be a better time to call? Thank you and I will call back at o'clock AM/PM on

We are working with the National Park Service to get feedback from visitors to national parks, and the purpose of this study is to understand the meanings and significance that visitors ascribe to Central High School National Historic Site. With your permission, I would like to record this conversation to aid in the data collection process, and to ensure your ideas are captured accurately. Can I begin recording? As before, your participation in this research is voluntary, and I would like to begin by reminding you of the Right to Informed Consent for Participation in Research document that you signed in Little Rock giving your agreement to participate in a follow-up survey. You may also refuse to answer any questions you do not want to answer and still remain in the study. You have a right to ask questions about the research project, obtain a copy of the results, and have your privacy respected throughout the process. Your identity will be protected. Any information that is obtained in connection with this study and can be identified with you will remain confidential and only disclosed with your permission or as required by law. (read the Dept of Interior form if requested).

If they say they do not want to participate in the interview, thank them, end the phone call, and move to next person on list.

If they say they will participate but do not want to be recorded, ask why, and see if you can alleviate any concern. We really need recordings for quality data.

0 .) You are respondent number

1.) Do you remember visiting CHS NHS?

2.) What do you remember about your visit/ the VC?

- Over the past months, have you thought about or reflected on, your visit to Central HS NHS since your visit last summer? What topics or ideas have you reflected on?

3.) What do you think the main idea of the exhibits was? Did anything stand out to you?

3a.) the theme? most important point? Key point?

4.) When exploring the exhibits, did you learn anything you didn't know before or did it reinforce something you already knew? Did you understand anything better or think about something differently?

4a.) Can you give me an example? what did you learn/ what was reinforced?

4b.) any exhibit element stand out to you?

5.) Did the exhibits trigger any emotions or feelings in you? Did you feel anything emotionally when you went through the exhibits?

5a.) were they positive or negative?

5b.) what kind of emotion?

5c.) Which exhibit made you feel that way?

5d.) Have any emotions lingered? Or Changed? 
6.) Was anything in the exhibits personally relevant to you?

6a.) Have you had any life experiences that you saw reflected in the exhibits?

7.) What do the exhibits tell us about civil rights then \& now?

8.) Since your visit, have you participated in any activities or projects for the betterment or improvement of your community/state/nation? Same level or more (increase commitment)? Are any of these things new (ones that you were not participating in before)? Did your visit motivate you to participate in these things?

8a.) done anything that promotes any democratic values?

- Justice

- Freedom

- Equality

- Diversity

- Authority
- Privacy

- Due process

- Property

- Participation

- Truth
- Patriotism

- Human rights

- Rule of law

- Tolerance

- Mutual assistance

- Self restraint

- Self respect

8b.) done anything that falls under civic responsibilities such as donate $\$$ to charity, serve on jury duty, or volunteered at some place you haven't before? Buy book, give gift from site?

- Form a more perfect union

- Establish justice

- Insure domestic tranquility

- Provide for common defense

- Promote general welfare

- Secure blessings of liberty for ourselves \& our posterity

8c.) Why did you do those activities/things? (If a friend asked you why you did those things, what would you tell them?)

9.) While you were onsite in July 2009 , did you buy anything at the Visitor Center, or take any materials home with you? If so, did you interact/reflect, etc. on those items?

10.) Have you visited CHS since your visit in July 2009?

9a) if yes, how many times

$9 b$ ) what made/ why did you return/ come back?

$9 \mathrm{c}$ ) what was purpose of the visit? (did your visit motivate you to bring them?)

9d) who with?

11.) If you were to drive by the school and site today, what thoughts (or feelings) would be going through your mind? (Looking for main idea again)

Now for some demographic questions...

12.) What category best describes your age?
$18-25$
26-35
$36-45$
$46-55$
$56-65$
66-75
over

75

13.) What is your highest level of education?

Less than high school high school

Masters/graduate degree

some college

Doctorate/post

Bachelor's

graduate

14.) What best describes your employment status:

Employed : what field

Unemployed

Other:

Homemaker

Student Retired 
15.) Is there anything else you would like to share about your visit to Central High School National Historical Site?

I want to thank you on behalf of the National Park Service and West Virginia University for participating in our research efforts. Thanks again and have a good afternoon!

Should they need contact info:

Theresa Coble, Associate Professor

Stephen F. Austin State University

Box 6109, SFA Station

Nacogdoches, TX 75962-6109

tcoble@sfasu.edu

Thank for your participation. 